Georgia State University

ScholarWorks @ Georgia State University

Nursing Dissertations (PhD)

School of Nursing

Summer 8-18-2010

\title{
Understanding the Health Beliefs of First Time Mothers who Request an Elective Cesarean versus Mothers who Request a Vaginal Delivery
}

Deborah T. MacMillan

Georgia State University

Follow this and additional works at: https://scholarworks.gsu.edu/nursing_diss

Part of the Nursing Commons

\begin{abstract}
Recommended Citation
MacMillan, Deborah T., "Understanding the Health Beliefs of First Time Mothers who Request an Elective Cesarean versus Mothers who Request a Vaginal Delivery." Dissertation, Georgia State University, 2010. doi: https://doi.org/10.57709/1701258
\end{abstract}

This Dissertation is brought to you for free and open access by the School of Nursing at ScholarWorks @ Georgia State University. It has been accepted for inclusion in Nursing Dissertations (PhD) by an authorized administrator of ScholarWorks@ Georgia State University. For more information, please contact scholarworks@gsu.edu. 
ACCEPTANCE

This dissertation, UNDERSTANDING THE HEALTH BELIEFS OF FIRST TIME MOTHERS WHO REQUEST AN ELECTIVE CESAREAN VERSUS MOTHERS WHO REQUEST A VAGINAL DELIVERY by Deborah Thompson MacMillan was prepared under the direction of the candidate's dissertation committee. It is accepted by the committee members in partial fulfillment of the requirements for the degree of Doctor of Philosophy in Nursing in the Byrdine F. Lewis School of Nursing in the College of Health and Human Sciences, Georgia State University.

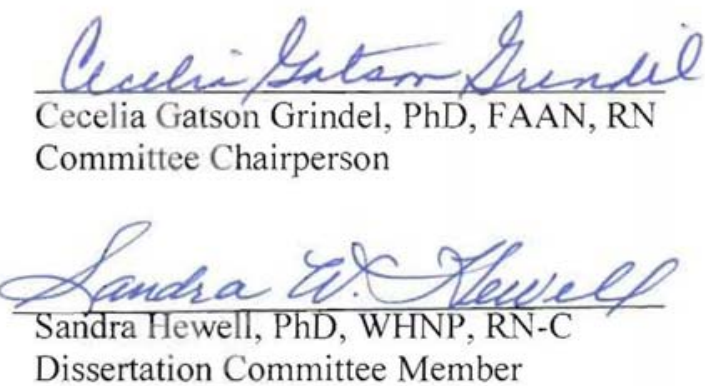

Laura P. kibble

Laura P. Nimble, PhD, RN

Dissertation Committee Member

Victoria Hance

Victoria Hands, MD

Dissertation Committee Member

$\frac{\text { mu y 14, 2010 }}{\text { Date }}$

i 
This dissertation meets the format and style requirements established by the College of Health and Human Sciences. It is acceptable for binding, for placement in the University Library and Archives, and for reproduction and distribution to the scholarly and lay community by University Microfilms International.

Cecelia Gatson Grindel, PhD, RN, FAAN

Associate Director for Graduate Nursing

Barbara C. Woodring, EdD, RN, CPN

Professor \& Director

Byrdine F. Lewis School of Nursing 


\section{AUTHOR'S STATEMENT}

In presenting this dissertation as a partial fulfillment of the requirements for an advanced degree from Georgia State University, I agree that the Library of the University shall make it available for inspection and circulation in accordance with its regulations governing materials of this type. I agree that permission to quote from, to copy from, or to publish this dissertation may be granted by the author or, in his/her absence, by the professor under whose direction it was written, or in his/her absence, by the Associate Director for Graduate Programs in Nursing, Byrdine F. Lewis School of Nursing, College of Health and Human Sciences. Such quoting, copying, or publishing must be solely for scholarly purposes and will not involve potential financial gain. It is understood that any copying from or publication of this dissertation which involves potential financial gain will not be allowed without written permission from the author.

Dehork thomptor machoulle Deborah Thompson MacMillan 


\section{NOTICE TO BORROWERS}

All dissertations deposited in the Georgia State University Library must be used in accordance with the stipulations prescribed by the author in the preceding statement.

The author of this dissertation is:

Deborah MacMillan

325 Woods Road

Juliette, GA 31046

The director of this dissertation is:

Dr. Cecelia Gatson Grindel

Associate Director for Academic Affairs

College of Health and Human Sciences

Georgia State University

P.O. Box 3995

Atlanta, GA 30302-4019

Users of this dissertation not regularly enrolled as students at Georgia State University are required to attest acceptance of the preceding stipulations by signing below. Libraries borrowing this dissertation for the use of their patrons are required to see that each user records here the information requested.

$\begin{array}{lll}\text { NAME OF USER ADDRESS } & \text { DATE } & \text { TYPE OF USE } \\ & & \text { (EXAMINATION ONLY } \\ & \text { OR COPYING) }\end{array}$


VITA

Deborah Thompson MacMillan

$\begin{array}{cll}\text { ADDRESS: } & \begin{array}{l}325 \text { Woods Road } \\ \text { Juliette, Georgia } 31046\end{array} \\ \begin{array}{c}\text { EDUCATION: } \\ \text { Ph.D. }\end{array} & 2010 & \begin{array}{l}\text { Georgia State University } \\ \text { Atlanta, Georgia }\end{array} \\ \text { M.S.N. } & 2000 & \begin{array}{l}\text { Emory University } \\ \text { Atlanta, Georgia }\end{array} \\ \text { B.S.N. } & 1997 & \begin{array}{l}\text { Georgia College \& State University } \\ \text { Milledgeville, Georgia }\end{array} \\ & & \begin{array}{l}\text { Macon State College } \\ \text { Macon, Georgia }\end{array}\end{array}$

PROFESSIONAL EXPERIENCE:

2009 Summer

2005 - Present

2004 - Present

$2004-2005$

$2000-2004$

$1995-2000$

$1981-1995$

$1975-1995$
Research Associate - Johns Hopkins Medical Institute Midwife - Felicia Kitchens M.D. PC

Assistant Professor, Georgia College \& State University Staff Nurse - Coliseum Medical Center

Midwife - Joyce A Rawls M.D. PC

Nurse Manager - Coliseum Medical Center

Staff Nurse - Coliseum Medical Center

Instructor - Childbirth Education Association

PROFESSIONAL ORGANIZATIONS AND CERTIFICATIONS:

$$
\begin{aligned}
& 2009 \text { - Present } \\
& 2006 \text { - Present } \\
& 2004 \text { - Present } \\
& 2004 \text { - Present } \\
& 2001 \text { - Present } \\
& 2000 \text { - Present } \\
& 2000 \text { - Present } \\
& 1998 \text { - Present } \\
& 1990 \text { - Present }
\end{aligned}
$$

Georgia Nursing Association

Southern Nursing Research Society

Association of Standard Patient Educators

Theta Tau Chapter Georgia College \& State University

Association of Nurse Practitioners in Georgia

Sigma Theta Tau International

ACNM Certification

American College of Nurse Midwives (ACNM)

Counselor - Resolve Through Sharing 


\section{PROFESSIONAL ORGANIZATIONS AND CERTIFICATIONS, CONTINUED:}

1985 - Present

1985 - Present

1983 - Present

1981 - Present

1981 - Present
Association of Women's Health Obstetrical and Neonatal Nursing Instructor - AWHONN Fetal Heart Rate Provider - Neonatal Resuscitation

Provider - American Heart Association

Georgia Board of Nursing 


\begin{abstract}
UNDERSTANDING THE HEALTH BELIEFS OF FIRST TIME MOTHERS WHO

REQUEST ELECTIVE CESAREAN VERSUS FIRST TIME MOTHERS WHO

REQUEST A VAGINAL DELIVERY

by

DEBORAH THOMPSON MACMILLAN
\end{abstract}

Little is known about how the decision for elective cesarean section comes about in the clinical environment. A prospective longitudinal study based on the Health Belief Model was conducted about first time mothers' decision making processes and their health beliefs which led to their satisfaction with their decision about their mode of delivery.

A convenience sample of 144 nulliparous women with singleton pregnancies and no medical indications requiring a cesarean delivery were recruited using internet based informational notices and with flyers. Women $(\mathrm{n}=127)$ planning a vaginal delivery (VDMR) represented $88.2 \%$ of the sample and women $(n=17)$ requesting a cesarean delivery (CDMR) represented $11.8 \%$ of the sample. Data were collected during the third trimester and six weeks after the delivery using an internet-based questionnaire.

Data were analyzed using t-tests and multiple linear regression to predict the effect of maternal health beliefs, maternal childbirth self efficacy, partner support, acceptance of the maternal role, and request group (VDMR vs. CDMR) on the dependent variables of maternal perception of the delivery and maternal satisfaction with her decision for the mode of delivery. Compared to women with VDMR, women with CDMR were significantly older, less educated, perceived more risk of emergent cesarean 
and less ability to deliver vaginally. Hypothesis testing indicated that the overall regression model did not significantly predict maternal perception of the delivery. The model accounted for a significant amount $(15.1 \%)$ of the variance in maternal satisfaction with the decision for mode of delivery. Acceptance of the maternal role and maternal request group significantly contributed to the model indicating that women with higher acceptance of the maternal role and women with CDMR had poorer satisfaction with their decision for the mode of delivery.

The findings showed that factors influencing maternal perceptions of the delivery and satisfaction with the mode of delivery are different. Health beliefs had less relevance for perception of the delivery. It is possible that experiences that occur within the context of the delivery are more salient for maternal perception. Women with higher acceptance of the maternal role and who request a cesarean delivery are at risk for less satisfaction with their delivery decision and more decisional conflict and thus may need more support during decision-making processes and after delivery. Future research should examine the long-term impact of dissatisfaction with delivery decision on maternal outcomes. 


\section{UNDERSTANDING THE HEALTH BELIEFS OF FIRST TIME MOTHERS WHO REQUEST ELECTIVE CESAREAN VERSUS FIRST TIME MOTHERS \\ WHO REQUEST A VAGINAL DELIVERY}

by

DEBORAH THOMPSON MACMILLAN

A DISSERTATION

Presented in Partial Fulfillment of Requirements for the Degree of Doctor of Philosophy in Nursing in the Byrdine F. Lewis School of Nursing in the College of Health Sciences Georgia State University

\section{Atlanta, Georgia}

2010 


\section{Copyright by}

Deborah Thompson MacMillan

2010 


\section{ACKNOWLEDGEMENTS}

"Birth is not only about making babies. Birth is about making mothers: strong, competent, capable mothers who trust themselves and know their inner strength." ...Barbara Katz Rothman (1986)

I would like to thank Dr. Cecelia Grindel for being willing to take on the responsibility of chairing my committee in midstream. Your flexibility and support have been invaluable. I would like to also thank Dr. Sandra Howell for serving on my committee and for being a smiling face of reassurance whenever I saw you. You were the first person I met at Georgia State during my interview and you have stuck with me for the journey.

I must acknowledge several mentors who have contributed greatly to this project. I would like to first acknowledge Dr. Cheryl Kish, who has been a constant influence in my life since I first entered nursing school. You have always supported and encouraged me to do more than I ever would have dreamed of doing. Whenever I felt I had reached the top of my capabilities, you seemed to be there whispering in my ear and challenging me to move forward one more step. I will never forget the day you called me to your office and told me that you thought I should apply to the doctoral program at Georgia State University. I applied without any anxiety or fear of my abilities to accomplish this challenge, because I knew I would never be accepted. Much to my surprise, I was accepted and found that your confidence in me helped to give me confidence as well. Thank you, Cheryl for being able to somehow look into my heart and know when I lacked the confidence to move ahead and for always giving me that gentle nudge that I needed. 
I would like to also thank Dr. Victoria Handa who took the time to read an email from a doctoral student from Georgia and to not only respond to me, but also to allow me to be a part of your research team for the last three years. You have provided me opportunities to work not only with you, but with your research team at Johns Hopkins. What a wonderful gift you have given me. Thank you, Vicky, for your willingness to take me on as a student and to help me become a fledgling scientist. Your help and guidance have been invaluable to me.

Dr. Laura Kimble deserves special thanks for her incredible guidance and support over the last four years. I can truly say without hesitation that I could not have done this without you. I simply can find no words to thank you for the hours you have spent providing me feedback and patiently guiding me through every step of the way. You, more than anyone else, have cared for me like a midwife as I have labored over this dissertation. You have stayed with me, long after your watch was over, to be here for the birth. If I can provide for my students even a small portion of what you have given to me, then perhaps I will in some way have thanked you.

I would like to thank Dr. Pat Clark for her willingness to go above and beyond to "get me ready" to make a presentation for Dr. Handa's research team. I will never forget the changes you made to my PowerPoint presentation as I flew to Baltimore. Your supportive email and encouragement made all the difference to me on that day. I really felt that you were there that day smiling in the back of the room and giving me thumbs up. Your help was so appreciated.

This study would not have been possible without the mothers who agreed to participate in the research and to share their stories. At this busy time in their lives, they 
gave of themselves to help us better understand what is important to women as they plan for their first baby. I hope that my research will help to make a difference for women and that the mothers in my study will know that they have been a tremendous part of that. Your willingness to be a part of this research is greatly appreciated.

I would like to thank my family who has stood by my side for these last four years while I accomplished this goal. Each of you has done so much to encourage and support me. The last person and to me the most important one I would like to acknowledge is my husband, Doug. You have surrounded me with your love and even when I was far from home, I have felt your unfailing support and confidence in me. No one could have asked for a better friend and husband. You never questioned my journey; you only offered your support. You are a joy and a delight to my soul. Thank you with all my heart. 


\section{TABLE OF CONTENTS}

$\underline{\text { Page }}$

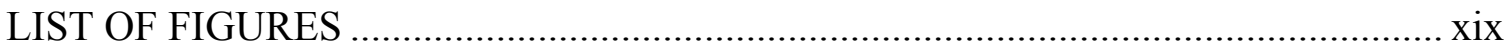

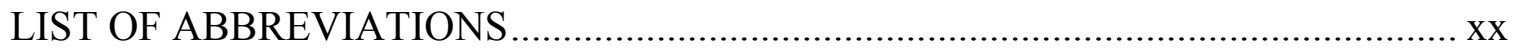

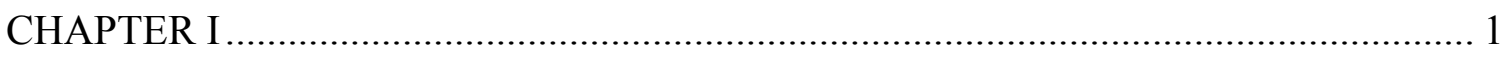

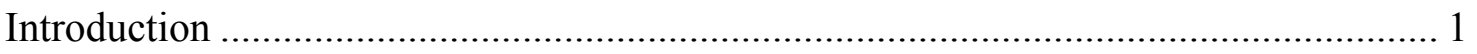

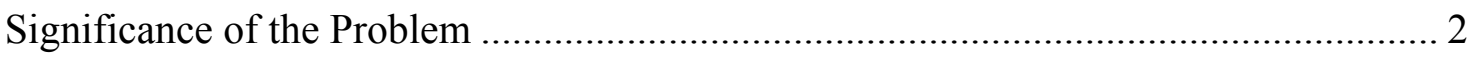

Significance of the Study for Nursing ............................................................. 4

Conceptual Framework .............................................................................. 7

Theoretical Definitions ................................................................................... 10

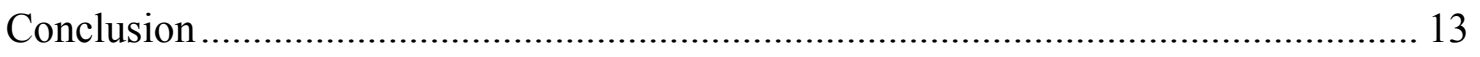

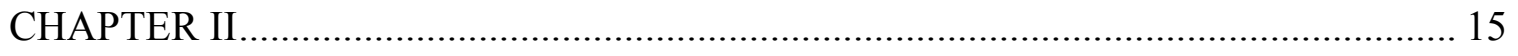

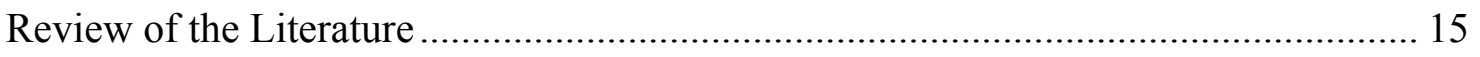

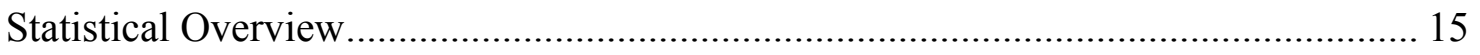

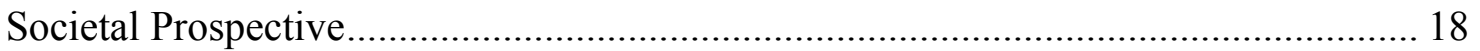

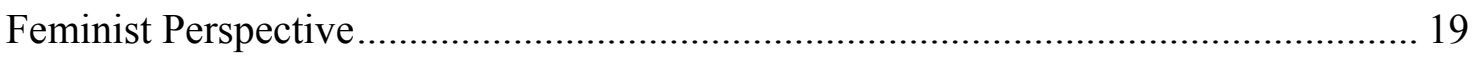

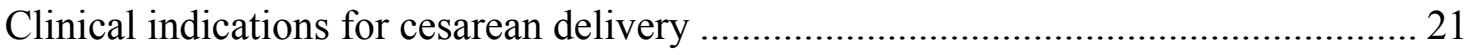

Maternal Risks and Benefits of Planned.............................................................. 24

Cesarean Delivery versus Planned Vaginal Delivery ............................................ 24

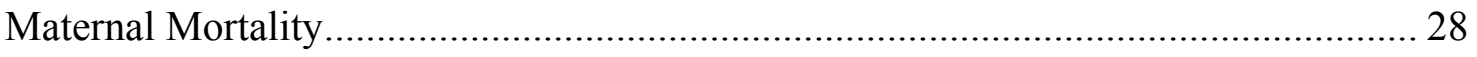

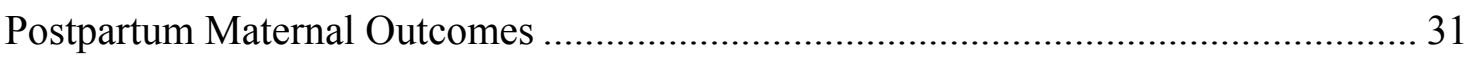

Variables Associated with Elective Primary Cesarean Delivery................................ 39

Previous Work by the Researcher in the Proposed Area .......................................... 45 


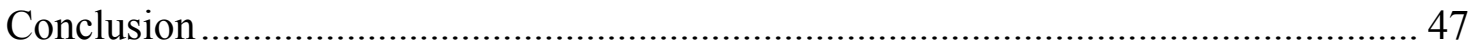

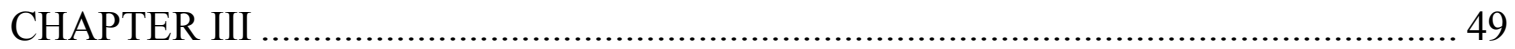

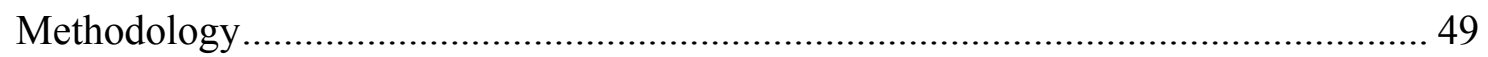

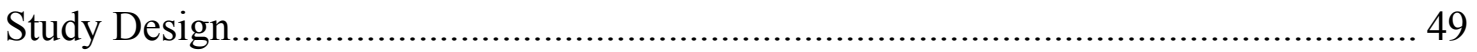

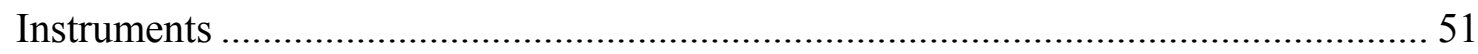

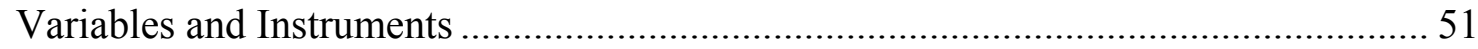

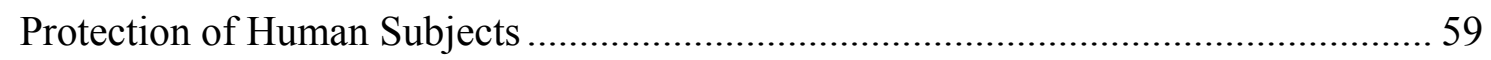

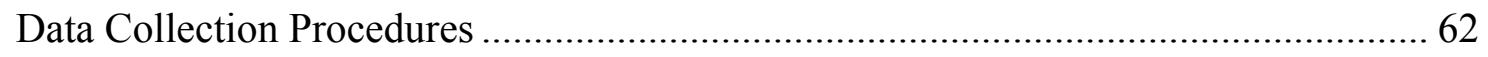

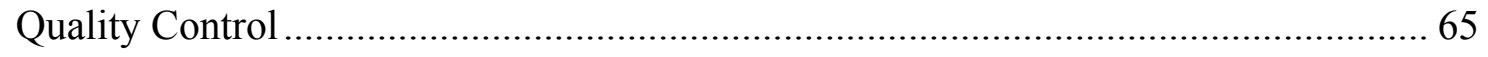

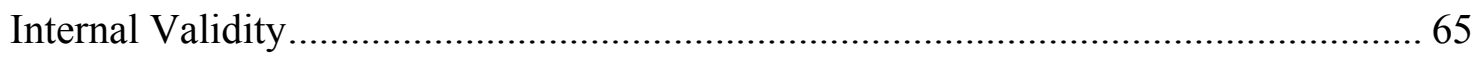

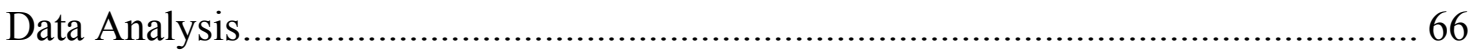

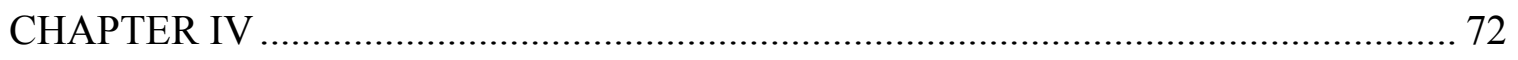

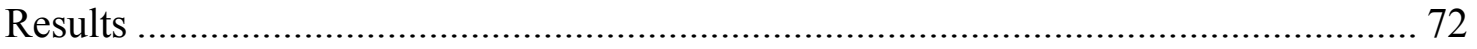

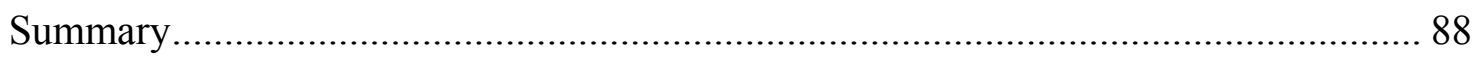

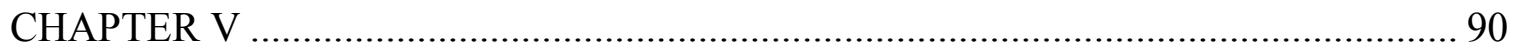

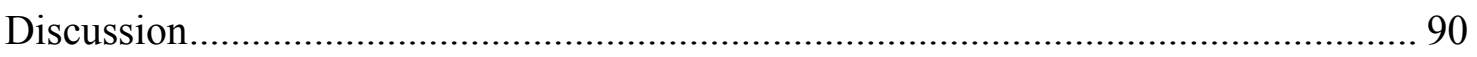

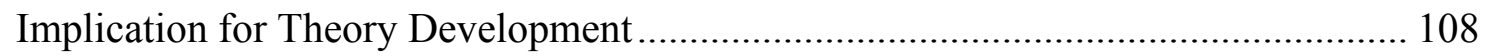

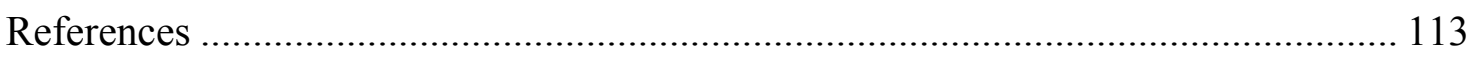

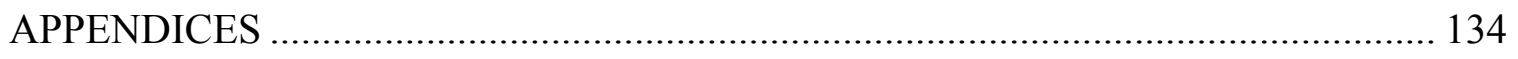

A. Prticipant Consent Form .............................................................................. 134

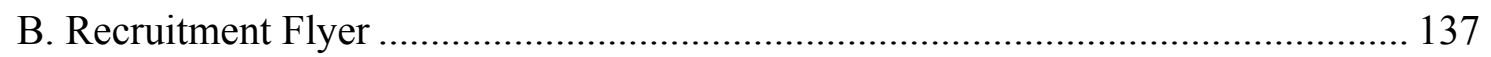

C. Maternal Health Beliefs Eligibility Questionnaire ………………........................ 139

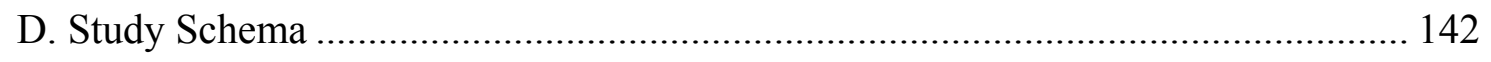


E. Questionnaire Measuring Attitudes About Labor and Delivery Experience Vaginal Delivery.

F . Modified Questionnaire Measuring Attitudes about Labor and Delivery

Experience — Cesarean Delivery ............................................................. 148

G. Decisional Conflict Scale ........................................................................ 151

H. Maternal Health Belief Questionnaire Pregnancy ............................................. 153

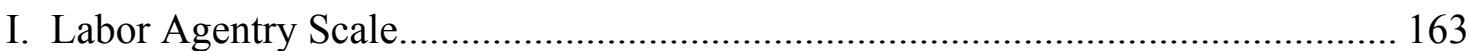

J. Maternal Health Belief Postpartum Questionnaire: Planned Vaginal Birth ........... 166

K. Maternal Health Beliefs Postpartum Questionnaire: Planned Cesarean Birth ....... 171

L. Medical Center of Central Georgia Letter of Exemption.................................. 175

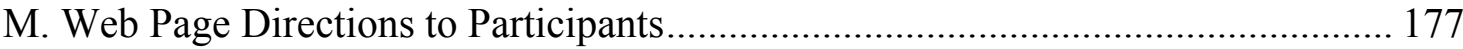

N. Letter of Introduction to Participants........................................................... 179

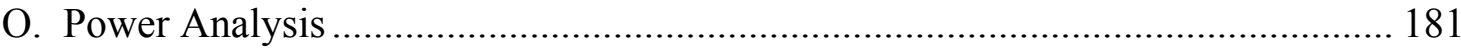

P. Paternal Reason for Planning Cesarean Delivery............................................ 184

Q. Maternal Reason for Planning Vaginal Delivery........................................ 186

R. Goal Categories with Selected Examples ...................................................... 188

S. Goals Reported by Women Planning Cesarean or Vaginal Birth ....................... 191

T. Correlation Tables for Study Variables....................................................... 193

U. Correlation Tables for Study Variables .......................................................... 195 


\section{LIST OF TABLES}

$\underline{\text { Table }}$

1. Milliman Clinical Indicators for Cesarean Section Delivery, Primary ...............22

2. Milliman Clinical Indicators for Cesarean Delivery, Repeat/Planned...............23

3. Indications for Primary Elective Cesarean (Gregory et al., 2002)....................24

4. Areas Lacking Sufficient Research Regarding Optimal Delivery Route..........27

5. Research Evidence Favoring Planned Cesarean Delivery ....................................27

6. Research Evidence Favoring Planned Vaginal Delivery ......................................28

7. Physician Reasons for Performing Elective Cesarean Delivery ............................40

8. Maternal Reasons for Choosing Elective Cesarean Delivery ...............................42

9. Overview of the Timeline for Data Collection......................................................64

10. Comparison of Maternal Request Groups on Demographic Characteristics......74

11. Comparison of Maternal Request Groups on Obstetrical Characteristics............75

12. Comparison of Maternal Request Groups on Perception of Maternal

Health Belief Variables.

13. Comparison of Maternal Request Groups on Maternal Satisfaction with Birth Experience and Satisfaction with Decision

Regarding Mode of Delivery.

14. Summary of Multiple Linear Regression Analysis for Health Belief Variables Predicting Maternal perception of the Birth Experience ….....84

15. Hierarchical Multiple Linear Regression for Health Belief Variables Predicting Maternal Perception of Birth Experience and Moderating effect of Maternal Request Group. .85 
16. Summary of Multiple Linear Regression Analysis for Health Belief Variables Predicting Maternal Satisfaction with the Decision Regarding Mode of Delivery 87

17. Hierarchical Multiple Linear Regression for Health Belief Variables Predicting Satisfaction with the Delivery Decision and Moderating Effect of Maternal Request Group. 88 


\section{LIST OF FIGURES}

Figure

Page

1. Adapted Model to Explain Health Belief of First Time Mothers

Who Request Cesarean Delivery. 


\section{LIST OF ABBREVIATIONS}

ACOG American College of Obstetricians and Gynecologists

ACNM American College of Nurse Midwives

AWHONN Association of Women's Health and Neonatal Nurses

AMA Advanced Maternal Age

CDC Centers for Disease Control

CDMR Cesarean Delivery Maternal Request

DCS Decisional Conflict Scale

DHHS Department of Health and Human Services

EPDS Edinburgh Postpartum Depression Screening Instrument

FICO International Federation of Gynecology and Obstetrics

HBM Health Belief Model

IP Internet Protocol

IRB Institutional Review Board

JACHO Joint Commission of the Accreditation of Healthcare Organization

LAS Labor Agentry Scale

MADRES Maternal Attitudes, Desires, Requests, and Expectations Study

MHBQ Maternal Health Belief Questionnaire

MQMAALD Modified Questionnaire Measuring Attitudes about Labor and Delivery

MRVB Maternal Requested Vaginal Birth

NIH National Institutes of Health

NCQA National Committee for Quality Assurance

QMAALD Questionnaire Measuring Attitudes about Labor and Delivery 
SPSS Statistical Package for the Social Sciences

WHO World Health Organization 


\section{CHAPTER I}

\section{Introduction}

The basic physiology of birth remains unchanged despite advances in maternity care. What has changed is the increased use of technology and interventions in the birthing process. Advancements in women's reproductive technology in the last few decades have resulted in women facing more decisions about the use of technological interventions in their pregnancies, such as whether to have amniocentesis, chorionic villus sampling, maternal serum screening or ultrasound screening. For some women, planning an elective cesarean may be another intervention to consider. Studies report that approximately $4 \%$ of planned primary cesarean deliveries in the United States are for no clear medical or obstetrical indication (Gregory, Korst, Gornbein, \& Platt, 2002). It has been suggested that maternal request of elective cesarean may partly explain this number (Zwelling, 2008). Childbirth is a natural, normal, and healthy process for the majority of women, yet increasing numbers of women are expressing fear for themselves or their babies as one factor in their reasons for requesting elective cesarean deliveries. These same women are also expressing the belief that cesarean delivery is the safest method of delivery for the baby (Weaver, Statham, \& Richards, 2007).

There appears to be an evolving attitude shift among healthcare providers and childbearing women in the United States that has resulted in the perception that women cannot or should not do what their bodies were made to do (Zwelling, 2008). This change in attitudes may explain the increase in the number of obstetric procedures and 
interventions performed solely for convenience (e.g. elective induction of labor, early artificial rupture of membranes), which lack evidence that they provide clear benefits for the mother or infant (Simpson \& Thorman, 2005). Women's source of knowledge about childbirth may have shifted from family and friends to reality television shows about childbirth, which creates a culture of heightened fear and anxiety around birth (Reiger \& Dempsey, 2006). This view of childbirth is perhaps most surprising, because it exists in a country where severe maternal morbidity and maternal mortality with vaginal births are rare and equally positive are neonatal outcomes.

The issue of maternal request for elective cesarean is complex. It appears to have interrelated factors that are not easily explained. A lack of evidence about the risks and benefits of elective cesarean versus vaginal delivery has been identified. Limited information is available about how the decision for elective cesarean section comes about in the clinical environment. It is important to view the phenomenon of maternal request from both the healthcare provider and the maternal vantage point. Pregnancy and birth are significant life events for first time mothers and their partners. Maternal outcomes depend not simply on the woman, the psychosocial environment, the healthcare provider, the birth attendant or hospital policies; rather it is in the weaving together of these complex interrelationships that creates the tapestry of each woman's birth experience including her decision to seek a cesarean versus a vaginal delivery.

\section{Significance of the Problem}

With over 4 million births in the U.S. each year, the public health impact of elective cesarean delivery is potentially enormous (Declercq, Barger, Cabral, Evans, Kotelchuck, \& Simon, 2007). A 1\% rise in elective cesarean would result in 40,000 
additional cesarean births. Compared with elective cesarean delivery, vaginal delivery costs $7.1 \%$ ( $\$ 853$ per delivery) less in direct cost than elective cesarean delivery (Caughey, 2003). This does not take into consideration the indirect cost incurred from potential complications and future costs that may be incurred in later pregnancies if repeat cesareans are necessary.

The issue of cost must also be considered in the broader context of burden to the already stressed healthcare system and the impact on finite resources. Cesarean delivery is associated with longer length of stay, higher occupancy rates, and maternal readmissions for post operative complications (Declercq et al., 2007; Druzin \& El-Sayed, 2006). It is important to understand that the acceptance of maternal request cesarean as a possible standard of care could deplete finite health care dollars; especially when in 2010, 4.9 million Americans did not even have access to basic health insurance (Druzin \& ElSayed, 2006; Garett, Buettgens, Headen, \& Hulahan, 2010). This represents $19.2 \%$ of the non elderly population in the United States.

No studies are available that compare the maternal risks and benefits of cesarean delivery by maternal request (CDMR) to maternal requested vaginal birth (MRVB) (MacDorman, Declercq, Menacker, \& Malloy, 2006; Miesnik \& Reale, 2007; National Institute of Health, 2006). Given that a primary cesarean virtually insures that all future births will also be cesarean, health outcomes and the economic impact of elective cesarean delivery should be considered. However, studies comparing medically indicated cesarean delivery to vaginal birth must be applied with caution when comparing CDMR to vaginal birth. Theoretically, maternal outcomes of fever, infection, pneumonia, and thromboembolic events are consistently increased with medically indicated cesarean 
delivery and would also be present in instances of CDMR (Declercq et al., 2007; Koroukian, 2004; Lydon- Rochell, Holt, Martin, \& Easterling, 2000; Liu \& Yang, 2003). Similarly, evidence for worse neonatal outcomes such as iatrogenic prematurity, increased length of stay, respiratory morbidity, and infection are associated with medically indicated cesareans, but limited research has compared CDMR to MRVB (MacDorman, et al., 2006; National Institute of Health, 2006).

Risks to the family unit in terms of negative perceptions of the birth experience, delayed bonding, and ineffective breastfeeding have been strongly associated with cesarean delivery (Declercq et al., 2007; Gamble \& Creedy, 2005; Nerum, Halvorsen, Sorlie, \& Oian, 2005; Saisto \& Halmesmaki, 2003; Waldenstrom, Hildingsson, Ryding, 2006). However, it is unclear the proportion of women in these studies who had medically necessary cesarean versus maternal requested cesarean deliveries. Consequently, in many obstetrical settings, fulfilling the maternal request for cesarean delivery is viewed as a key component to a positive birth experience despite nonexistent data to support this conclusion.

\section{Significance of the Study for Nursing}

To date, we know very little about how the decision for elective cesarean section comes about in the clinical environment. A study by Childbirth Connection suggested that physician preference may be a factor in elective cesarean delivery more so than a mother's request. This study indicated that $9 \%$ of women reported experiencing pressure from a healthcare professional to undergo cesarean delivery. It is also not understood what effects media, pressure from family, partner or peers may play in this phenomenon. No published studies in the United States and limited studies in other countries have 
asked nulliparous women directly about the decision to proceed with an elective cesarean delivery, as compared to women who choose vaginal delivery. This research study involved asking women directly about the decision making process and their health beliefs which led to their decision about their delivery request. The prospective study obtained data prior to the delivery, to reduce the risk that the events of delivery might bias mothers' answers. The aim was to describe the maternal health beliefs and maternal perceptions of the decision making process regarding mode of delivery among first time mothers planning a vaginal birth versus women planning an elective cesarean delivery. The specific aims and associated hypotheses or research questions for the study were as follows:

Specific Aim I. Compare first time mothers who request cesarean delivery and first time mothers who request vaginal delivery, to investigate differences in health beliefs, maternal outcomes, and goals for the birth experience.

QI.1 Do women who request cesarean delivery and women who request vaginal delivery differ on maternal characteristics, perceived self efficacy, perceived threat, perceived risk, perception of the birth experience and satisfaction with delivery decision?

QI.2 Do women who request vaginal delivery and women who request cesarean delivery differ in maternal goals for the birth experience?

Specific Aim II. Examine the effects of selected health beliefs, assessed in the third trimester, on maternal perceptions of the birth experience and maternal satisfaction with the delivery decision, both assessed after delivery among first time mothers.

H II.1 Antenatal maternal characteristics (control, acceptance of motherhood role), perceived self efficacy, perceived threat, perceived risk, cues to action 
(husband/partner support, perception of provider opinion), and maternal request group will account for a significant amount of the variance in postpartum maternal perception of the birth experience controlling for selected maternal demographic and obstetrical history variables.

HII.2 Antenatal maternal characteristics (control, acceptance of motherhood role), perceived self efficacy, perceived threat, perceived risk, cues to action (husband/partner support, perception of provider opinion) and maternal request group will account for a significant amount of the variance in postpartum maternal satisfaction with the delivery decision, controlling for selected maternal demographic and obstetrical history variables.

Specific Aim III. Examine maternal request group as a moderator of the relationship between perceived threat and maternal outcomes of perception of the birth experience and satisfaction with the delivery decision.

H III.1 Maternal request group will moderate the relationship between perceived threat and perception of the birth experience, controlling for selected maternal demographic and obstetrical history variables.

H III.2 Maternal request will moderate the relationship between perceived threat and maternal satisfaction with the delivery decision, controlling for selected maternal demographic and obstetrical history variables.

These specific aims listed above were consistent with the priorities of research that have been identified during the 2006 NIH State of the Science Panel on "Cesarean Delivery on Maternal Request" as needed to address the limitation of current knowledge about maternal decision process for CDMR, patient satisfaction after CDMR, and quality of life 
outcomes after CDMR versus other modes of birth. This study represents an initial step in a program of research with the long term goals of developing and testing potential nursing interventions aimed at reducing maternal fear and anxiety of childbirth, promoting health maternal decision making and increasing maternal satisfaction with birth experience.

\section{Conceptual Framework}

The conceptual framework selected to examine the phenomenon of CDMR was a modification of the Health Belief Model. Giving birth is an important life event for women. During childbirth, there is always the potential for psychological benefits or damage (Simpkin, 2006). Identifying a conceptual framework that would provide sound theoretical basis for understanding women's decision making about childbirth was vitally important.

The Health Belief Model (HBM) developed in the 1950's (Maiman \& Becker, 1974) is an example of a rational choice model of decision making based on a valueexpectancy theory (Janz, Champion, \& Strecher, 2002). The HBM was developed to explain decisions around individuals' participation in preventative health care. It was later used to explain people's responses to symptoms and diagnosed illnesses. The HBM hypothesizes that individuals' perceptions about their susceptibility to a condition and the perceived seriousness of the effects of the condition along with the perceived benefits and barriers associated with the action or treatment available will influence whether they will participate in preventative health care activities (Maiman \& Becker). The combined levels of susceptibility and threat provide the energy or force to act and the perception of benefits (less barriers) provides a preferred path of action. The stimulus necessary to trigger the decision making process or cue to action may be internal or external (e.g. mass 
media, interpersonal interactions, and communications with healthcare providers) (Rosenstock, 1974). Unfortunately, few HBM studies have attempted to assess the contribution of cues to predicting health actions, and no studies have studied this variable in the context of the model (Janz \& Becker, 1984; Janz et al., 2002). The HBM assumes that demographic, socio-psychological, and structural variables might affect the individual's perception and indirectly influence health-related behavior (Janz \& Becker). Applied to the maternal request for elective cesarean decision making process, the perceived susceptibility to the condition corresponds to the risk of having an emergent cesarean after the onset of labor. Perceived threat is conceptualized as the maternal perception of seriousness or risks associated with planning a vaginal delivery vs. planning a cesarean delivery. Perceived self efficacy corresponds to the maternal belief that she will be able to accomplish a vaginal delivery. The Maternal Health Belief Model is shown on the following page in Figure 1. 
Figure 1. Maternal Health Belief Model

Adapted Model to Explain Health Beliefs of First Time Mother Who Request Cesarean Delivery

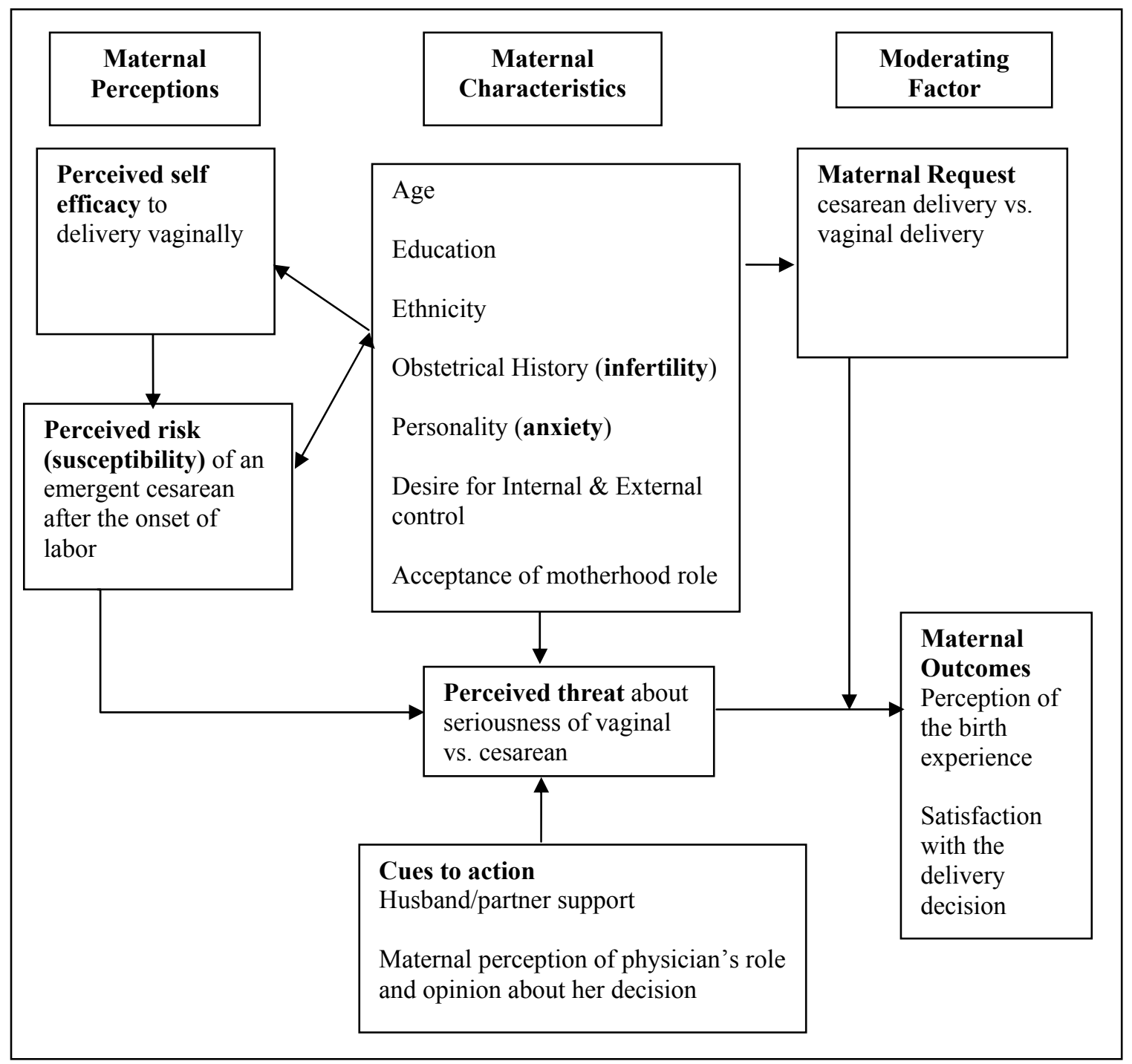




\section{Theoretical Definitions}

The following are the theoretical definitions for the Health Belief Model applied to the situation of maternal request.

\section{Perceived Risk}

Perceived risk is conceptualized as the maternal perception of the risk of an emergent cesarean after the onset of labor. Maternal evaluations of risk speak to feelings of personal vulnerability of requiring a cesarean delivery.

\section{Perceived Threat Regarding Risk of Vaginal Delivery vs. Cesarean Delivery}

Perceived threat is conceptualized as the maternal perception of seriousness or risks associated with planning a vaginal delivery vs. planning a cesarean delivery. Maternal evaluations of threat include both medical and clinical consequences (e.g. perineal damage, neonatal meconium aspiration, severe fear of vaginal birth, fear of vaginal exams and pain) and possible social consequences (e.g. lack of a support person in labor, concern for behavior in response to pain or fear).

\section{Perceived Self Efficacy for Vaginal Delivery}

Perceived self efficacy is conceptualized as the maternal perception of her ability to delivery vaginally if she is in labor. Maternal evaluation of self efficacy related to her physical ability to accomplish the task of dilation of the cervix and delivery of the infant.

\section{Cues to Action Regarding Vaginal Delivery vs. Cesarean Delivery}

The concept of cues to action in this study is conceptualized as a trigger mechanism to the action of making a request for mode of delivery. Maternal perception of the healthcare provider's opinion will be defined as the mother's understanding of the communication between herself and the healthcare provider regarding the mode of 
delivery most appropriate for her situation. Media publicity or modeling of behavior (e.g. knowing someone or being aware of someone who chooses an elective cesarean) could potentiate the readiness to request a cesarean delivery by increasing the maternal perception of cesarean delivery as an acceptable method of delivery. Partner support and family support have been identified as important factors in maternal decision making. The role of partner or family in cues to action is as of yet unknown. For hypothesis testing, the cues to action of healthcare provider and the support of husband/partner will be the focus as these address gaps in the literature.

\section{Maternal Characteristics}

Diverse demographic, social, psychological, and structural variables may affect the mother's perceptions and ultimately indirectly influence health-related behavior and decision making. For the purposes of hypothesis testing and to contribute to gaps in the literature, the variables of control and acceptance of the motherhood role are included in the model. Data will be collected on sociodemographic factors, particularly educational attainment and maternal age to serve as potential control variables as they are theorized to influence perceptions of susceptibility and threat. Additionally pregnancy anxiety, severe fear of childbirth, and prolonged history of infertility will also be included as potential control variables that could influence health beliefs.

\section{Desire for Internal and External Locus of Control}

Control is conceptually defined as being in control of the birth process and the woman feeling she is an active participant in birth rather than a passive object of care. Control of the birth process will be further defined as internal locus of control (control of pain, control of emotions such as fear and anxiety), and external locus of control (control 
of the environment, of staff and procedures). By being in control women may feel themselves competent to overcome perceived barriers to choosing vaginal birth. Sense of control is defined as one's perception of the need to or ability to control the overall process of giving birth. Sense of control additionally reflects at the concepts of giving birth on one's own terms and self determined closure of pregnancy (Kitzinger, 2006).

\section{Maternal Perception of the Birth Experience}

The perception of the childbirth experience is highly personalized, and maternal views may vary about what factors are important in a positive and satisfying experience. Satisfaction is a construct that is complex and multidimensional. Hodnett (2002) stated that satisfaction is a positive affective response to an experience and a cognitive evaluation of the emotional response. It is possible to be satisfied with aspects of the experience and dissatisfied with others (Waldenstron, 2004). Research has indicated that $60 \%$ of women make the same assessment of their birth experience at 1 year after delivery as they did at 2 months, but that $24 \%$ become more negative over time and $16 \%$ will become more positive (Waldenstrom). Reasons for this change where considered when making decisions about timing data collection. Measurements taken immediately following delivery can be affected by the euphoric reactions that labor is over and the birth resulted in a healthy baby. Retrospective analysis of the birth experience by the mother may be affected by complex psychosocial events that are hard for the researcher to anticipate and control. Consequently, a prospective longitudinal design was used for this study with maternal health belief data assessed 4 to 8 weeks prior to delivery and maternal perceptions of the birth experience and satisfaction with the delivery decision measured six weeks after the delivery. 


\section{Maternal Satisfaction with the Delivery Decision}

Individuals seek different roles regarding their level of involvement (e.g., active versus passive) in decisions about their care, and conflict and satisfaction with this process is likely to reflect the ability to provide their preferred level of involvement (Sampietro-Colom, Phillips, \& Hutchinson, 2004). Research conducted with women making decisions about prenatal and genetic screening has provided some insight about decision making during pregnancy. Lawson and Pierson (2007) reported the importance of partner support and physician communication in the satisfaction with the decision, and that women often expressed dissatisfaction when they felt pushed into making the decision alone. Women making a decision about prenatal testing may feel pressure from their physicians or significant others to make certain decisions. Women who feel supported in the decision making process; report greater self-efficacy, decreased conflict and more satisfaction with the decision (Marteau, Plenicar, \& Kidd, 1993).

\section{Conclusion}

An absence of research is noted using a conceptual model to specify how the process of maternal decision making and maternal choice of delivery method may interact with maternal outcomes. A review of current literature provided consistent evidence about the maternal characteristics and the perceptions of women who reported requesting an elective cesarean delivery in the United States. Women requesting cesarean delivery are older, married, well educated, primarily Caucasian. They also expressed fear of childbirth, a desire for their partner to be supportive, and a desire for childbirth to be a pleasant and satisfying experience (Bryanton, Gagnon, Johnson, \& Hatem, 2008; McCourt, Weaver, Statham, Beake, Gamble, \& Creddy, 2007; Miesnik \& Reale, 2007; 
Soet, Brack, \& Diloria, 2003; Suplee, Dawley, \& Block, 2007; Weaver, Statham, Richards, 2007; Wiklund, 2007). Women planning a cesarean have consistently expressed the belief that a cesarean delivery was safe or safer for themselves and their baby than a vaginal delivery (Bryanton et al.2008; McCourt et al., 2007; Miesnik \& Reale, 2007; Soet et al., 2003; Weaver et al.; Suplee et al., 2007; Wiklund, 2007). No studies have examined the complex relationships among individual, interpersonal, and societal factors which may be contributing to the phenomenon of maternal request. The effects of changing societal norms, provider influence and partner and family involvement in the decision process need to be examined. Asking women to identify the barriers they perceive to planning a vaginal delivery is an important factor in the development of nursing interventions that can shape hospital policies and support women who are making decisions about childbirth. 
CHAPTER II

\section{Review of the Literature}

\section{Statistical Overview}

This review discusses the current literature regarding cesarean delivery; clinical indications for cesarean delivery, maternal and infant outcomes, and ethical viewpoints related to performing a cesarean without specific medical indications. Maternal characteristics and variables (psychological, social, or clinical) associated with maternal request of elective primary cesarean delivery in past studies will be identified. Rationales for the selection of those variables identified as salient in studying maternal request will be discussed. The importance of maternal satisfaction with her delivery and her decision to request a specific mode of delivery will also be discussed.

The United States cesarean section rate was $4.5 \%$, when it was first measured in 1965 (Taffel, Placek, \& Liss, 1987). The National Center for Health Statistics reported the United States cesarean delivery rate for 2006 was 31.1\% (U.S. National Center for Health Statistics). An increase in the cesarean delivery rates has been observed in all industrialized countries (National Institute of Health [NIH], 2006). These rates vary widely by country, health care facilities, and delivering physicians. The variance in rates is partly explained by differing perceptions of healthcare providers and women regarding the benefits and risks of cesarean delivery (McCourt et al., 2007; Suplee et al., 2007; Weaver et al., 2007; Women's Health Care Physicians, 2000). This increased acceptance 
of cesarean delivery, as a reasonable elective option for childbirth, may be attributed to the relative safety of cesarean delivery combined with a change in perceptions regarding the risks and benefits of vaginal delivery (American Journal of Obstetricians and Gynecologists [AJOG], 2003; Hannah, 2004; MacDorman et al, 2006; McCourt et al., 2007; Weaver et al., 2007; Women's Health Care Physicians, 2000).

Historically, cesarean deliveries were primarily emergent and took place directly because of, or in association with obstetrical complications or maternal illness (Terhaar, 2003). Today it is estimated that $4 \%$ to $18 \%$ of all cesarean deliveries are elective primary cesareans deliveries with no clear medical or obstetrical indication (National Institute of Health, 2006). Any decision for an elective primary cesarean delivery is best viewed in the context of the maternal and infant health outcomes that can be expected. To date, insufficient evidence is available to evaluate the short and long term risks and benefits of maternal planned primary cesarean delivery compared with planned vaginal deliveries (Liu \& Yang, 2007; Miesnik \& Reale, 2007; National Institute of Health).

The current debate surrounding cesarean delivery rates arises from a wide variety of national organizations that monitor healthcare quality including the following: National Institutes of Health (NIH), Department of Health and Human Services (DHHS), National Committee for Quality Assurance (NCQA), American College of Obstetricians and Gynecologists (ACOG), Joint Commission of the Accreditation of Healthcare Organization (JACHO), American College of Nurse Midwives (ACNM), and Association of Women's Health and Neonatal Nurses (AWHONN). These organizations, policy makers, and health care advocates have expressed concern over the wide variation in cesarean delivery rates based on clinical and non-clinical factors (Gregory, Korst, 
Gornbein, \& Platt, 2002). Part of this discussion is related to the evaluation of cesarean rates by third-party payers, health system accrediting bodies such as NCQA and JCAHO, and national organizations as a measure of hospital performance and maternal health care quality (Gregory et al.). This concern has stimulated discussion and research regarding the appropriate clinical indicators for emergent, preplanned elective and repeat cesarean delivery.

A number of national organizations have offered position statements regarding the endorsement or rejection of maternal choice as an appropriate indicator and ethically justified. In 2003, the American College of Obstetrics and Gynecology (ACOG) recommended acceptance of medically elective cesarean delivery based on the principles of patient autonomy and informed consent, if the physician believes it will promote the overall health and welfare of the woman and her fetus (ACOG, 2003). The International Federation of Gynecology and Obstetrics (FIGO) guidelines state that because hard evidence of net benefit does not exist, performing cesarean delivery for nonmedical reason is not ethically justified (International Federation, 2004). The American College of Nurse Midwives (ACNM) identified vaginal birth as the optimal mode of delivery for women without a medical indication for cesarean delivery (ACNM, 2004). The Association of Women's Health, Obstetric, and Neonatal Nurses (AWHONN) opinion statement strongly encourages dissuading women from having medically elective cesareans delivery prior to 39 weeks and supports further research into the issue (AWHONN News and Views, 2004). 


\section{Societal Prospective}

"Birth is everywhere socially marked and shaped" (Jordan, [1978] 1993, 1). The expectation of a perfect outcome is fueled by the myth, subscribed to by both physicians and patients, that technology can predict and solve all problems (Rosen \& Thomas, 1989). Women feel tremendous social pressure to produce the perfect child, while remaining sexually attractive, and performing the task of childbirth in a timely manner that avoids inconveniencing others (Reiger \& Dempsey, 2006). Physicians are also under pressure to provide perfect outcomes in a world where childbirth has to fit around financial productivity, limited healthcare resources, fear of litigation and rising cost of malpractice insurance (Bergeron, 2007). Research about internal sense of control based on perceptions of gender has indicated that white middle class women worry about being nice, polite, kind, and selfless in their interactions during labor and childbirth (Martin, 2003). Worries about interactions during childbirth for minority women are largely unknown. The climate in which birth takes place in the United States today has been described as a culture of fear for both women and their healthcare providers (Reiger \& Dempsey).

As women have climbed the corporate ladder, the pressures to not let childbirth interrupt the corporate schedule have increased. The financial and social pressure to remain employed in today's culture is strong (Martin, 2003). Women move frequently, often far away from extended family and close friends so that the traditional social support for women during pregnancy and childbirth is disappearing. All of these factors may combine to create a social environment where women perceive they have no support and limited choice when making decisions about delivery. Women face advice and 
comments from strangers, acquaintances, co-workers, family members and healthcare providers about the best way to make decisions about their delivery. The idea that childbirth should be managed and controlled for the least inconvenience of the most people has perhaps limited women's perceived choice to options that she perceives as most appropriate or convenient for others and not the choices which she may perceive as being more appropriate or convenient for her personally. For example she may feel that waiting for the onset of labor rather than scheduling the date and time for delivery may be more convenient for her family and co-workers.

\section{Feminist Perspective}

No single voice was found that represents the feminist viewpoint regarding maternal choice of an elective cesarean. A feminist perspective would certainly support the autonomy of a woman's choice to be in control of her body and to what happens to her body during childbirth (Beckett, 2005). Support is found in feminist scholarship that gives women a privileged position in decisions about their health care and in the ethical analysis of these decisions (Bergeron, 2007). Feminist critique of maternal choice has argued however, that this new option in childbirth merely masquerades as increased autonomy while supporting interests unrelated to women's health and welfare (Bergeron, 2007). This criticism is based on the viewpoint that gender-based oppression in general society and the medical model of childbirth, which is based on pathology, inhibits the viewpoint of childbirth from a woman's perspective with her priorities in mind (Arney, 1982). The feminist viewpoint argues that since childbirth no longer belongs to women, the range of autonomous choices they have is only what is given to them by those in charge. Insurance providers, healthcare providers, and hospitals control the range of 
options that are presented to women about their childbirth choices which effectively restricts women's autonomy in regards to making decisions about childbirth (Bergeron, 2007).

It has also been argued that the emphasis on autonomy, with the exclusion of other ethical principles (e.g., beneficence) is misleading. Meaningful consent assumes that women receive information to make decisions and that the information available to them is adequate and will address not only this pregnancy but also future pregnancies. At this time comprehensive beneficence based judgments using both suggested and documented benefits of planned cesarean delivery versus planned vaginal delivery present powerful arguments for not embracing planned cesarean delivery until further research is available (Minkoff, Powderly, Chervenak, \& McCullough, 2004).

The application of the ethical principal of justice generally requires both a fair process of allocating benefits and burdens and assurance that the process will distribute this fairly (Minkoff et al., 2004). A feminist's viewpoint would argue that when current data indicate it would require large numbers of elective cesareans to prevent each instance of morbidity thought to be related to vaginal delivery (e.g. urinary incontinence, Erb's palsy, cerebral palsy) it offends justice to impose iatrogenic burdens on so many patients to produce benefits for so few (Williams, 2008). It can also be argued that the application of resources to do cesareans that are not medically indicated distracts from the greater challenges of obstetrical care that would distribute more fairly the benefits (Christilaw, 2006). Some feminists will find fault with this argument, and emphasize that individual freedoms for reproductive decisions have been too difficult to obtain to risk compromise at this point (Bergeron, 2007). No past studies have examined if women are 
satisfied with the decisions they are making about their delivery regarding cesarean delivery and if they feel that they are fully informed and supported in their decisions.

\section{Clinical indications for cesarean delivery}

There is at this time, no consensus regarding absolute clinical indications for cesarean delivery or an accepted benchmark rate for cesarean delivery (NIH, 2006). Healthy People 2010 from DHHS focused on reducing the national rate of first time cesarean, low-risk patients (low-risk equals a low likelihood of requiring cesarean delivery; full-term, singleton, vertex position) to $15.5 \%$. These goals were revised from Health People 2000 proposed benchmark for an overall cesarean rate of $15 \%$, which received criticism from some experts claiming this benchmark inadequately addressed patient case mix or patient safety factors (Health Grades, 2003).

The Milliman Care Guidelines are evidence-based clinical indicators for emergent, preplanned primary, and repeat cesarean delivery which are updated annually and are used by nine of the eleven largest managed care organizations in America. The American College of Obstetricians Position Statements are frequently cited in the Milliman Guidelines. These guidelines can be found in Table 1 and Table 2. Maternal choice as a clinical indicator is only discussed in connection with repeat cesarean delivery. It is stated that the documentation of the mother to forego a trial of labor, is considered an appropriate indicator for planning a repeat cesarean. 
Table 1

Milliman Clinical Indicators for Cesarean Section, Primary

Failed trial of labor, non-reassuring fetal status, or other obstetric indication

Dystocia $^{1}$, protraction disorder or arrest disorder, with adequate contractions

Fetal malposition (E.g., breech ${ }^{2}$, brow, transverse lie)

Multiple intrauterine pregnancy (i.e., Twins, Triplets, Quads)

Non-reassuring fetal status, fetal distress ${ }^{3}$ (e.g., fetal acidosis)

Cord prolapse, placenta previa, or placenta abruption

Previous myomectomy or uterine reconstruction, which is full thickness or enters the uterine cavity

Previous intra-uterine fetal surgery

HIV, active herpes

Medical or obstetrical complications precluding vaginal delivery

Suspected macrosomia by sonographic estimated fetal weight greater than 4250 grams in diabetic individuals

${ }^{1}$ See ACOG Technical Bulletin \# 218 definition of dystocia.

${ }^{2}$ See ACOG Committee Opinion \# 202 Breech

${ }^{3}$ See ACOG Committee Opinion \#197 definition of fetal distress 
Table 2

Milliman Clinical Indicators for Cesarean Section, Repeat/ Planned

Clinical indication listed above for primary cesarean section would apply to repeat or planned cesarean section.

Previous low vertical uterine incision or classical C-section ${ }^{1}$

Previous T-shaped extension of lower transverse uterine incision

Unknown type of uterine scar (i.e., cannot be determined)

Documented choice of patient to forgo a trial of labor in favor of a scheduled repeat C-section

Abnormal lie with failure or refusal of version

Contraindication to vaginal birth: clinically inadequate pelvis, previous rupture, placenta previa, limited emergency facilities (physician, anesthesia, personnel, facility)

${ }^{T}$ There are few absolute contraindications to a trial of labor and few reliable predictors of success or failure of a trial of labor.

Gregory et al. (2002) undertook a large population based retrospective study to develop a standardized methodology to identify indications for elective primary cesarean and describe appropriate rates using routinely available administrative data from medical records. Women in the study population that had experienced a previous cesarean were excluded. Findings suggested that in this study population elective primary cesarean delivery accounted for approximately $4 \%$ of all births. For $92.9 \%$ of these births, 12 specific clinical indications could be assigned. The remaining $7.1 \%$ were unspecified and can be possibly attributed to maternal choice cesarean or inadequate coding (Gregory et al., 2002). Statistical analysis using this algorithm identified 12 conditions that accounted for $92.9 \%$ of elective primary cesarean deliveries for this study. The clinical conditions identified can be found in Table 3 . 
Table 3

Indications for Primary Elective Cesarean (Gregory et al., 2002)

Clinical Condition \% Patients Undergoing Elective Primary Cesarean

Mal-presentation

Antepartum Bleed

Herpes

Severe hypertension

Other uterine scar

Multiple gestation

Macrosomia

Unengaged fetal head

Maternal soft tissue disorder

Hypertension, other

Preterm labor

Fetal congenital anomaly

Unspecified
$57.10 \%$

$10.75 \%$

$5.56 \%$

$3.96 \%$

$1.11 \%$

$2.29 \%$

$4.51 \%$

$1.70 \%$

$1.53 \%$

$2.85 \%$

$1.66 \%$

$0.11 \%$

$4.27 \%$

\section{Maternal Risks and Benefits of Planned}

\section{Cesarean Delivery versus Planned Vaginal Delivery}

The elements for evidence based decision making about the most appropriate method of delivery are lacking. Evidence continues to be limited about the actual number of planned primary cesarean deliveries that are not associated with a medical indication. The National Institutes of Health (NIH) convened a State-of-the-Science Conference in March of 2006 to assess the available scientific evidence relevant to cesarean delivery on maternal request. The broad aim of the study was based on the consensus that cesarean delivery by maternal request should be guided by the best possible information regarding potential health outcomes for both the mother and the baby. The following questions were addressed at the conference. 1 . What is the trend and incidence of cesarean delivery over time in the United States and other countries? 2. What are the short-term (under 1 
year) and long-term benefits and harms to mother and baby associated with cesarean delivery by request versus attempted vaginal delivery? 3 . What factors influence benefits and harms? 4. What future directions need to be considered to get evidence for making appropriate decisions regarding cesarean delivery on request or attempted vaginal delivery? The framework of the evidence analysis adopted was to assess the state of the science regarding outcome differences in women who elect planned cesarean delivery versus planned vaginal delivery. The panel utilized the following evidence quality grading scale: Level I - strong, Level II - moderate, Level III - weak, Level IV - absent. For the evidence to be rated as strong it had to meet the following criteria. The evidence is from studies of strong design; results are both clinically important and consistent with minor exceptions at most; results are free from serious doubts about generalizability, bias, or flaws in research design. Studies with negative results have sufficiently large samples to have adequate statistical power. Moderate quality evidence was defined as evidence from studies of strong design, but some uncertainty because of inconsistencies or concern about generalizability, bias, research design flaws, or adequate sample size. Moderate quality evidence was also defined as consistent evidence, but derived from studies with weaker designs. Weak quality evidence was defined as evidence from a limited number of studies of weaker design or studies with strong design with results that are inconclusive. If no evidence or no published literature was found the quality assigned was absent.

For the maternal and neonatal outcomes listed in Tables 4, Table 5, and Table 6; no Level I evidence was found. Three outcomes had Level II evidence, and the remaining outcomes were Level II or IV. No prospective studies comparing the short and long term 
risks and benefits of planned primary cesarean delivery versus planned vaginal delivery were identified. The relevant data that are available are from retrospective studies that have attempted to create comparison groups using proxy definitions for maternal planned primary cesarean (e.g. breech presentation, repeat cesarean,) or have compared maternal and fetal outcomes from emergent cesarean delivery and planned cesarean delivery with vaginal births populations. Limited studies are available regarding maternal psychological outcomes which compared women who planned a primary cesarean when no medical indications were present with women who planned a vaginal birth (Saisto, Salmela, Nurmi, Kononen, \& Halmesmaki, 2001). Existing studies comparing medically indicated cesarean delivery or proxy planned cesarean to vaginal birth should be viewed with caution, since differences in these groups may exist. A summary of that research can be seen in Table 4, Table 5, and Table 6 on the following pages. 
Table 4

Areas Lacking Sufficient Research Regarding Optimal Delivery Route

\begin{tabular}{lcc}
\hline Maternal \& Neonatal Outcome & Quality of Evidence & Research Source \\
\hline Maternal Anorectal Function & Inadequate study & NIH (2006) \\
Sexual Function & Weak & NIH \\
Pelvic Organ Prolapse & Weak & NIH \\
Subsequent Stillbirth & Inadequate study & NIH \\
Maternal Mortality & Inadequate study & NIH \\
Postpartum Depression & Inadequate study & NIH \\
Fetal mortality & Weak & NIH \\
\hline
\end{tabular}

Table 5

Research Evidence Favoring Planned Cesarean Delivery

\begin{tabular}{lcc}
\hline Maternal \& Neonatal Outcome & Quality of evidence & Research Source \\
\hline $\begin{array}{l}\text { Postpartum Hemorrhage } \\
\text { Urinary incontinence }\end{array}$ & Moderate & NIH (2006) \\
$\begin{array}{l}\text { Surgical and traumatic } \\
\text { complications }\end{array}$ & Weak & NIH \\
$\begin{array}{l}\text { Neonatal hemorrhage, } \\
\text { asphyxia, \& encephalopathy }\end{array}$ & Weak \\
Birth Injury and laceration & Weak & NIH \\
\hline
\end{tabular}


Table 6

Research Evidence Favoring Planned Vaginal Delivery

\begin{tabular}{|c|c|c|}
\hline Maternal \& Neonatal Outcome & Quality of evidence & Research Source \\
\hline $\begin{array}{l}\text { Maternal length of hospital } \\
\text { Stay }\end{array}$ & Moderate & $\begin{array}{l}\text { National Institute of Health } \\
\text { (2006); Liu \& Yang (2007) }\end{array}$ \\
\hline Maternal Infection & Weak & $\begin{array}{l}\text { National Institute of Health } \\
\text { (2006) }\end{array}$ \\
\hline Maternal Morbidity & Weak-Moderate & $\begin{array}{l}\text { National Institute of Health } \\
\text { (2006); Liu \& Yang (2007); } \\
\text { Declercq et al. (2007); } \\
\text { Deneux-Tharaux, } \\
\text { Carmona, Bouvier-Colle, \& } \\
\text { Breat (2006); Villar, } \\
\text { Valladares, Wojdyla, } \\
\text { Zavaleta, Carroli, \& Velazco, } \\
\text { (2006) }\end{array}$ \\
\hline Anesthetic complication & Weak-Moderate & $\begin{array}{l}\text { National Institute of Health } \\
\text { (2006); Deneux-Tharaux et al } \\
\text { (2006); Villar et al (2006); } \\
\text { Liu \& Yang (2007) }\end{array}$ \\
\hline $\begin{array}{l}\text { Subsequent placenta previa, } \\
\text { accreta }\end{array}$ & Weak-Moderate & $\begin{array}{l}\text { National Institute of Health } \\
\text { (2006); Getahum, Oyelese, } \\
\text { Salihu, Ananth (2006) }\end{array}$ \\
\hline $\begin{array}{l}\text { Successful and Sustained } \\
\text { Breastfeeding }\end{array}$ & Weak & $\begin{array}{l}\text { National Institute of Health } \\
(2006)\end{array}$ \\
\hline Iatrogenic prematurity & Weak & $\begin{array}{l}\text { National Institute of Health } \\
(2006)\end{array}$ \\
\hline Neonatal Infection & Weak & $\begin{array}{l}\text { National Institute of Health } \\
\text { (2006) }\end{array}$ \\
\hline Neonatal length of stay & Weak & $\begin{array}{l}\text { National Institute of Health } \\
(2006)\end{array}$ \\
\hline Respiratory morbidity & Moderate & $\begin{array}{l}\text { National Institute of Health } \\
\text { (2006) }\end{array}$ \\
\hline
\end{tabular}

\section{Maternal Mortality}

The NIH (2006) state-of-the-science conference on cesarean delivery on maternal request reported that the research available at the time was inadequately powered to 
evaluate maternal mortality. Maternal mortality is considered a basic health indicator that reflects the adequacy of health care for a nation (Panting-Kemp, Geller, \& Nguyen, 2000). In 2003, the maternal mortality rate was 12.1 deaths per 100,000 live births in the United States (Hoyert, 2007). This rate is increased from the previous time period from 1996 to 2002 where the rate fluctuated from 8.0 to 9.9 and is probably reflective of enhanced surveillance efforts by the CDC and the addition of a separate question on death certificates regarding recent pregnancy history in a growing number of states. This change is thought to capture more accurately late maternal deaths which are defined as the deaths of a woman from direct or indirect causes more than 42 days, but less than one year after delivery (Hoyert).

Embolism, hemorrhage, and pregnancy-induced hypertension complications were the leading cause of pregnancy-related deaths between 1996 and 2003 (Hoyert, 2007). An increase in the percentage of maternal deaths attributable to cardiomyopathy and other medical conditions has been observed and may be related to the inclusion of a separate question regarding pregnancy within the last year on death certificates in a number of states (Hoyert). The maternal morbidities that are frequently associated with maternal death, need to be examined closely in regards to elective primary cesarean delivery and vaginal birth so that women can be given appropriate information about the risks and benefits of both modes of delivery.

The increasing number of deaths attributed to other medical conditions may be associated with the increased age distribution of women giving birth in the United States. The prevalence of chronic illness has been shown to increase with age (Hoyert, 2007). Additionally it has been shown that women 35 years of age or older are at increased risk 
for pregnancy related death and adverse reproductive health outcomes (Hoyert). Risk ratios for pregnancy-related mortalities are reported as 3 to 4 times higher for black women than for white women, and this increases for black women who are 35 years of age or older (Hoyert). Research has indicated that women planning elective primary cesareans in the United States are more likely to be older (Suplee et al., 2007). This knowledge should be considered when comparing the outcomes of maternal mortality between women planning elective primary cesarean delivery versus vaginal birth.

Since the NIH (2006) conference, two studies have been published with large enough sample sizes to be adequately powered to study maternal mortality. DeneuxTharaux, Carmona, Bouvier-Colle, \& Breat (2006) conducted a large population-based case-control study that showed higher rates of severe maternal morbidity and increased risk for maternal death from anesthesia complications, infection, and venous thromboembolism with cesarean delivery. Villar et al. (2006) used the WHO 2005 global survey containing data about 100,000 deliveries from Latin America to compare maternal outcomes between cesarean and vaginal deliveries. Results showed higher rates of severe maternal morbidity and mortality for cesarean delivery when compared to vaginal deliveries. Despite the fact that both studies controlled for risks, it is important to note that the studies were not conducted in the United States and generalizability to the U.S. population must be made with caution. It would be important to conduct similar research in this country, before conclusions about risks and benefits are possible. The National Institute of Health (2006) reported weak quality evidence favoring planned vaginal delivery over planned cesarean delivery when anesthetic complications were examined. A higher percentage of general anesthesia was utilized in these studies than is currently 
seen in the U.S. practice today, and this would be an important confounding variable. In light of these recent studies, additional research is indicated.

\section{Postpartum Maternal Outcomes}

The postpartum period has been defined as beginning 1 hour after delivery of the placenta and lasting for 6 weeks, at which time the uterus will have completed the process of involution and regained its pre-pregnant size (Cunningham et al., 2001). It is important to look beyond this time frame to adequately determine how method of delivery may affect the psychosocial and physical health of women, their infants, and the interaction between them during this important period. Variables associated with prolonged maternal recovery during the postpartum period, both physically and emotionally, have been extensively researched. However, an absence of research is noted using a conceptual model to specify how the process of maternal decision making and maternal choice of delivery method may interact to influence maternal outcomes.

Findings in the literature consistently support that women with spontaneous vaginal deliveries report more positive birth experiences and increased maternal adaptation than either women with operative vaginal deliveries or emergency cesarean deliveries (Bryanton et al., 2008). Stressful labor and delivery, emergency cesarean birth, and psychosocial stress or pain related to delivery have been associated with delayed lactogenesis, ineffective breastfeeding, post-traumatic stress disorder, and postpartum depression (Beck, 2004a; Beck \& Watson, 2008; Bailham \& Joseph, 2003; Soet,et al., 2003). A meta-analysis found that women who had cesarean (both planned and unplanned) had significantly decreased rates of breastfeeding than women who had vaginal deliveries (National Institute of Health, 2006). Compared to women with 
spontaneous vaginal delivery, women with assisted vaginal delivery reported significantly worse sexual, bowel, and urinary function and delayed return to sexual activity at 6 months postpartum (Culligan, 2008; Lydon-Rochelle, Holt, Martin, \& Easterling, 2000).

\section{Postpartum Depression}

At this time, prenatal or postpartum depression appears unrelated to method of delivery, but lack of relevant research has been noted (National Institute of Health, 2006). A recent unpublished study of 558 first time mothers by Wilklund (2007) found no difference in postpartum depression between the vaginal group and the cesarean group. The only measurement for postpartum depression in this study was at 3 months, using the Edinburgh Postpartum Depression Screening Instrument (EPDS). This study was not done in the United States, but in Sweden, so findings may not be applicable to the U.S. population. Studies conducted in the United States reported that approximately $10 \%$ of women will experience depression in the immediate postpartum period (Borders, 2006; Beck, 2004a). Postpartum depression occurring during the first year following delivery ranges from $7 \%$ to $30 \%$ depending on how postpartum depression is defined (Borders). Future studies may benefit from using a pre and post delivery depression screening which is now available using the EPDS.

\section{Maternal Perception of the Birth Experience}

Satisfaction with birth during the postpartum period and over the course of the women's life is an important maternal outcome measure. Past studies of patient satisfaction reviewed have concentrated on identifying the correlates of satisfaction and not on defining the underlying construct or in developing a theoretical model to predict or 
explain the multidimensional aspects of satisfaction. Childbirth does not occur in a void, many confounding variables may impact maternal perception of birth and postpartum recovery such as history of infertility, sexual abuse, interpersonal violence, absent or limited social support, and maternal expectations for her birth experience (Bryanton, Gagnon, Johnson, \& Hatem, 2008; Beck, 2004a).

The difficulty in measuring satisfaction is in defining what it means. Past research has distinguished between the feelings a person has about an experience and their evaluation of the event (Bramadat \& Driedger, 1993). The body of existing literature provides evidence for the argument that satisfaction with the birth experience (a feeling or affect) and perception (cognition) of the birth experience are two separate but correlated constructs. These findings support the argument that a woman evaluates her birth experience against her personal beliefs, desires, or expectations about childbirth and feels either satisfied or dissatisfied depending on how well the birth experience correlated with these variables (Green, Coupland, \& Kitzinger, 1990).

A number of different theoretical models and a body of research using these models contribute to the understanding of the difficulty in adequately evaluating satisfaction with childbirth because they suggest that, for many women, a single measure of overall satisfaction may be misleading. Models of patient satisfaction have been heavily influenced by consumer satisfaction research, and while it is certainly common for patients to be viewed as consumers, making a connection between consumer satisfaction with a service or product and a mother's response to childbirth has not been sufficiently documented in the literature. 
Fulfillment theory relates patient satisfaction solely to the outcome of the experience (Day, 1977). This theory does not take into account the individual's psychological feeling about what they should or want to receive from the experience, only the amount they receive. Discrepancy theories hypothesis that satisfaction may be predicted based on differences between what is expected or desired and perceived outcomes (Risser, 1975). Two other related models which have been used in studies of patient satisfaction, are the value -expectancy and social comparison models (Day, 1977). Value-expectancy takes into consideration the value placed on an event or outcome, while social comparison examines a person's perception about the type or quality of care to which they perceive themselves to be entitled (Pasco, 1988). Adding to the concepts of discrepancy theory, Pasco (1988) reported that whether the experience was better or worse than expected was a more important indicator of satisfaction than congruency between expectations and the experience. Contrast models predict that when consumers perceive a discrepancy between expectations and outcomes, this difference will be magnified (Day, 1977).

Because of the multiple theoretical approaches to measuring maternal satisfaction with the birth experience, the instruments used in past studies were often simple with limited information about the reliability and validity of the instruments. A number of studies were found that used single item scales that measured the women's willingness to return to the same hospital or provider for subsequent births and this was accepted as an indicator of satisfaction with care (Bramadat \& Driedger, 1993). More current literature has used forced choice questionnaires, which has shown a number of limitations in that these instruments may measure constructs that are relatively unimportant to the mother 
and potentially report an overestimation of satisfaction when compared with maternal responses to open ended questions (Borders, 2006; Bryanton et al., 2008; Childbirth Connections, 2006; Green \& Baston, 2003; Kingdon, Baker, \& Lavender, 2006; Lazarus, 1997; McCourt et al., 2007).

Timing of the measurement has been show to be extremely important and poses additional problems. Studies measuring satisfaction immediately following delivery may result in a euphoric response that may masks other reactions (Cranley, Hedahl, \& Pegg, 1983). The initial reaction to the baby and the survival of childbirth are tremendous psychological events for women during the first days after delivery (Marut \& Mercer, 1979). Satisfaction scores appear to remain stable from twenty four to forty eight hours after delivery to three to four months after delivery. Changes in satisfaction scores were noted in the literature to be more common after a period of at least seven months. Fifteen to twenty years after the event of childbirth, women still reported vivid memories of the experience. At this time frame, those who reported greater levels of satisfaction were notable from those with lower levels, by the feelings they reported of being in control, high self-esteem, and positive memories of the relationship between themselves and the nursing or medical staff (Bramadat \& Driedger, 1993). This is an important finding that suggests that measuring maternal satisfaction with the birth experience over a long period of time may be important.

Research is needed that examines maternal outcomes utilizing a framework that considers the complexity of childbirth in the context of the woman's personal, cultural, and societal setting. It is important to note that how women's expectations and preferences for elective cesarean or vaginal birth are related to satisfaction with childbirth 
is uncertain. To date the importance of different aspects of the experience, and exactly what beliefs or values women place on the mode of delivery and how this affects her evaluation of and feelings about the childbirth event are unknown.

\section{Maternal Decision Making Process}

Decision making is the process of choosing between alternative courses of action, including the choice of inaction (Prochaska \& Velicer, 1997). Orem (1995) describes the process of decision making as the first phase of deliberative self-care. In order to examine the literature about the maternal decision- making process and elective cesarean without medical indication, a search of key databases using a range of search terms was completed. This search produced over 200 articles, of which 80 were potentially relevant. Of these, 38 were research-based articles and 40 were opinion-based articles. A total of 17 articles fitted the basic criteria for review. Of these articles, all 17 focused on determining the reasons why women requested a cesarean and none examined the process of how the decision occurred in the clinical setting or the patient's evaluation of the decision process before or after the delivery.

Clinical practice guidelines and consensus statements were found to recommend that health care providers ensure that patients are aware of the treatment options and the potential benefits and harm. The need for health care providers to assist patients to make informed decisions in keeping with their personal values and circumstances is view as an important aspect of the decision making process.

Unfortunately, many health care decision involving obstetrical patients have alternates that are likely to produce both desirable and undesirable outcomes. Examples of these include choosing a pain control method during labor, deciding to undergo 
amniocentesis, or prenatal genetic testing. The realistic possibility is that no choice will satisfy fully the personal goals of a patient and no choice is free from all undesirable outcomes. This type of situation can create decisional conflict for the patient. Studies on decision making reveal that a high percentage ( $>50 \%$ ) of women reported feeling uncertainly or decisional conflict when making choices about options for osteoporosis, considering tamoxifen as breast cancer chemoprevention, or when considering hormone replacement therapy (O’Conner, Jacobsen, \& Stacey, 2002).

Decisional conflict is described by Janis and Mann (1977) as a person having simultaneous opposing tendencies to both accept and reject a particular course of action. The North American Nursing Diagnosis Association (1992) includes decisional conflict as a nursing diagnosis:

Decisional Conflict (specific) is the uncertainty about which course of action to take when choice among competing actions involves risk, loss, regret, or challenge to personal life values (specify the focus of conflict, such as personal health, family relationships, career, finances, or other life events.)

The primary characteristic manifested by the patient during times of decisional conflict has been documented in the literature as verbalized uncertainty (Janis \& Mann, 1977). Other characteristics presented may be expressing concern about undesired outcomes, wavering between choices, delaying decisions, questioning personal values, being preoccupied with the decision, and feeling emotionally distressed by the decision (North American Nursing Diagnosis Association, 1992; O’Conner, 1997).

The literature supports two main sources from which decisional conflict is thought to arise for patients; the first is the inherent difficulty of the decision being made 
related to the possible benefits or harms and the second source includes modifiable factors that contribute to the difficulty of the already difficulty decision being made. These modifiable factors include lack of knowledge, unrealistic expectations, unclear values, unclear perceptions of others opinions, social pressure, lack of support, lack of skills or self-confidence, and lack of resources (O’Connor, 1995, 1997).

A body of literature related to decision making has focused on parents perspectives of the decision making process that takes place after antenatal diagnosis of a congenital abnormality. This literature provides a reference point for understanding the decision making process of women requesting an elective cesarean. Parents described the decisions about the plan of care for their unborn child as their first parenting decisions (Rempel, Cender, Lynam, Sandor \& Farquharson, 2003). Parents expressed differing degrees of conflict with the decision that was related to opinions of professionals, amount of knowledge about the pros and cons of the situation, and their individual decision making style (Rempel et al., 2003).

Women planning an elective cesarean have discussed their perception that cesarean is safer for the baby and for the mother. It may be that women view the request of an elective cesarean as a parenting decision as well. The amount of conflict women experience as they make decisions about the mode of delivery has not been studies in the context of elective cesarean delivery. The information that women receive from their health care provider has not been identified and no apparent standard exists for what information should be provided as the risks or benefits of elective vaginal delivery versus elective cesarean delivery. It is possible that this is viewed as a difficult decision that is compounded by lack of information, lack of support, unclear perceptions of the health 
care provider's opinions, and lack of confidence in the ability to be successful if a vaginal delivery is attempted. Additionally, women may view some aspects of requesting an elective cesarean as being likely to be beneficial to themselves or their baby while also viewing other aspects of this decision as increasing the risk of negative outcomes, e.g. more pain, potential for anesthesia complications etc. The relationship between global satisfaction with the birth experience and satisfaction with the decision for the mode of delivery is unstudied.

\section{Variables Associated with Elective Primary Cesarean Delivery}

\section{Healthcare Provider Opinion}

Many complex factors may contribute to a providers' viewpoint about maternal choice and elective cesarean delivery, and attitudes among healthcare providers appear to be changing. A number of studies examined maternal choice of cesarean from the obstetrician's viewpoint (Gonen, Tamir, \& Degani, 2002; Harer, 2000; Land, Parry, Rane, \& Wilson, 2002; Wax, Cartin, Pinette, \& Blackstone, 2007) and identified the majority of obstetricians supported the women's right to choose a cesarean without medical indication. Physicians gave different reasons for agreeing to perform cesarean delivery based solely on women's choice. Ghetti, Chan, \& Guise (2004) reported that physicians were more likely to agree to maternal choice when the patient had a high socioeconomic level, or to offer elective cesarean if women conceived with assisted reproductive technology (Kalish, McCullough, Gupta, Thalker, \& Chervenak, 2004).

It is unclear what affect the healthcare provider's opinion or the maternal perception of that opinion plays in the woman's choice of mode of delivery. It has been suggested that physicians may play an important factor in promoting elective cesarean 
delivery to individual women (Mayberry, 2006). Bernstein (2007) reports the current legal environment as contributing to practitioners' reluctance to allow patients to labor. Lack of research comparing the long term outcomes of maternal choice cesarean versus vaginal delivery has caused healthcare providers to advocate the need for a randomized controlled trial comparing these two groups (Kingdon, Baker, \& Lavender, 2006). The major indicators reported by physicians in the literature as impacting their reasons for performing elective cesarean can be found in Table 7.

Table 7

Physician Reasons for Performing Elective Cesarean Delivery

\begin{tabular}{ll}
\hline Physician Reason & \multicolumn{1}{c}{ Research Source } \\
\hline Fear of childbirth & $\begin{array}{l}\text { Loebel, Zelop, Egan, \& Wax (2004); Tillett (2005); Wax, } \\
\text { Cartin, Pinette, \& Blackstone (2007); Weaver, Statham \& } \\
\text { Richards (2007) }\end{array}$ \\
Patient pain & Wax et al. (2007); Loebel et al. (2004) \\
Fear of perineal injury & $\begin{array}{l}\text { Bergholt, Ostberg, Legarth, \& Weber (2004); Bettes et al. } \\
\text { (2007); Ghetti, Chan, \& Guise (2004); Loebel et al. (2004); }\end{array}$ \\
Wax et al. (2007); Tillet (2005) \\
Fear of urinary or anal incontinence & $\begin{array}{l}\text { Bergholt et al. (2004); Bettes et al. (2007); Ghetti et al. (2004); } \\
\text { Loebel et al. (2004); Wax et al. (2007); Tillet (2005) }\end{array}$ \\
Possibility of sexual dysfunction & Loebel et al. (2004); Wax et al. (2007); Tillet (2005) \\
Fear of fetal injury & $\begin{array}{l}\text { Bettes et al. (2007); Tillet (2005); Loebel et al. (2004); Wax } \\
\text { et al. (2007) }\end{array}$ \\
Patient convenience & Loebel et al., (2004); Wax et al. (2007); Tillet, (2005) \\
Physician convenience & Bettes et al. (2007); Loebel et al. (2004); Wax et al. (2007) \\
Previous adverse birth outcome & Loebel et al. (2004); Wax et al. (2007) \\
Fear of litigation & Wagner (2000) \\
\hline
\end{tabular}




\section{Maternal Reasons for Choosing Elective Cesarean}

The estimated number of women in the U.S., who choose elective cesarean, ranges from 4\% to $18 \%$ (Childbirth Connections, 2006; Gamble \& Creedy, 2001; National Institute of Health, 2006; Weaver, Statham, \& Richards, 2007). Recent studies have provided data about maternal reasons for choosing an elective cesarean as seen in Table 8 . Studies indicate women widely perceive cesarean delivery to be safe and many view it as safe as or safer than vaginal birth for their infants (Weaver, Statham, \& Richards, 2007; Wagner 2000). As many as $6 \%$ to $10 \%$ of all pregnancies may be complicated by severe fear of childbirth (Saisto \& Halmesmaki, 2003). Prior traumatic birth is associated with maternal choice of elective cesarean (Gardner, 2003).

Psychosocial benefits derived from maternal choice of elective cesarean have not been demonstrated (Nerum et al., 2005; Saisto et al., 2001; Waldenstrom et al., 2006). 
Table 8

Maternal Reasons for Choosing Elective Cesarean Delivery

\begin{tabular}{|c|c|}
\hline Maternal Reasons & Research Source \\
\hline Concern for safety of self and infant & $\begin{array}{l}\text { Evanaki, Khakbazan, Babaei, \& Noori } \\
\text { (2004); Weaver et al. (2007); MacMillan } \\
\text { Unpublished (2008) }\end{array}$ \\
\hline Fear of childbirth & $\begin{array}{l}\text { Lavender, Hofmeyr, Neilson, Kingdon, } \\
\text { \& Gyte, G. et al.(2007); Saisto \& } \\
\text { Halmesmaki (2003); Tillet (2005); Weaver } \\
\text { et al. (2007); Liu \& Yang (2003) }\end{array}$ \\
\hline Fear of pain & Evanaki et al. (2007); Weaver et al. (2007) \\
\hline $\begin{array}{l}\text { Perception of cesarean delivery as safe } \\
\text { or safer than vaginal delivery }\end{array}$ & Wagner (2000); Weaver et al. (2007) \\
\hline Fear of Damage to perineal floor & $\begin{array}{l}\text { Evanaki et al. (2004); Weaver et al. (2007); } \\
\text { MacMillan Unpublished (2008) }\end{array}$ \\
\hline Prior complicated/traumatic birth & $\begin{array}{l}\text { Bettes et al. (2007); Gardner (2003); Weaver } \\
\text { et al. (2007) }\end{array}$ \\
\hline Social convenience & $\begin{array}{l}\text { Bettes et al (2007).; Tillet (2005); Wagner } \\
\text { (2000); Weaver et al. (2000) }\end{array}$ \\
\hline Stress and anxiety & $\begin{array}{l}\text { Evanaki et al (2004); Gamble \& Creedy } \\
\text { (2001); Nerum et al. (2005); Saisto et al. } \\
\text { (2001); Waldenstrom et al. (2006) }\end{array}$ \\
\hline
\end{tabular}

\section{Maternal Characteristics Associated with Maternal Choice}

Consistent research findings indicate that women in the United States who

choose elective cesarean tend to be older (Lin \& Xirasagar, 2005) and are more likely to be married than unmarried (Kalish, McCullough, Gupta, Thalker, \& Chervenak, 2004) and primarily white (Bryanton et al., 2008). Increase in cesarean section rates among older nulliparous women can be partially explained by characteristics of social advantage, in that women expect and request elective cesarean (Byrom, 2004, p.780). Since 1990, 
birth rates in the United States for women between the ages of 35 and 39 increased by $43 \%$ and those aged 40 to 44 increased by $62 \%$ (Center for Disease Control [CDC], 2005). Advanced maternal age (AMA) places women in a risk category where screening and diagnostic tests for chromosomal abnormalities are routinely offered. AMA is associated with infertility and assisted reproductive technology (Benzies et al., 2006; Center for Disease Control, 2005). These factors may contribute to a maternal viewpoint of the pregnancy as being high risk and requiring additional medical intervention (Suplee et al., 2007). Researchers have not clarified whether older mothers report higher anxiety levels compared to younger mothers because of their age, or because of other coexisting health and psychosocial factors (Boivan, Sanders, \& Schmidt, 2006; Byrom, 2004; Robb, Alder, \& Prescott, 2005; Schardt, 2005).

\section{Social Class}

Social class influences the planning for childbirth, feelings of control in childbirth, and women's identities. Middle-class women take a more active role in the birth process and working-class women are more fatalistic about their role in the birth process (Martin, 2003; Nelson, 1983; Zadoroznyj, 1999). Lazarus (1997) reported differences in access to choices and control between socioeconomic classes. Poorer women were often unemployed, had less education, more unplanned births, and were often unmarried. A recent study noted that $42 \%$ of women with private insurance delivered before 39 weeks compared with $29 \%$ of those without private insurance (Suplee et al., 2007). This difference is most likely explained by scheduled induction of labor or cesarean delivery (Suplee). Additionally, middle class women who were health 
professionals or spouses of physicians had greater knowledge about the healthcare system and were able to exercise more control over childbirth (Martin, 2003).

Maternal Psychological Factors Associated with Maternal Choice

Psychological factors, especially fear of vaginal birth and anxiety have been identified as factors related to the request of cesarean delivery (Poikkeus et al., 2006; Ryding, 1993; Waldenstrom, 2006). A prospective study using between-group comparisons (Waldenstrom, 2006) showed a 3 to 6 times higher rate of elective cesarean sections in women who underwent counseling for fear of childbirth, than for women who reported positive feeling about childbirth. Severe fear of childbirth complicates $6 \%$ to $10 \%$ of all pregnancies (Saisto \& Halmesmaki, 2003), and it is thought to complicate an increased percentage of pregnancies in women who request an elective cesarean. A number of studies (Nerum et al., 2005; Saisto et al., 2001; Waldenstrom et al., 2006) have consistently reported that pregnancy-related anxiety, general anxiety and lack of partner support were significant predictors of severe fear of vaginal delivery. A number of studies have proposed an association between postpartum depression and maternal choice of cesarean, but no evidence has supported that link (Wiklund, 2007). Lack of social support and dissatisfaction with the partner relationship were also associated with fear and negative feelings about vaginal birth (Nerum et al. 2005; Saisto et al. 2001; Waldenstrom et al. 2006; Wijma, Wijma, \& Zar, 1998; Zar, Wijma, \& Wijma, 2002). A long duration of infertility ( 7 or more years) increased the risk (odds ratio $4.4,95 \% \mathrm{CI}$ 1.2 -16.9) of severe fear of childbirth (Poikkeus et al., 2006).

\section{Internal and External Locus of control}

Studies have revealed that a sense of control is a major contributing factor to a 
woman's birth experience (Block, 2007; Davis-Floyd \& Johnson, 2006; Kitzinger, 2006; Lazarus, 1997). Both internal and external control has been identified as important to women during birth: feeling in control of what is done by healthcare provider and staff, feeling in control of behavior, and feeling in control during contractions (Green \& Baston, 2003). It has been suggested that maternal perception of cesarean birth as easier to control than vaginal birth may be associated with maternal request of cesarean delivery (Bryanton et al., 2008).

A women's perceived sense of mastery over internal and environmental forces during the childbirth birth experience has been extensively researched in women planning vaginal deliveries (Dilks \& Beal, 1997; Green \& Baston, 2003; Lowe, 1993; Kitzinger, 2006). This control has been linked to improved learning and functioning on various tasks and decreased need for analgesia and anesthesia during childbirth, and is considered to be a key component of birth satisfaction (Lederman, Work, \& McCann, 1995). Perceived loss of control has been inversely related to prenatal anxiety (Green \& Baston, 2007) with prenatal education and partner support associated as a mediator to this problem. Understanding maternal perception of sense of control with respect to CDMR would be an important step in developing interventions, and for researching the influence of expectations in both physiological and psychological outcomes of pregnancy and birth.

\section{Previous Work by the Researcher in the Proposed Area}

The proposed study will build upon a previous study conducted by this researcher related to understanding the attitudes and experiences of women who requested a primary elective cesarean without medical indication (MacMillan, 2008). In this phenomenological pilot study, 8 nulliparous women who self identified themselves as 
having requested an elective cesarean were interviewed. A qualitative, phenomenological design was chosen to obtain the women's unique perspective. Interpretive hermeneutics were used so that taken-for-granted meanings could be revealed. Face to face interviews which lasted from 45 minutes to two hours were conducted. Verbatim transcripts were analyzed line by line to identify themes. Comparative analysis was ongoing throughout data collection and peer review was used to validate findings.

Three of the eight women experienced long periods of infertility and all but one (age 34 years) met the criteria for advance maternal age ( $>35$ years). Four of the eight women interviewed were registered nurses, and one woman was a physician. These healthcare professionals reported witnessing a birth which they found distressing while acting in their professional role. Postpartum depression was reported by three of the women in the study, and at 6 months after delivery depression continued for two of the women.

Three major themes were identified as being important in the request for elective cesarean: Planning and Control, Knowledge Not as Important as Control, and Looking Back on the Experience of Birth. Without exception, women reported that they requested a cesarean in an attempt to control the unknown aspects of birth. Benefits of controlling the birth allowed the woman to choose the time of birth, the support people who were present, and minimize the unexpected. Fear of childbirth and their potential behavior during labor and birth in response to pain or unplanned events was the driving force for their choosing a cesarean, despite knowing risks associated with a surgical delivery. Physician support for CDMR and the woman's faith in her physician to "make sure 
everything was safe" and to provide information that was accurate about risks and benefits of mode of delivery was reported by all the participants.

\section{Conclusion}

The National Institute of Health (2006) state-of-the-science conference on cesarean delivery on maternal request outlined important research directions to be considered. Much of this research, which addresses the long term risk and benefits of method of delivery, will take an extended period of time to accomplish. It is challenging for healthcare providers to obtain informed consent when benefits and risks of a given procedure are not understood clearly; as is the case with maternal choice of elective cesarean delivery. What researchers need to address at this time is the decision making process for women planning their method of delivery. No research was found that examined the maternal decision making process about maternal choice cesarean delivery. Identifying the specific variables that explain the decision making process and the moderating role of maternal decisions will be an important step in providing support and education for women making decisions about their delivery and in determining what relationship satisfaction with the decision making process has with the overall satisfaction with the birth experience.

The body of research about maternal decision making has focused on prenatal and genetic screening and maternal choice for repeat cesarean vs. vaginal birth after cesarean delivery (Lyerly et al., 2007). Maternal perceptions about the risks and benefits of amniocentesis (French, Kurezynski, Weaver, \& Pituch, 1993) were shown to be more important than specific information about amniocentesis in the maternal decision to choice an amniocentesis. In regards to prenatal testing, women have identified multiple 
factors that are important in their decision making process (e.g., medical information, personal beliefs, family opinions and desires, and societal norms) (Wohlgemuth \& Lawson, 2007). This is important in considering the concept of maternal choice and women's decision making process. No studies have examined the relationships among individual, interpersonal, and societal factors in decisions regarding method of delivery. It is important to examine a woman's decisions not in isolation, but in the framework of her values and social context. The failure to understand the decision making process of women requesting primary elective cesarean delivery and the lack of data available related to the education and counseling needs of these women may result in a further increase in the number of women making this choice. 


\section{CHAPTER III}

\section{Methodology}

This chapter describes the methodology that was used to conduct the study. The following sections are included: study design, sample, setting, methods used to protect human subjects instruments, instruments to measure the study variables, data collection procedures, and data analysis plan.

\section{Study Design}

A prospective longitudinal design was used. Participants completed internet based questionnaires regarding health beliefs and maternal outcomes at 32-36 weeks gestation. Maternal outcomes were assessed at 6 weeks postpartum.

\section{Sample and Setting Inclusion Criteria}

Participants in the study were nulliparous women in the third trimester of a singleton pregnancy. The study included women in the United States who were able to read and write English. Women of all ages, including adolescents who were considered emancipated minors, were eligible for in the study.

\section{Exclusion Criteria}

Women were excluded from for the study if they had experienced a previous pregnancy with a delivery past 20 weeks, or the presence of a risk factor providing an absolute medical indication for cesarean delivery (e.g., placenta previa, prior myomectomy, known fetal congenital anomaly that would influence delivery). Women with non-vertex presentation (breech, transverse lie) were also excluded. The exclusion 
criteria were based on the aim of the study to recruit only participants who are candidates for either CDMR or MRVB and are nulliparous.

\section{Cesarean Delivery Maternal Request Group (CDMR)}

The study recruited all eligible women who self identified themselves as requesting a cesarean delivery in their response to advertisements about the study. Only women requesting a cesarean delivery without any medical indications for the cesarean were enrolled into the study.

\section{Maternal Requested Vaginal Birth Group (MRVB)}

The study recruited all eligible women who self identified themselves as planning a vaginal birth in their response to advertisement about the study. The number of women planning a vaginal birth was substantially greater than those planning a cesarean delivery and thus recruitment for the vaginal birth group was completed prior to the CDMR group.

For both groups, the participation rate was tracked as the number of women who complete the informed consent and agree to participate in the study divided by the women who visit the internet site and decline to participate. Participation rate for the MRVB was $66 \%$. Participation rate for the CDMR group was $58 \%$. A copy of the informed consent is found in Appendix A.

\section{Sample}

A total of 408 women responded to an internet or flyer invitation to participate in the study and visited the web site for more information. A copy of the flyer is located in Appendix B. Of those visiting the web site, $65.2 \%$ expressed an interest in the study and signed the informed consent, 247 primigravidas planning a vaginal delivery and 21 primigravidas planning an elective cesarean were enrolled in the study. Because no 
information was provided by the women who visited the web site, but decided not to complete the screening criteria, no information is available to characterize the women who were not interested in participating in the study. After additional screening criteria were obtained, 67 women in the vaginal group and 4 women in the cesarean group were found to be ineligible. Most common reason for ineligibility was a gestational age less than 32 weeks gestation (75.3\%), followed by multiple gestation (12.5\%), previous surgery on the uterus (4.2\%) and previous pregnancy that delivered past 20 weeks gestation but did not result in a viable delivery (8.1\%). This resulted in a planned vaginal group $(\mathrm{n}=180)$ and a planned cesarean group $(\mathrm{n}=17)$ who completed baseline data collection. Time two data collection was completed by $70.5 \%$ of the vaginal participants $(\mathrm{n}=127)$ and $100 \%$ of the planned cesarean participants $(\mathrm{n}=17)$. The Health Belief Eligibility Screen form and the study schema are located in Appendix C and Appendix D.

\section{Instruments}

Copies of all instruments are included in the Appendix. The following items were included in the third trimester questionnaire: eligibility screen, demographic and socioeconomic information, and obstetrical data.

\section{Variables and Instruments}

A demographic data and clinical history questionnaire (Appendix $\mathrm{H}$ ) and five scales comprised the instruments for this study. Antenatal data elements in the demographic data and clinical history questionnaire included age, ethnic background, marital status, educational level, number of children planned, history of depression, history of infertility, medical comorbidies present and surgical history. Information about delivery history was collected at six weeks postpartum and elements included were 
delivery date, type of delivery, length of labor, use of interventions and medications, and goal achievement. Separate questionnaire were provided for the vaginal and cesarean group for the postpartum time measure. Instruments measuring the outcome variables are presented first, followed by the independent variables and the potential control variables.

\section{Maternal Perception of Birth Experience}

Maternal perception of the birth experience for women requesting a vaginal delivery was measured with the Questionnaire Measuring Attitudes About Labor and Delivery (QMAALD) shown in Appendix E. Birth perception was defined as a woman's perception of her childbirth experience with respect to the degree to which it was positive or negative. This 29 item questionnaire was adapted by Marut and Mercer (1979) from a 15 item tool developed by Samko and Schoenfeld (1975). The instrument measures attitudes about labor and birth on a 5 point, Likert-type scale. The Cronbach's alpha coefficient reliability has ranged from .76 to .80 (Cranley, Hedahl, \& Pegg, 1983; Fawcett \& Knauth, 1996; Marut \& Mercer, 1979). The higher the total score, the more positively the childbirth experience is perceived, for a possible total score of 29 to 145 . Cronbach's alpha in this study was .90 .

Birth perception was measured for women requesting a cesarean birth by cesarean used the Modified QMAALD located in Appendix F. This 29 item questionnaire adaptation was developed by Cranley et al. (1983). Items related specifically to labor were replaced with ones measuring perception of the preoperative experience. This adaptation has alpha reliabilities ranging from .84 to .91 (Cranley et al., 1983; Fawcett, Pollio, \& Tully; 2007, Mercer \& Stainton, 1984). Scoring for the Modified QMAALD is the same as for the original. This scale was chosen because recent use with planned 
cesarean delivery and planned vaginal delivery sample showed acceptable validity and reliability (Bryanton et al., 2008). Cronbach's alpha coefficient for the current study was .91 for the Modified QMAALD.

\section{Maternal Satisfaction with Delivery Decision}

Maternal satisfaction with the decision regarding mode of delivery was measured with selected subscales of the Decisional Conflict Scale (DCS). This 16 item questionnaire asked the participant to think about the choice made and to respond to the comments made by some people when making decisions. The decisional conflict scales measures perceptions of uncertainty in choosing options, modifiable factors contributing to uncertainty such as feeling uninformed, unclear about personal values and unsupported in decision making; and effective decision making such as feeling the choice is informed, values based, likely to be implemented and expressing satisfaction with the choice. The DCS required an eighth grade reading level and five to ten minutes to complete. Responses to each statement were scored from 0 (strongly agree) to 4 (strongly disagree); with negative statements having reverse scoring so that high scores indicate higher decisional conflict (O'Conner, 1995). A copy of the DCS is located in Appendix G. The DCS has five subscales: the informed subscale, values clarity subscale, support subscale, uncertainty subscale, and effective decision subscale. The effective-decision subscale is used only when a decision has already been made; the other four subscales can be used during deliberation or after a decision is made. The uncertainty subscale has an internal consistency coefficient of .78 to .92 , the effective decision-making subscale, .77 to .84 , and the factors-contributing to uncertainty subscale .58 to .70 , with an overall coefficient of .78 to .92 (Bunn \& O’Conner, 1996). 
Prior use of the scale has been with women making difficult decisions regarding their health care choices (O’Connor, Jacobsen \& Stacey, 2002). Items were developed from the construct of decisional conflict developed by Janis and Mann (1977) and validated by a panel of decision-making experts (Bunn \& O’Conner, 1996). Decisional conflict is a state of uncertainty about a course of action and is associated with decisional regret. Past research has shown that for every unit of increase in the DCS, patients were 19\% more likely to blame their doctor for bad outcomes (Gattelari \& Ward, 2004). Decisional conflict was an independent predictor of blame, separate from other predictors such as knowledge and age of the patient (Gattelari). Since women who were recruited into the study indicated that their decision about requesting a cesarean or planning a vaginal delivery was already made, the effective - decision subscale, uncertainty subscale and the factors-contributing to uncertainty subscale were used.

The 16 items were summed, divided by 16 , and multiplied by 25 . The DCS is Scored from 0 to [no decisional conflict] to 100 [extremely high decisional conflict]. For the current study the Cronbach's alphas were: uncertainty subscale .85 , support subscale .92 , values clarity subscale .94 , informed subscale .88 , and effective decision subscale 81. Cronbach's alpha for the total scale was .90 .

\section{Maternal Health Beliefs}

The Maternal Health Belief Questionnaire (MHBQ), a 26 item instrument with six subscales which asked the mother to choose the best answer to each question about her decision to request a cesarean or a vaginal birth. The six subscales measures: maternal acceptance and adaptation to the pregnancy role, maternal perception of partner/family support, maternal self efficacy regarding ability to delivery vaginally if in 
labor, maternal perception of risk for an emergency cesarean if in labor, maternal perception of threat associated with a vaginal delivery and maternal perception of her physician's role in the decision). MHBQ is not summed as a total score, but each subscale is summed and treated as a separate construct in the Maternal Health Belief Model. At the end of the MHBQ women were give an opportunity to answer a series of open ended qualitative questions regarding their beliefs about the risk or benefits of either a vaginal delivery or a cesarean delivery. Additionally, the MHBQ asked the women during the prenatal period to list their wishes, goals, and expectations for the whole birthing process (from when the process begins until the first hours after birth). The original form was developed for the MADRES study, and a panel of experts was used during the development of this questionnaire and preliminary validation with expectant women was completed. Modifications to the questionnaire were done by this researcher with the permission of the authors to add constructs of maternal role acceptance, partner and family support, self efficacy, susceptibility, and threat. Items were also converted from a "yes" or "no" answer to a Likert scale to enhance scale variability. This questionnaire took approximately 15 minutes to complete and was on an $8^{\text {th }}$ grade reading level. The following discusses the individual subscales of the MHBQ that operationalized health beliefs. A copy of the MHBQ can be located in Appendix H.

\section{Maternal Self Efficacy}

Maternal self efficacy, which was defined as the ability to delivery vaginally if in labor, was measured using a single item 5 point Likert type scale in the MHBQ. Women were asked to think about what they believed to be true about what labor would be like for them if they were in labor. They were then asked to choose the best answer for the 
statement: I will be able to delivery vaginally. The choices ranged from "strongly agree" to "strongly disagree". Lower scores reflected higher self efficacy related to ability to delivery vaginally.

\section{Maternal Perception of Risk}

Maternal perception of risk for an emergency cesarean if in labor was measured using a single item 5 point Likert type scale in the MHBQ. Women were asked to think about what they believed to be true about what labor would be like for them if they were in labor. They were then asked to choose the best answer for the statement: If I am in labor, I am at risk for an emergency cesarean delivery. The choices ranged from "strongly agree" to "strongly disagree". Lower scores reflected increased risk for an emergency cesarean delivery.

\section{Maternal Perception of Threat}

Maternal perception of threat related to a vaginal delivery was measured using the MHBQ threat subscale. This is an eight item scale that asked the mother to indicate if she perceived that a scheduled cesarean or a planned vaginal birth was safer for the mother or safer for the baby. Choices for the participant ranged from "yes I believe this" or "no I don't believe this". Scale score ranges from 8 to 16 with higher scores indicating vaginal birth has a greater threat. Cronbach's alpha for this study was .58.

\section{Cues to Action}

Cues to action were measured using the MHBQ doctor's role subscale. This single item single item 8 point Likert type scale asked women to reflect on the role of their physician of healthcare provider in making the decision regarding mode of delivery. The question was as follows: When you decided what type of delivery method you would 
choose, which best describes the role of your doctor or healthcare provider played. Participant choices ranged from no discussion with doctor to doctor made me feel I had no other choice. Midrange of the scale reflected that the woman and physician talked about mode of delivery together and made a decision. Scores ranged from 0 to 8 with higher scores indicating that the mother felt less in control of the decision outcome.

\section{Partner/Husband Support}

Partner/husband support was measured with the MHBQ support subscale which is a 5 item 5 point Likert type scale with a possible range of scores from 5 to 25 . Scale ranges from "strongly agree" to "strong disagree". Conceptually higher scores indicate increased partner/husband support. Questions specifically ask about the partner/husband's role in the decision making process and the participant's perception of the support she received during pregnancy from her partner/husband. Internal consistency for this study was assessed. The Cronbach's alpha for this study was .90 .

\section{Acceptance of Motherhood Role}

Acceptance of the motherhood role was measured using the MHBQ acceptance of motherhood subscale. This 8 item scale asked women to respond to statements about their perception of the pregnancy to examine and clarity their acceptance of the motherhood role. Participants responded to each statement with 5 point Likert like scale from "strongly agree" to "strong disagree". Cronbach's alpha for the current study was .87. Subscale scores range from $8-40$ with lower scores indicating increased acceptance of maternal role and pregnancy.

\section{Internal and External Locus of Control}

Internal and external locus of control over the childbirth experience was measured 
using the Labor Agentry Scale (LAS) which was developed by Ellen Hodnett. A copy of this instrument is located in Appendix I. This 10 item scale measures a woman's perceived control during childbirth (mastery over internal and environmental forces). The 7 point Likert type scale ranges from "almost always" to "rarely". The LAS is normally administered during the first few days following childbirth; however scores have been demonstrated to be stable at 2 weeks, 1 month, and 3 months postpartum (Hodnett \& Abel, 1986). Cronbach's alpha for past studies range from 0.91 to 0.98 (Hodnett \& Abel, 1986). All 10 items are summed to obtain a total score. Conceptually, higher scores indicate increased perception of control. Cronbach's alpha for the current study was .85 for the total sample.

\section{Maternal Request}

Maternal request was measured using the MHBQ. Participants were asked to indicate if they were planning a vaginal birth or planning a scheduled cesarean. To further examine and clarify the maternal perception of the request the participants were asked the following question: Which of the following best describes the reason you are planning a scheduled cesarean delivery? The options given to the participant were: (1.)"My preference" (no medical necessity), (2.) "My doctor or midwife thinks this would be best for my baby because of a specific condition", and (3.) "My doctor or midwife thinks this would be best for me because of a specific condition". If participants selected option (2) or (3) they were asked to list the specific condition. Participants who were planning a vaginal delivery were given similar items regarding vaginal birth.

\section{Anxiety}

Anxiety was measured using a 5 point Likert scale which addressed the 
construct of state anxiety specific to the upcoming birth. Participants were asked to rate how anxious or nervous they were about childbirth. They were asked to describe their state of anxiety or nervousness using a scale which ranged from "not at all nervous" to “extremely nervous". This single item scale is part of the MHBQ.

\section{Postpartum Delivery Information}

The postpartum delivery information data are collected with a 14 item questionnaire that asks the mother to confirm that when she entered the hospital her plan for delivery was the same as she had described in the antenatal questionnaire. If her delivery plan had changed she was asked to tell us the reason why. Other information obtained was date of delivery, type of anesthesia, use of interventions, and length of labor if appropriate. Participants had received an email prompting them to complete the postpartum questionnaire that listed their goals from the antenatal questionnaire. Participants were asked to enter their goals and to report on the achievement of the goals. A separate questionnaire was provided for vaginal and cesarean participants which can be found in Appendix $\mathrm{J}$ and Appendix $\mathrm{K}$.

\section{Protection of Human Subjects}

The proposal was presented to the Georgia State University Institutional Review Board (IRB) and Medical Center of Central Georgia IRB (Appendix L). The researcher explained the study in full detail to participants during the initial and follow-up internet contacts. Written informed consent was provided and explained the ethical responsibilities of the researcher and the rights of participants. IRB approval was obtained for the participants to receive a monthly nutritional and health newsletter as partial compensation for their time and effort. 
Adolescent status was not considered an exclusion criterion based on review of adolescent pregnancy statistics (Online Analytical, 2009). This review indicated that the single most common risk factor for pregnant adolescents is delivery prior to 32 weeks. Our recruitment took place after that time and any adolescent eligible for the study was identified as low to moderate risk. Additionally, pregnant adolescents were considered emancipated minors and as such were able to give consent for participation in the study. Ethnicity was not used as exclusion criterion and efforts to include minority subjects were made.

Protection against Risks and Confidentiality: Participants were informed of the complete time commitment and benefits prior to consent. Participants were assured of confidentiality in storing and reporting of research results. All data were coded by the participants' identification numbers and kept on a secure dedicated server in the principal investigator's office. Only the research team had access to the data. No participant identifying information was recorded on the data collection forms; only identification numbers. Email addresses that linked participants with the identification numbers were kept on a separate external hard drive, which was locked in a safe in the researcher's office. After the study was completed, all data were kept according to regulation in a locked file. After the final collection was completed, the list of email addresses was permanently deleted from the external hard drive. Participants were able to withdraw from the study at any time, but no participants withdrew from the study. No members of the research team were involved in providing care to any of the participants at any time during the study.

The project website conformed to the guidelines and policies of the Georgia State University. The website was deployed on an independent server and linked to the 
researcher's website. The PI was responsible for monitoring the website daily and for maintaining the security of the server on which the information was stored. Only the researcher and IRB approved members of the research team had access to server. The independent server was maintained in the PI's locked office and was password protected. The security of the server was enforced by the use of a firewall and secure socket layer which restricted the telnet and ftp access to the server. The researcher reviewed all the access records daily for any evidence of hacking attempts. An expert in computer system management reviewed the records on a weekly basis and served as a resource person for the researcher.

When the participants transfer inputs through the Internet, the only information that could be linked to personal identity was the Internet Protocol address (IP address). One could find the person's identity that uses the IP address only if the network manager who manages the IP address disclosed the identity of the user, which did not happen. Therefore, for the purposes of this study the participants were anonymous.

The participants only interacted with the research team via the internet and no face to face communications were carried out. To maintain privacy, the only contact information that was obtained from the participant was her email address. Participants received a monthly newsletter using Constant Contact. The PI maintained a detailed audit of number of potential participants who visited the web site and either decided not to continue with the eligibility survey, or who did not qualify once the survey was completed. No participants requested to be removed from the study by going to the web site and selecting the icon "Remove Me from the Study". 
The researchers informed the participants during the informed consent process about how participants' messages and communications were used and that interception of messages was possible, but unlikely. Participants were informed that complete anonymity, confidentiality, or security was impossible on the Internet.

\section{Data Collection Procedures}

An overview of the time line for data collection is provided in Table 9. All data collection was internet based. Women were recruited into the study when they responded to either a paper flyer or internet based flyer which briefly explained the study. Potential participants who visited the research web site indicated if they wanted to participate after reading an informed consent (Appendix A) and additional information about the eligibility requirements of the study. Informed consent was obtained electronically at the time of enrollment.

The eligibility questionnaire (Appendix C) was formatted so that if the woman answered yes to certain questions (e.g., had a previous cesarean delivery), she was thanked for her participation and the internet-based interaction ended. If she was eligible for the study, she was invited to continue to the next step in the study which involved answering the main study questionnaires (Appendix F - I). After this set of questionnaires was completed she was thanked for her participation so far in the study (Appendix N). The participant was asked for her email address and told that the pregnancy questionnaire and the six week postpartum questionnaire would be linked using the email address.

Participants were informed that they would receive monthly newsletters using Constant Contact with comfort and nutritional tips for the remainder of the study as a thank you for participating in the study. They were assured that no information given by 
them, especially personal information (i.e., email addresses) would be used by the researcher in any way other than to contact them. After the final questionnaires were completed, the researcher permanently deleted the list of email addresses and answers were identified using the assigned study numbers.

Women were prompted by an email at six weeks after the delivery of their baby to complete the final questionnaire. Each participant's individual goals were listed in the email and the participant was asked to use this email for reference when she completed the postpartum questionnaire. Participants who did not respond to the initial follow-up email were sent up to two additional emails. The third email thanked the participant and encouraged her again to complete the final questionnaire; additionally the participant was informed that this would be the final attempt to contact her. Receipt of the email and validity of the email addresses were tracked during the study. Emails were sent from the study web site instead of using Constant Contact to ensure confidentiality and to address the occasional issue of span blockers on the participants email service. Some participants did not receive the newsletter initially because of spam blockers. Those participants were then contacted by email and the link to the newsletters was provided to the participants. No participant requested to be removed from the study. Emails were received from participants thanking the researcher for the newsletters. Participants who had completed both data collection times were thanked for their participation in the study by an email from the researcher. Retention rate was $70.5 \%$ for the planned vaginal group and $100 \%$ for the requested cesarean group. 
Table 9

Overview of Timeline for Data Collection

\begin{tabular}{|c|c|c|c|}
\hline & & $\begin{array}{l}\text { Time 1 } \\
\text { Baseline }\end{array}$ & $\begin{array}{l}\text { Time } 2 \\
6 \text { weeks } \\
\text { postpartum } \\
\end{array}$ \\
\hline Outcome Variables & Instruments & $\begin{array}{l}32 \text { to } 36 \text { weeks } \\
\text { gestation }\end{array}$ & $\begin{array}{l}6 \text { weeks } \\
\text { postpartum }\end{array}$ \\
\hline $\begin{array}{l}\text { Maternal Outcomes } \\
\text { Maternal perception of } \\
\text { Birth Experience }\end{array}$ & $\begin{array}{l}\text { Questionnaire Measuring Attitudes About } \\
\text { Labor and Delivery } \\
\text { (QMAALD) }\end{array}$ & & $\mathrm{X}$ \\
\hline $\begin{array}{l}\text { Maternal Satisfaction } \\
\text { with Decision }\end{array}$ & Decisional Conflict Scale (DCS) & & $\mathrm{X}$ \\
\hline \multirow[t]{2}{*}{ Predictor Variables } & Instruments & $\begin{array}{l}\text { Time } 1 \\
\text { Baseline }\end{array}$ & $\begin{array}{l}\text { Time } 2 \\
6 \text { weeks } \\
\text { postpartum }\end{array}$ \\
\hline & $\begin{array}{l}\text { Maternal Health Belief Questionnaire } \\
\text { (MHBQ) }\end{array}$ & & \\
\hline Partner/husband support & MHBQ support subscale & $\mathrm{X}$ & \\
\hline $\begin{array}{l}\text { Maternal perception of } \\
\text { doctor's role in decision }\end{array}$ & MHBQ doctor's role subscale & $\mathrm{X}$ & \\
\hline $\begin{array}{l}\text { Acceptance of maternal } \\
\text { role }\end{array}$ & & & \\
\hline Perceived self efficacy & $\begin{array}{l}\text { MHBQ acceptance of maternal role } \\
\text { subscale }\end{array}$ & $\mathrm{X}$ & \\
\hline Perceived threat & MBQH self efficacy subscale & & \\
\hline Perceived risk & & $\mathrm{X}$ & \\
\hline $\begin{array}{l}\text { Internal and external } \\
\text { control }\end{array}$ & $\begin{array}{l}\text { MBHQ threat subscale } \\
\text { MBHQ risk subscale }\end{array}$ & $\mathrm{X}$ & \\
\hline $\begin{array}{l}\text { Control Variables } \\
\text { Secondary Research } \\
\text { questions }\end{array}$ & $\begin{array}{l}\text { Labor Agentry Scale } \\
\text { Instruments }\end{array}$ & $\begin{array}{l}\mathrm{X} \\
\text { Time 1 } \\
\text { Baseline }\end{array}$ & $\begin{array}{l}\text { Time } 2 \\
6 \text { weeks } \\
\text { postpartum }\end{array}$ \\
\hline Anxiety & State-Anxiety Likert Scale & $\mathrm{X}$ & \\
\hline $\begin{array}{l}\text { Patient centered goals } \\
\text { for birth }\end{array}$ & MHBQ Goals & $\mathrm{X}$ & $\mathrm{X}$ \\
\hline
\end{tabular}




\section{Quality Control}

Prior to initiating the data collection, all forms, and procedures were evaluated and specific protocol manuals were established. Recruitment procedures, informed consent procedures, and administration of questionnaires via the internet were detailed in the manual. A panel of experts ( 1 obstetrician, 1 nutritionist, and 1 obstetrical nurse midwife), and 5 pregnant women were asked to evaluate the research web site for ease of use, appropriateness of information, and readability. Modifications were made following their evaluations before the deployment of the study.

Forms were adapted to prompt participants to complete all items and an option given to indicate that a question was intentionally being left blank. Questionnaires were posted to the website in a manner to reduce errors and missing data, such as allowing the participant to review responses prior to final submission and using forced-choice answers for questionnaires or rating scales.

\section{Internal Validity}

Internal validity was addressed in this proposed study with several approaches. The internet administration of the study questionnaires lends itself to uniformity in data collection procedures. During the first two weeks of deployment, the questionnaire malfunctioned resulting in 10 participants having incomplete questionnaires. The problem was corrected and no further malfunctions were observed during the data collection period. The questionnaires and forms were set up so that the data was downloaded directly into the data management programs (Excel and SPSS) that were used for the study. 


\section{Data Analysis}

Data were analyzed with descriptive and inferential statistics using Statistical Package for the Social Sciences (SPSS) for Windows Release 16.0. Preliminary analysis included standard data cleaning. Interval/ratio level data was examined for normal distributions and patterns of missing data were examined. The reliability of scaled instruments was determined. An exploratory analysis was conducted to identify potential covariates when the hypotheses were tested. Statistical methods included frequency, percentage, mean, standard deviation, bivariate correlations, and hierarchical multiple regression.

\section{Demographic Data}

Descriptive statistics including frequencies, percentages, means, and standard deviations were performed and reported on the following demographic variables: age, ethnic background, marital status, education background. The maternal characteristics of history of infertility, use of reproductive technology, history of depression and anxiety or fear of childbirth were examined as potential covariates using bivariate correlations and reported on.

\section{Research Questions and Hypotheses}

Descriptive statistics including frequencies, percentages, means, standard deviations and bivariate correlations were performed and reported on internal and external control, acceptance of motherhood role, perceived partner support, perceived threat, perceived risk, perceived susceptibility, and perceived provider opinion. Prior to analysis of the hypothesis it was determined that the MHBQ perception of the physician's role in the decision subscale did not meet the assumptions for regression analysis, so this 
variable was not enter into the equations. Descriptive statistics including frequencies, percentages, means, standard deviations and bivariate correlations were performed and reported on maternal perception of the birth experience and maternal satisfaction with the decision for mode of delivery. Specifically, individual research questions, hypothesis and sub-hypothesis were analyzed in the following manners.

Specific Aim I. Compare first time mothers who request cesarean delivery and first time mothers who request vaginal delivery, to investigate differences in health beliefs, maternal outcomes, and goals for the birth experience.

QI.1 Do women who request cesarean delivery and women who request vaginal delivery differ on maternal characteristics, perceived self efficacy, perceived threat, perceived risk, perception of the birth experience and satisfaction with delivery decision?

Independent samples t-tests were used to compare the cesarean delivery request group and the vaginal delivery request group on the selected health belief model constructs. Means and SD were reported for control, acceptance of the motherhood role, perceived susceptibility, perceived threat, husband/partner support. Significant differences between the groups were discussed.

QI.2 Do women who request vaginal delivery and women who request cesarean delivery differ in maternal goals for the birth experience?

In order to identify themes or categories within the goals reported, all goals for all participants (without consideration of delivery group or within-participant goal context) were pooled. A conscious effort to eliminate bias was undertaken by only viewing the files that contained the participants ID number and the goals written before delivery (Lincoln \& Guba, 1985). Specific words or concepts were then identified that 
were used by multiple participants in their goals. For example, one concept identified in the goals of multiple participants was the desire for adequate pain relief during the birth process. Another desire that was frequently expressed by multiple women in their goals addressed the safety of the baby during birth. Credibility was maintained by next examining the goals within the context of the individual participants other goals, to see if this changed the meaning of what the participant had reported (Mauthner, 2007). To establish trustworthiness and rigor the initial analysis of the goals was then reviewed by another researcher experienced in mixed methods research as well as childbirth (Creswell, 2003). The goals were then sorted into preliminary categories, to identify the themes. Through a discussion with another researcher, a set of goal categories was developed that maintained the full character of maternal perspective but allowed for a quantitative description of goals. Each woman's goals were then assigned to a category. Any uncertainly about categorization of the goals was resolved by returning to the original data and looking at the participant's goal in context or by contacting the participant for validation of the meaning if indicated (Lincoln \& Guba, 1985).

The types of goals reported between women planning a vaginal birth and those requesting a cesarean birth were compared. For each category, a Pearson's chi-square test was used to compare the proportions of women reporting goals and to investigate differences in goals between these groups. Goal achievement was examined for each group.

Specific Aim II. Examine the effects of selected health beliefs, assessed in the third trimester, on maternal perceptions of the birth experience and maternal satisfaction with the delivery decision, both assessed after delivery among first time mothers. 
H II.1 Antenatal maternal characteristics (control, acceptance of motherhood role), perceived self efficacy, perceived threat, perceived risk, cues to action (husband/partner support, perception of provider opinion), and maternal request group will account for a significant amount of the variance in postpartum maternal perception of the birth experience controlling for selected maternal demographic and obstetrical history variables.

Hypothesis II.1 was analyzed using hierarchical multiple linear regression analysis. At the first step, state anxiety was entered into the equation as a covariate. At the second step, control, acceptance of the motherhood role, perceived susceptibility, perceived threat, husband/partner support and maternal request were entered. Maternal perception of the birth experience was the dependent variable. The beta weights of the predictors were examined for significance to determine which were significant predictors of the outcome variable.

HII.2 Antenatal maternal characteristics (control, acceptance of motherhood role), perceived self efficacy, perceived threat, perceived risk, cues to action (husband/partner support, perception of provider opinion) and maternal request group will account for a significant amount of the variance in postpartum maternal satisfaction with the delivery decision, controlling for selected maternal demographic and obstetrical history variables.

Hypothesis II.2 was analyzed using hierarchical multiple linear regression analysis. At the first step, history of infertility was entered into the equation as a covariant. At the second step, control, acceptance of the motherhood role, perceived susceptibility, perceived threat, husband/partner support and maternal request were 
entered. Maternal satisfaction with the delivery decision was the dependent variable. The beta weights of the predictors were examined for significance to determine which were significant predictors of the outcome variable.

Specific Aim III. Examine maternal request group as a moderator of the relationship between perceived threat and maternal outcomes of perception of the birth experience and satisfaction with the delivery decision.

H III.1 Maternal request group will moderate the relationship between perceived threat and perception of the birth experience, controlling for selected maternal demographic and obstetrical history variables.

Hypothesis III.1 was analyzed using hierarchical multiple linear regression analysis. Prior to conducting the analysis, an interaction term will be created by using the SPSS compute new variable command to multiply the perceived threat and maternal request variables. At the first step, state anxiety was entered into the equation. At the second step, control, acceptance of the motherhood role, perceived susceptibility, perceived threat, husband/partner support and maternal request were entered. At the third step the perceived threat $\mathrm{X}$ maternal request interaction term was entered. Maternal perception of the birth experience was the dependent variable.

H III.2 Maternal request will moderate the relationship between perceived threat and maternal satisfaction with the delivery decision, controlling for selected maternal demographic and obstetrical history variables.

Hypothesis III.2 was analyzed using hierarchical multiple linear regression analysis. Prior to conducting the analysis, an interaction term was created by using the SPSS compute new variable command to multiply the perceived threat and maternal 
request variables. At the first step, history of infertility was entered into the equation. At the second step, control, acceptance of the motherhood role, perceived susceptibility, perceived threat, husband/partner support and maternal request were entered. At the third step the perceived threat X maternal request interaction term was entered. Maternal satisfaction with the delivery decision was the dependent variable.

\section{Summary}

This chapter described the methodology used to conduct the research study. The following sections were delineated: study design, sample, setting, methods, methods used to protect human subjects, instruments used to measure the study variables, data collection procedures, and data analysis plan. Power analysis considerations were also discussed. Power analysis considerations were not discussed in this chapter, but can be found in Appendix O. 


\section{CHAPTER IV}

\section{Results}

The results of this prospective study of maternal request group (vaginal vs. cesarean delivery), maternal health beliefs and the outcomes variables of maternal perception of the birth experience and satisfaction with the delivery decision will be discussed in this chapter. A description of the pre analysis data screening procedure, hypothesis testing and other descriptive data from the questionnaires will be reported.

\section{Pre Analysis Data Screening}

Pre analysis data screening was conducted prior to statistical analysis and included screening for errors of data entry, undefined missing values, unintended sampling, or outliers. Normality was assessed for all interval/ratio level variables and indicated that the satisfaction with the delivery decision variable and the maternal perception of the provider role (cues to action) in the decision scale were not normally distributed. A natural logarithmic transformation was conducted on the delivery decision variable and a near normal distribution was achieved. In examining the frequencies of responses to the maternal provider opinion variable, it was noted that 110 of the participants had selected the option on the scale "I never discussed a cesarean with my doctor." Because of this lack of variability, the scale could not be adequately transformed to meet normality assumptions and therefore was not included in the hypothesis testing. However, the construct cues to action were still reflected in the 
hypothesis testing with the variable partner/husband support. One outlier was identified in the vaginal group with an age of 17 years. Between group comparisons on age were performed with this participant removed; but differences between the groups still remained significant $(\mathrm{p}<.001$, therefore the participant was retained in the dataset.

\section{Specific Aim I}

Specific Aim I was to investigate differences between first time mothers who request cesarean delivery and first time mothers who request vaginal delivery on health beliefs, maternal outcomes, and goals for the birth experience. Independent samples t tests and Pearson's Chi Squares were performed to analyze group differences for these measures. The two research questions that were associated with this aim will also be discussed.

Q3.1 Do women who request cesarean delivery and women who request vaginal delivery differ on maternal characteristics, perceived susceptibility, perceived threat, perception of the birth experience and satisfaction with delivery outcomes?

Q3.2 Do women who request vaginal delivery and women who request cesarean delivery differ in maternal goals for the birth experience?

\section{Characteristics of the Participants}

Table 10 summarizes differences between the groups on demographic characteristics. The majority of the sample were white, married, women with a college education. Women in the cesarean group were significantly older and a smaller proportion had a college degree than women planning a vaginal delivery. 
Table 10

Comparison of maternal choice groups on demographic characteristics (Vaginal $n=127$, Cesarean $n=17$ )

\begin{tabular}{lccccc}
\hline Variables & Vaginal & $\% / \mathrm{M}(\mathrm{SD})$ & Cesarean & $\% / \mathrm{M}(\mathrm{SD})$ & $\mathrm{t}$ statistic/ $\chi^{2}$ \\
\hline \multirow{2}{*}{ Age in years } & Range & 25.4 & Range & 30.6 & \multirow{2}{*}{$4.92 * * *$} \\
& $17-37$ & $(3.96)$ & 3035 & $(5.05)$ &
\end{tabular}

Marital status

Married

Not married

Race/Nationality

White

Non White

Education

High School graduate or less

College or more
93

34

26.7

73.2

11

6

35.3

64.7

101

26

20.5

79.5

15

2

11.8

88.2

.73

8

$* \mathrm{p}<.05$ two tailed $* * \mathrm{p}<.01$ two tailed $* * * \mathrm{p}<.001$ two tailed

\section{Obstetrical Characteristics of the Participants}

Table 11 summarizes comparisons of the groups on obstetrical history.

Significantly fewer women in the cesarean group planned to have more than one child. There was significant difference in the provider type, with women planning a vaginal delivery being more likely to report their provider as being a family practice doctor, midwife, or collaborative team of obstetrician and midwife than women planning a 
cesarean delivery. The number of women in both groups who reported depression and state anxiety related to the upcoming birth was not significantly different. No significant differences were observed between the cesarean group and vaginal group in reporting the pregnancy as being planned and that they were happy about being pregnant at this time.

Obstetrical history regarding miscarriages and infertility were also similar in both groups.

Table 11

Comparison of maternal request groups on obstetrical characteristics (Vaginal $n=127$, Cesarean $n=17$ )

\begin{tabular}{lccccc}
\hline Variables & Vaginal & $\% / \mathrm{M}$ & Cesarean & $\% / \mathrm{M}$ & $\begin{array}{r}\mathrm{t}-\mathrm{statistic} \\
\mathrm{t} /{ }^{2}\end{array}$ \\
\hline Hx of Miscarriages & 36 & 28.3 & 2 & 11.8 & 2.12 \\
Hx of Infertility & 28 & 22.0 & 5 & 29.4 & .46 \\
Pregnancy planned & 68 & 53.5 & 8 & 47.0 & 0.25 \\
Pregnancy unplanned & 59 & 46.4 & 9 & 52.9 & \\
Planning one child & 7 & 5.5 & 5 & 29.4 & $18.344^{* * *}$ \\
Planning two or more & 102 & 80.3 & 6 & 35.2 & \\
Uncertain & 18 & 14.2 & 6 & 35.3 & \\
Provider Obstetrician & 73 & 57.5 & 17 & 100.0 & $\mathrm{x}$ \\
Provider other & 54 & 42.5 & 0 & 0.0 & \\
State anxiety & 127 & $2.7(1.1)$ & 17 & $3.2(1.3)$ & 17.37 \\
Hx Depression Yes & 26 & 20.4 & 3 & 17.6 & \\
Hx Depression No & 101 & 79.5 & 14 & 82.3 & $\mathrm{x}$ \\
\hline
\end{tabular}

${ }^{*} \mathrm{p}<.05$ two tailed ${ }^{* *} \mathrm{p}<.01$ two tailed ${ }^{* * *} \mathrm{p}<.001$ two tailed 


\section{Reasons for the Request}

Participants reported what factors influenced them in making their decisions to have a cesarean delivery or a vaginal delivery and also about their specific perceptions of the safety or risk of either a vaginal or cesarean delivery. Participants, who reported that their physician had suggested a cesarean delivery to them, also reported their perceptions of why this suggestion was made by the physician. A detailed description of these findings can be found in Appendix P and Appendix Q. Perceived reasons for the suggestion by the physician to plan an elective cesarean delivery were history of endometriosis and infertility, history of polycystic ovary syndrome and infertility, advanced maternal age, past medical concerns related to back surgery and high risk pregnancy with positive AFP Screening.

Table 12 summarizes comparisons of the groups on maternal self efficacy, perceived threat, perceived risk and mode of delivery. Significant differences were observed regarding maternal perception of their ability to delivery vaginally if in labor; with women planning a cesarean reporting significantly lower self efficacy than women planning a vaginal birth. Women planning a cesarean delivery were also significantly more likely to perceive themselves as being at risk for an emergency cesarean if they were in labor, than women planning a vaginal birth. The planned cesarean group perceived that a vaginal delivery held significantly greater threat than the planned vaginal group.

Women planning a vaginal delivery reported slightly higher scores regarding their perceived ability to control internal and environmental factors surrounding the experience of childbirth, than women in the cesarean group but this difference was not statistically 
significant. There was no significant difference between the planned vaginal group and the planned cesarean group in acceptance of the maternal role. Examination of the means and standard deviations showed that women in the planned vaginal group reported a slightly higher but not significant difference in maternal perception of partner support, than women requesting a cesarean delivery.

Table 12

Comparisons of maternal request group on perceptions of maternal health belief variables

(Vaginal $n=127$, Cesarean $n=17$ )

\begin{tabular}{lcccc}
\hline Variables & Vaginal M & SD & C-section $M$ & SD \\
\hline Internal and external control & 43.8 & 8.7 & 40.0 & 8.4 \\
Maternal role acceptance & 30.5 & 6.5 & 29.7 & 3.9 \\
Perceived support & 18.2 & 4.4 & 17.9 & 4.1 \\
Perceived threat*** & 11.1 & 1.4 & 13.2 & 1.4 \\
$\begin{array}{l}\text { Perceived risk emergent } \\
\text { Cesarean*** }\end{array}$ & 3.6 & 1.1 & 2.2 & 0.8 \\
$\begin{array}{l}\text { Self efficacy (Perceived ability } \\
\text { to deliver vaginally) } * * *\end{array}$ & 1.7 & 0.8 & 3.7 & 1.5 \\
\hline$*$ p & & & & \\
\hline
\end{tabular}

$* \mathrm{p}<.05$ two tailed $* * \mathrm{p}<.01$ two tailed $* * * \mathrm{p}<.001$ two tailed

\section{Maternal Perception of the Birth Experience}

The means and standard deviations of maternal perception of the birth experience for the planned cesarean group and the planned vaginal group are shown in Table 4 . Women who planned a vaginal birth perceived their birth experience slightly less positively than women who planned a cesarean delivery, however this difference was not statistically significant. Additional analysis using one way Analysis of Variance Between 
Groups (Anova), showed significant $(\mathrm{p}<.001)$ between group differences with the sample categorized into three groups: planned cesarean $(n=17)$, planned successful vaginal $(n=104)$, and emergent cesarean $(n=23)$. The planned successful vaginal group reported the most positive birth perception $(\mathrm{M}=109.68, \mathrm{SD}=15.44)$, followed by the planned cesarean group $(\mathrm{M}=107.39, \mathrm{SD}=13.72)$, and with the emergent cesarean group reporting the lowest mean scores $(\mathrm{M}=88.22, \mathrm{SD}=15.75)$. The Tukey post hoc tests showed that perception of the birth was significant less positive for mothers in the emergent cesarean group than for mothers in either the planned cesarean group or the planned successful vaginal group $(\mathrm{p}<.001)$. The Games-Howell tests reported the same significant differences between the groups $(\mathrm{p}<.001)$.

\section{Maternal Satisfaction with Delivery Decision}

The means and standard deviations of maternal satisfaction with the delivery decision for the planned cesarean group and the planned vaginal group are shown in Table 4. Women who planned a vaginal birth had significantly less decisional satisfaction than women who planned a cesarean delivery.

Examination of the subscales scores for the DCS showed that women planning a cesarean felt significantly less supported and less informed in the decision making process than women planning a vaginal birth. The planned cesarean group also reported feeling significantly less clear about their personal values related to the benefits and risks of their decision than the planned vaginal group. Additionally, women planning a cesarean reported being significantly more uncertain about the decision being the best choice; and were significantly more likely to express the viewpoint that this may have been a bad decision than women who planned a vaginal delivery. Additional analysis 
using one way Anova, showed significant $(\mathrm{p}<.001)$ between group differences with the sample categorized into three groups: planned cesarean $(n=17)$, planned successful vaginal $(n=104)$, and emergent cesarean $(n=23)$. The planned cesarean group reported the most conflict and dissatisfaction with the decision $(\mathrm{M}=34.06, \mathrm{SD}=8.36)$, followed by the emergent cesarean group $(\mathrm{M}=28.98, \mathrm{SD}=7.28)$, and with the planned successful vaginal group reporting the lowest mean scores $(M=20.74, S D=7.28)$. The Tukey post hoc tests indicated that there was no significant difference in satisfaction with the delivery decision between the planned cesarean group and the emergent cesarean group $\mathrm{p}$ $=.08$. However, the Tukey post hoc tests indicated that women in the planned successful vaginal group reported significantly less dissatisfaction with their delivery decision than both the planned cesarean group or the emergent cesarean group $(\mathrm{p}<.001)$. The GamesHowell post hoc tests also reported significant differences for the planned successful vaginal group and either the planned cesarean group or the emergent cesarean group $(\mathrm{p}<$ $.001)$. 
Table 13

Comparison of maternal request groups on maternal satisfaction with birth experience and satisfaction with decision regarding mode of delivery

(Vaginal $n=127$, Cesarean $n=17$ )

\begin{tabular}{lccccc}
\hline Variables & Vaginal M & SD & C-section M & SD & Significant*** \\
\hline DCS Total & 9.8 & 12.6 & 28.2 & 13.5 & $* * *$ \\
Effective Decision & 9.4 & 13.72 & 16.9 & 10.5 & $* * *$ \\
Subscale & 8.3 & 12.9 & 29.9 & 14.7 & $* * *$ \\
Support Subscale & 9.2 & 15.3 & 33.8 & 20.7 & $* * *$ \\
$\begin{array}{l}\text { Values Clarity } \\
\text { Subscale }\end{array}$ & 9.8 & 15.4 & 25.0 & 12.8 & $* * *$ \\
$\begin{array}{l}\text { Informed Subscale } \\
\begin{array}{l}\text { Uncertainty Subscale } \\
\text { Maternal }\end{array}\end{array}$ & 12.1 & 15.3 & 39.2 & 20.4 & $* * *$ \\
$\begin{array}{l}\text { Perception of Birth } \\
\text { Experience }\end{array}$ & 105.9 & 17.6 & 108.2 & 13.7 & \\
\end{tabular}

$* \mathrm{p}<.05$ two tailed $* * \mathrm{p}<.01$ two tailed $* * * \mathrm{p}<.001$ two tailed

\section{Expectancies and Goals for Delivery}

The 144 participants in the study reported a total of 693 goals. Based on these 693 goals, thirteen goal categories were identified. In order to identify themes or categories within the goals reported, all goals for all participants (without consideration of delivery group or within-participant goal context) were pooled. A conscious effort to eliminate bias was undertaken by only viewing the files that contained the participants ID number and the goals written before delivery (Lincoln \& Guba, 1985). Specific words or concepts were then identified that were used by multiple participants in their goals. For example, one concept identified in the goals of multiple participants was the desire for 
adequate pain relief during the birth process. Another desire that was frequently expressed by multiple women in their goals addressed the safety of the baby during birth. Credibility was maintained by next examining the goals within the context of the individual participants other goals, to see if this changed the meaning of what the participant had reported (Mauthner, 2007). To establish trustworthiness and rigor the initial analysis of the goals was then reviewed by another researcher experienced in mixed methods research as well as childbirth (Creswell, 2003). The goals were then sorted into preliminary categories, to identify the themes. Through a discussion with another researcher, a set of goal categories was developed that maintained the full character of maternal perspective but allowed for a quantitative description of goals. Each woman's goals were then assigned to a category. Any uncertainly about categorization of the goals was resolved by returning to the original data and looking at the participant's goal in context or by contacting the participant for validation of the meaning if indicated (Lincoln \& Guba, 1985). Examples of the goals expressed and the percentages are located in Appendix R.

The types of goals reported between women planning a vaginal birth and those requesting a cesarean birth were compared. No women in the planned cesarean group expressed the goal of avoiding interventions or a goal related to maternal role. Women in both groups expressed similar percentages of goals related to avoiding complications, having a healthy baby, receiving adequate pain control and having the birth be a fulfilling and rewarding experience. Women in the planned vaginal group reported a higher percentage of goals related to a desire for internal control over their behavior, external control over the environment of birth, and the duration of birth experience than women planning a 
cesarean delivery. For women planning a cesarean, a higher percentage of their goals related to healthy mother, ease of recovery, partner/family support and involvement and bonding/breastfeeding than for women planning a vaginal delivery. Participants were asked at 6 weeks postpartum to report if their goals were fully achieved, somewhat achieved or not achieved at all. Women planning a cesarean delivery reported that $63.5 \%$ of their goals were fully achieved, $23.8 \%$ of their goals were somewhat achieved, and $12.7 \%$ of their goals were not achieved at all. Women planning a vaginal delivery reported that $59.0 \%$ of their goals were fully achieved, $21.6 \%$ of their goals were somewhat achieved, and $19.4 \%$ of their goals were not achieved at all. Examples of the goals expressed and the percentages are located in Appendix R.

\section{Hypothesis Testing}

Prior to conducting hypothesis testing, relationships between the demographic and obstetrical characteristics and the outcome variables of maternal perception of the birth experience and satisfaction with the delivery decision were examined. Tables reporting these correlations are located in Appendix T and Appendix U.

Four hierarchical multiple linear regressions were performed to test the hypotheses. To make the models more parsimonious only demographic and obstetrical variables that were significantly correlated with the outcome variable were entered into the regression models as covariates.

H II.1 Antenatal maternal characteristics (control, acceptance of motherhood role), perceived self efficacy, perceived threat, perceived risk, cues to action (husband/partner support, perception of provider opinion), and maternal request group will account for a significant amount of the variance in postpartum maternal perception 
of the birth experience controlling for selected maternal demographic and obstetrical history variables.

For this hypothesis test, the dependent variable was maternal perception of the birth experience. Table 14 presents the multiple linear regression analysis results. State anxiety was included as a control variable along with the other the variables of control, acceptance of the motherhood role, perceived susceptibility, perceived threat, perceived risk, perceived partner support and maternal request group. As previously discussed, perception of provider opinion was not included as a variable in the model because of its low variability. Multiple linear regression results indicated that the overall model did not significantly predict the dependent variable of maternal perception of the birth experience. The model accounted for only $1.8 \%$ of the variance in the dependent variable. Review of the $\beta$ weights indicated that only one predictor variable, maternal role acceptance, $\beta=.206, \mathrm{t}(144)=2.121, \mathrm{p}=.036$ significantly contributed to the model with greater maternal role acceptance predicting more positive maternal perception of the birth experience. 
Table 14

Summary of Multiple Linear Regression Analysis for Health Belief Variables Predicting Maternal perception of the Birth Experience $(n=144)$, Controlling for State Anxiety

\begin{tabular}{lccc}
\hline Predictor & B & SE B & $\beta$ \\
\hline $\begin{array}{l}\text { Self efficacy towards birth } \\
\text { (control) }\end{array}$ & .218 & .212 & .110 \\
Acceptance of maternal role & .560 & .264 & $.206 *$ \\
Partner support & -.484 & .365 & -.124 \\
$\begin{array}{l}\text { Ability to deliver vaginally } \\
\text { (susceptibility) }\end{array}$ & .566 & 1.711 & .038 \\
Risk of emergent cesarean (risk) & -1.222 & 1.558 &. .082 \\
Threat of vaginal delivery & .152 & 1.025 & .014 \\
(threat) & & & .021 \\
Maternal request group & 1.095 & 5.674 & -.657 \\
State Anxiety & -1.056 & 1.609 & \\
$\mathrm{R}^{2}$ & .074 & & \\
Adjusted R & & & \\
F (p-value for model) & .018 & & \\
\hline
\end{tabular}

$* \mathrm{p}<.05$ two tailed $* * \mathrm{p}<.01$ two tailed $* * * \mathrm{p}<.001$ two tailed

H III.1 Maternal request group will moderate the relationship between perceived threat and perception of the birth experience, controlling for selected maternal demographic and obstetrical history variables.

For this hypothesis test, state anxiety was entered at Step 1 in the equation. Step 2 consisted of entering the maternal health belief variables (perceived risk, perceived susceptibility, threat of vaginal delivery, maternal role acceptance, perceived partner support, and labor self efficacy) not being tested for unique variance. In Step 3, the 
interaction between maternal request group and perceived threat was entered into the equation. Table 15 represents the results of the hierarchical multiple linear regression. The interaction between maternal request group and perceived threat was not significant, consequently maternal request group did not moderate the relationship between perceived threat and perception of the birth experience, the change in $\mathrm{R}^{2}$ from the $2^{\text {nd }}$ to the $3^{\text {rd }}$ step was not statistically significant, $\mathrm{R}^{2}=.077, \mathrm{R}^{2}{ }_{\text {adj }}=.014, \mathrm{~F}(1,133)=.474, \mathrm{p}=.492$

Table 15

Hierarchical Multiple Linear Regression for Health Belief Variables Predicting Maternal Perception of Birth Experience and Moderating effect of Maternal Request Group $(n=$ 144).

\begin{tabular}{|c|c|c|c|c|c|c|c|c|c|}
\hline & Step1 & & & Step 2 & & & Step 3 & & \\
\hline Variable & B & SE B & $\beta$ & B & SE B & $\beta$ & B & SE B & $\beta$ \\
\hline State Anxiety & -1.769 & 1.273 & -.116 & -1.056 & 1.609 & -.069 & -.972 & 1.617 & -.064 \\
\hline $\begin{array}{l}\text { Maternal Request } \\
\text { Group }\end{array}$ & & & & 1.095 & 5.674 & .021 & 30.056 & 42.446 & .572 \\
\hline Perceived risk & & & & -1.222 & 1.558 & -.082 & -.990 & 1.597 & -.066 \\
\hline Perceived threat & & & & .152 & 1.025 & 0.14 & .377 & 1.078 & .035 \\
\hline $\begin{array}{l}\text { Perceived } \\
\text { susceptibility }\end{array}$ & & & & .566 & 1.711 & .038 & .711 & 1.727 & .047 \\
\hline $\begin{array}{l}\text { Maternal role } \\
\text { acceptance }\end{array}$ & & & & .560 & .264 & .206 & .577 & .266 & .212 \\
\hline $\begin{array}{l}\text { Perceived partner } \\
\text { support }\end{array}$ & & & & -.484 & .365 & -.124 & -.460 & .368 & -.117 \\
\hline $\begin{array}{l}\text { Maternal self } \\
\text { efficacy }\end{array}$ & & & & .218 & .212 & .110 & .208 & .213 & .105 \\
\hline Interaction & & & & & & & -2.228 & 3.235 & -.564 \\
\hline $\mathrm{R}^{2}$ Change & & 0.14 & & & .060 & & & .003 & \\
\hline $\mathrm{R}^{2}$ & & 0.14 & & & 0.74 & & & .007 & \\
\hline Adjusted $\mathrm{R}^{2}$ & & .007 & & & .018 & & & .014 & \\
\hline $\begin{array}{l}\text { F } \\
\text { (p value model) }\end{array}$ & & $\begin{array}{l}1.931 \\
\mathrm{P}=.167\end{array}$ & & & $\begin{array}{l}1.242 \\
p=.284\end{array}$ & & & $\begin{array}{l}.474 \\
\mathrm{P}=.492\end{array}$ & \\
\hline
\end{tabular}

$* \mathrm{p}<.05$ two tailed $* * \mathrm{p}<.01$ two tailed $* * * \mathrm{p}<.001$ two tailed 
HII.2 Antenatal maternal characteristics (control, acceptance of motherhood role), perceived self efficacy, perceived threat, perceived risk, cues to action (husband/partner support, perception of provider opinion) and maternal request group will account for a significant amount of the variance in postpartum maternal satisfaction with the delivery decision, controlling for selected maternal demographic and obstetrical history variables.

For this hypothesis test, the dependent variable was maternal satisfaction with the delivery decision. Table 16 presents the multiple linear regression analysis results. History of infertility was included as a control variable along with the other the variables of control, acceptance of the motherhood role, perceived susceptibility, perceived threat, perceived risk, perceived partner support and maternal request group. As previously discussed, perception of provider opinion (cues to action) was not included as a variable in the model. Multiple linear regression results indicated that this model accounted for $15.1 \%$ of the variance in the dependent variable, maternal satisfaction with the delivery decision. Review of the $\beta$ weights indicated that two predictor variables; maternal role acceptance $\beta=-.236, \mathrm{t}(144)=-2.610, \mathrm{p}<.01$ and maternal request group for mode of delivery $\beta=.337, \mathrm{t}(144)=3.353, \mathrm{p}<.001$ significantly contributed to the model. Greater maternal role acceptance predicted less maternal satisfaction with the decision regarding mode of delivery. Women who requested cesarean delivery had significantly less satisfaction with the delivery decision. 
Table 16

Summary of Multiple Linear Regression Analysis for Health Belief Variables Predicting Maternal Satisfaction with the Decision Regarding Mode of Delivery $(n=144)$, Controlling for history of infertility

\begin{tabular}{|c|c|c|c|}
\hline Predictor & B & SE B & $\beta$ \\
\hline $\begin{array}{l}\text { Self efficacy towards birth } \\
\text { (control) }\end{array}$ & .006 & .015 & .039 \\
\hline Acceptance of maternal role & -.053 & .020 & $-.236^{*}$ \\
\hline Partner support & .037 & .028 & .113 \\
\hline $\begin{array}{l}\text { Ability to deliver vaginally } \\
\text { (susceptibility) }\end{array}$ & .025 & .132 & .020 \\
\hline Risk of emergent cesarean (risk) & -.067 & .117 & -.054 \\
\hline $\begin{array}{l}\text { Threat of vaginal delivery } \\
\text { (threat) }\end{array}$ & -.009 & .078 & -.010 \\
\hline Maternal request group & 1.472 & .439 & $.337 * *$ \\
\hline History of infertility & -.484 & .266 & -.143 \\
\hline $\mathrm{R}^{2}$ & .199 & & \\
\hline Adjusted $\mathrm{R}^{2}$ & .151 & & \\
\hline $\mathrm{F}$ (p-value for model) & $4.404(\mathrm{p}<.001)$ & & \\
\hline \multicolumn{4}{|c|}{${ }^{*} \mathrm{p}<.05$ two tailed $* * \mathrm{p}<.01$ two tailed $* * * \mathrm{p}<.001$ two tailed } \\
\hline \multicolumn{4}{|c|}{ H III. 2 Maternal request will moderate the relationship between perceived threa } \\
\hline and maternal satisfaction with $t$ & elivery decisio & $\operatorname{ing} f$ & ternal \\
\hline
\end{tabular}

For this hypothesis test, history of infertility was entered at Step 1 in the equation. Step 2 consisted of entering the maternal health belief variables (perceived risk, perceived susceptibility, threat of vaginal delivery, maternal role acceptance, perceived partner support, and labor self efficacy). In Step 3, the interaction between maternal request group and perceived threat was entered into the equation. Table 17 represents the results of the regression analysis. The interaction between maternal request group and perceived threat was not significant, thus maternal request group did not moderate the relationship between perceived threat and maternal satisfaction with the decision for 
mode of delivery. The change in $\mathrm{R}^{2}$ from the $2^{\text {nd }}$ Step to the $3^{\text {rd }}$ Step was not statistically significant, $\mathrm{R}^{2}=.204, \mathrm{R}_{\text {adj }}^{2}=.150, \mathrm{~F}$ change $(1,133)=.868, \mathrm{p}=.353$.

Table 17

Hierarchical Multiple Linear Regression for Health Belief Variables Predicting Satisfaction with the Delivery Decision and Moderating Effect of Maternal Request Group $(n=144)$.

\begin{tabular}{|c|c|c|c|c|c|c|c|c|c|}
\hline & Step 1 & & & Step 2 & & & Step 3 & & \\
\hline Variable & B & SE B & $\beta$ & $\mathrm{B}$ & SE B & $\beta$ & $\mathrm{B}$ & SE B & $\beta$ \\
\hline Infertility & -.405 & .283 & -.120 & -.484 & .266 & -.143 & -.474 & .267 & -.140 \\
\hline $\begin{array}{l}\text { Maternal } \\
\text { Request Group }\end{array}$ & & & & 1.472 & .439 & .337 & -1.541 & 3.264 & -.353 \\
\hline Perceived risk & & & & -.067 & .117 & -.054 & -.090 & .120 & -.072 \\
\hline Perceived threat & & & & -.009 & .078 & -.010 & -.033 & .083 & -.038 \\
\hline $\begin{array}{l}\text { Perceived } \\
\text { susceptibility }\end{array}$ & & & & .025 & .132 & .020 & .010 & .133 & .008 \\
\hline $\begin{array}{l}\text { Maternal role } \\
\text { acceptance }\end{array}$ & & & & -.053 & .020 & -.236 & -.055 & .020 & -.243 \\
\hline $\begin{array}{l}\text { Perceived } \\
\text { partner support }\end{array}$ & & & & .037 & .038 & .113 & .035 & .028 & .106 \\
\hline $\begin{array}{l}\text { Maternal self } \\
\text { efficacy }\end{array}$ & & & & .006 & .015 & .039 & .008 & .015 & .048 \\
\hline Interaction & & & & & & & .232 & .249 & .707 \\
\hline $\mathrm{R}^{2}$ Change & & .014 & & & .184 & & & .005 & \\
\hline & & .014 & & & .199 & & & .204 & \\
\hline Adjusted $\mathrm{R}^{2}$ & & .007 & & & .151 & & & .105 & \\
\hline $\begin{array}{l}\text { F } \\
\text { (p value model) }\end{array}$ & 2.046 & $\mathrm{p}=.155$ & & 4.404 & $\begin{array}{l}\mathrm{p}=.000 \\
* *\end{array}$ & & & .868 & $\mathrm{p}=.353$ \\
\hline
\end{tabular}

Compared to women with VDMR, women with CDMR were significantly older, less educated, perceived more risk of emergent cesarean, more threat association with a vaginal delivery, and less ability to deliver vaginally.

Hypothesis testing indicated that the overall regression model did not significantly predict maternal perception of the delivery. The model accounted for a significant amount $(15.1 \%)$ of the variance in maternal satisfaction with the decision for mode of 
delivery. Acceptance of the maternal role and maternal request group significantly contributed to the model indicating that women with higher acceptance of the maternal role and women with CDMR had poorer satisfaction with their decision for the mode of delivery. Maternal request group did not moderate the relationship between perceived threat and perception of the birth experience or satisfaction with the decision. 


\section{CHAPTER V}

\section{Discussion}

The overall aim of this research study involved asking healthy first time mothers with normal pregnancies about the decision making process and the health beliefs which led to requesting an elective cesarean delivery in the absence of obstetrical indication and subsequent maternal outcomes of maternal perceptions of the birth experience and satisfaction with the delivery decision. The sample included 144 women, 17 of whom had requested cesarean delivery without a specific indication. Because the maternal request

group was small, differences between the planned vaginal group and planned cesarean group must be interpreted with caution. However, the results of the study do provide insights into differences between these groups.

This study found that first time mothers planning a cesarean delivery in the absence of a medical or obstetrical indication differed in several aspects from those who planned a vaginal delivery. Women in the cesarean group were significantly older and a smaller proportion had a college degree than women planning a vaginal delivery. Significantly, fewer women in the cesarean group planned to have more than one child. Women planning a cesarean delivery were significantly more likely to be cared for by an obstetrician than by a family practice physician, midwife, or a collaborative team consisting of a midwife and a physician. All of the above findings are consistent with 
what has been reported in the literature regarding women who planned a cesarean, except for education (Gamble \& Creedy, 2001; Suplee et al., 2007). In this study, the vaginal group had significantly higher levels of education than the cesarean group. This is different from past findings in the literature which have indicated request of cesarean delivery to be associated with higher level of education. This study was conducted using the internet, and this may partly explain the differences from past studies.

Despite being significantly older, women planning a cesarean delivery reported similar rates of miscarriages and infertility as compared to women planning a vaginal delivery. Women planning a cesarean delivery were not more likely to report depression than women who were planning a vaginal delivery. No significant differences were found between the groups in reporting the pregnancy as being planned and or well accepted. Women in the planned cesarean group did report a slightly lower perception of partner support during pregnancy and the decision making process as compared to women planning a vaginal delivery. The groups reported similarly percentages of marital status.

In spite of the fact that women planning a cesarean who were recruited for the study reported themselves as healthy, they reported different health beliefs about childbirth from women planning a vaginal delivery. Women planning a cesarean delivery considered themselves to be significantly less likely to be able to deliver vaginally if they were in labor, at more risk for harm if they did deliver vaginally, and to be more likely to need an emergency cesarean delivery. Additional women in the planned cesarean group reported a lower perception of being able to control their behavior and the environment surrounding a vaginal delivery than women who planned a vaginal delivery. This study 
adds information about nulliparous women to the existing body of literature that reports these viewpoints as increasing among women in general. This perception has been reported in the literature, but no prior study had exclusively examined nulliparous women. (Zwelling, 2008). This change in attitudes may explain the apparent increase in the number of requests for elective cesarean delivery over the last decade. This lack of self efficacy towards vaginal birth, may also explain the dramatic rise in other obstetric procedures and interventions performed solely for convenience (e.g., elective induction of labor, early artificial rupture of membranes), which lack evidence that they provide clear benefits for the mother or infant (Simpson \& Thorman, 2005). Maternal age has been reported as an independent risk factor for cesarean delivery. The reasons for this increased risk remain unclear, but other studies have suggested that it may be due to physician and patient concern over pregnancy outcomes in older women. (Byrom, 2004).

State anxiety about upcoming childbirth did not differ significantly between the groups, even though women planning a cesarean delivery did report slightly higher state anxiety. This is interesting because high anxiety and fear of childbirth have consistently been associated with maternal request of elective cesarean in the literature. It is important to note however, than these were studies comprised of both mutiparous and nulliparous women and in many cases involved study samples intended to simulate maternal request by looking at women considering vaginal birth after an emergent cesarean or traumatic vaginal delivery. Past research conducted outside of the U.S., has also focused on measuring the effectiveness of an intervention to reduce fear of childbirth and the women in those studies were often in the process of making a decision (Saisto \& Halmesmaki, 2003; Saisto et al., 2001). Only one study, an unpublished dissertation from Sweden, was 
found that examined only nulliparous women requesting cesarean (Wiklund, 2007). This sample of first time mothers also reported no significant differences in anxiety with their vaginal counterparts. Women in both this current study and the Wiklund study had made their decision about their method of delivery prior to the data collection regarding state anxiety related to childbirth. It is logical to argue that if they no longer anticipated a vaginal delivery, the state anxiety about that event might be lessened. Additionally, research is needed to determine if state anxiety towards childbirth decreases after a decision is made to request an elective cesarean instead of delivering vaginally.

Maternal acceptance and adaptation to the pregnancy was slightly higher for the planned cesarean group. Maternal acceptance and adaptation to the pregnancy can best be defined as the maternal psychosocial development during pregnancy that leads to maternal role attainment after delivery. There are two dimensions of maternal adaptation: motivation for and acceptance of the pregnancy, and the evolving maternal role attainment. During the first trimester women are turned inward and focus on their own wellbeing. This focus shifts to the baby as she moves into the second trimester. During the final trimester the focus is on surviving labor and birth. Theories about maternal role attainment and the developmental tasks of pregnancy have identified maternal willingness and ability to make personal sacrifices for the wellbeing of fetus/infant as a common goal for women with high levels of acceptance and attachment to the pregnancy (Mercer \& Stainton, 1984; Rubin, 1967). For the older planned cesarean, who reported high levels of threat and risk as being associated with vaginal birth, it is logical that they would request a mode of delivery that they perceive as insuring their baby's and their own well-being. It may be also important that they are planning only one child. Women 
planning a vaginal birth reported believing that they had chosen the delivery method that was safest for their baby and were willing to avoid medications and interventions that they perceived as potentially harmful to their baby or themselves.

\section{Goals and Expectations for the Delivery Experience}

This study adds to the literature about what is important to first time mothers as they plan their delivery. No comparison has been made of first time mothers planning a cesarean delivery with first time mothers planning a vaginal delivery in terms of goals and expectation of their delivery. Only one other study has compared goals and expectations for women planning a cesarean and women planning a vaginal delivery (MADRES). This study sample included multiparous women, and in fact $36.2 \%$ of the elective cesarean group was multiparous as compared with $1.8 \%$ of the planned vaginal group. The current study reported very similar goals to the recently completed MADRES study by Blomquist, J., MacMillan, D., Quiroz, L., and Handa, V. (unpublished) with some exceptions which will be discussed in this section. Importantly this study provides information about the mother's perception of the goals for her delivery being achieved. Women from both groups reported similar goals for their upcoming delivery with some exceptions. Women reported significant difference in goal achievement at six weeks postpartum; with women in the planned cesarean group having a higher percentage of their goals fully achieved.

No women in the planned cesarean group expressed the goal of avoiding interventions. For women planning a vaginal birth $92.9 \%$ reported at least one goal that related to avoiding some type of intervention. For women planning a cesarean delivery this was not a goal. It would be anticipated that women planning a cesarean would not 
have listed goals associated with specific obstetrical interventions used during a vaginal delivery like episiotomy or fetal monitoring. Women planning a vaginal delivery often mentioned wanting to avoid medication for example, and specifically reported the reason as fear of harm to the baby. Women planning a cesarean delivery did not seem to have this same belief. Additionally, it may be that women planning a cesarean feel differently amount interventions than women planning a vaginal delivery and believe the use of technology actually makes their delivery safer. This confidence in technology has been reported in the literature in other studies (Green \& Baston, 2007)).

Women in the planned vaginal group expressed a number of goals about being a good mother and providing for the baby by getting a better job or more education. No woman in the planned cesarean group expressed this concern as one of her goals. This goal was not identified in the MADRES study. The current study reported a lower mean age for the planned vaginal group of 25.4 vs. 30.9 for the MADRES study. It may be important to consider that the women planning a cesarean in the current study were significantly older and also reported higher acceptance and adaptation to the pregnancy than the planned vaginal group. These two facts may explain the differences in this goal expression. For younger women, issues related to financial situation and new careers may make the prospect of providing for the baby more concerning than to older women. This study chose not to collect income information, so this is not available to make comparisons on that variable.

Women in both groups expressed similar percentages of goals related to avoiding complications, having a healthy baby, receiving adequate pain control and having the birth be a fulfilling and rewarding experience. This differs from the MADRES study, 
where similar goals were expressed regarding having a healthy baby and receiving adequate pain control, but no women in the planned cesarean group expressed the goal of wanting their birth to be a fulfilling and rewarding experience. The conclusion expressed in the MADRES study was that women having a first baby are more likely to view their delivery as an important life changing event. Birth for first time mothers is the transition from self to maternal role and as such is a life changing event, even if the mother does not expressly state that as a goal. The information from this study supports that finding and helps to remind caregivers that this should be remembered when planning care and providing support for women requesting an elective cesarean.

Women in the planned vaginal group reported a higher percentage of goals related to a desire for internal control over their behavior, external control over the environment of birth, and the duration of birth experience than women planning a cesarean delivery. For women planning a cesarean, a higher percentage of their goals related to healthy mother, ease of recovery, partner/family support and involvement and bonding/breastfeeding than for women planning a vaginal delivery. These findings may provide information that women planning a cesarean delivery feel that by not being in labor they do not have to be concerned about how they will act when contractions begin or other events of labor occur. Additionally, they may feel that by planning a cesarean the environment and circumstances surrounding the birth are no longer issues that have to be controlled. The duration of labor is again, a fairly well defined event that would not concern women planning a cesarean.

Participants were asked at six weeks postpartum to report if their goals were fully achieved, somewhat achieved or not achieved at all. Women planning a cesarean delivery 
reported that $63.5 \%$ of their goals were fully achieved, $23.8 \%$ of their goals were somewhat achieved, and $12.7 \%$ of their goals were not achieved at all. Women planning a vaginal delivery reported that $59.0 \%$ of their goals were fully achieved, $21.6 \%$ of their goals were somewhat achieved, and $19.4 \%$ of their goals were not achieved at all.

\section{Maternal Perception of the Birth Experience}

Women, who planned a cesarean for the delivery of their first baby, reported slightly more positive, but not significantly different, perceptions of the birth experience from women in the planned vaginal group six weeks after their delivery. Of course not all the women in the planned vaginal group experienced a vaginal delivery. Of the 127 participants who were planning a vaginal birth, 23 (18.4\%) women experienced an emergent cesarean. Comparisons between the three groups (planned cesarean, successful vaginal and emergent cesarean) showed significant differences in the perception of the birth experience. The planned vaginal group had a significantly more positive perception of the birth experience than either the planned cesarean group or the emergent cesarean group. The emergent cesarean group had the least positive perception of their birth experience. This finding is consistent with the body of literature comparing these three groups (Bramadat \& Driedger, 1993; Bryanton, Gagnon, Johnson, \& Hatem, 2008; Byrom, 2004; Kitzinger, 2006). Women who have expressed goals and expectations for limited or no interventions, may feel that they have failed to achieve their goals and this is reflected in their less positive perception of their birth experience. Women, who give birth to a healthy baby, often feel increased guilt about expressing disappointment about their delivery method. For women planning a cesarean, the achievement of their goals for delivery may have been easier for them to achieve and this may also contribute to a 
more positive perception of the birth experience. Debriefing and talking about the birth experience is an important part of the taking in phase of early postpartum. If women are not given an opportunity and encouraged to express their disappointment about unmet expectations, it may negatively impact their birth perception.

\section{Maternal Satisfaction with the Decision for Mode of Delivery}

The findings from this study showed that women who planned a cesarean delivery, continued to feel significantly more less satisfaction with their decision even six weeks after their delivery than women who planned a vaginal delivery. Overall, the planned cesarean group felt less supported and less informed about their decision for a cesarean delivery. Importantly, they continued to report being less clear about personal values that related to the risks and benefits of their decision. Despite reporting no short term complications or problems following the cesarean, the planned cesarean group expressed significantly more uncertainty that their choice for a cesarean may not have been the "best choice for them to make". This seems especially important to consider in light of the fact that these women reported a positive perception of their birth experience.

When comparing the planned cesarean group with women who experience both unplanned emergent cesarean and planned successful vaginal birth, we continue to see significant difference between the groups. Women who experienced an unplanned emergent cesarean reported more satisfaction with the decision to plan a vaginal birth than women who planned for a cesarean, even while they reported a significantly less positive perception of their birth. No other research has examined maternal request in relation to the decision making process. This study suggests that the constructs of 
satisfaction with decision about mode of delivery and satisfaction with the birth experience are viewed differently by women.

Decisional conflict and dissatisfaction have been reported in the literature as independent predictors of blame (Gattelari \& Ward, 2004). Decisional satisfaction has not however been studied in women planning their mode of delivery. This study provides needed information about the complexity of maternal decision making. The literature, examining other study populations, supports that decisional dissatisfaction can be lowered with decision supporting interventions (O'Connor, 1995; O'Connor et al., 2002). Information about options, benefits, risks, and side effects of a particular medical decision are essential in helping women to feel informed. Values can be clarified using strategies such as: encouraging expectant women to describe the outcomes they are anticipating from their decision. By discussing the physical, emotional and social impact of their decision they can be encouraged to make a judgment about the values of these outcomes to them and they can rate the personal importance of the outcomes. Women may feel more supported in decision making if they are guided in the steps of deliberation and shared decision making. If women feel they have made a more informed and value laden decision, the result be increased satisfaction regarding the decision.

\section{Hypothesis Testing}

\section{Maternal Perception of the Birth Experience}

Hierarchical multiple linear regression results indicated that the overall model which included state anxiety, internal and external control, acceptance of the maternal role, perceived self efficacy, threat and risk, perceived partner support and maternal request did not significantly predict the dependent variable of maternal perception of the 
birth experience and accounted for only $1.8 \%$ of the variance in perception of the birth experience. Acceptance of the maternal role was the only predictor variable found to significantly contribute to the model. It was additionally hypothesized maternal request would moderate the relationship between perceived threat and perception of the birth experience. This hypothesis was not supported. In this study acceptance of the maternal role predicted maternal perception of the birth experience. Higher maternal acceptance and adaptation to the pregnancy was associated with a more positive perception of the birth experience. In making decisions about the mode of delivery; women with greater acceptance and adaptation to the pregnancy perceived vaginal birth as more threatening to them and to be a task that they were less likely to successfully accomplish. They also viewed themselves at more risk for an emergent cesarean while in labor and reported lower rates of state anxiety related to childbirth.

While no studies were found that specifically examined the effects of maternal acceptance and adaptation to pregnancy in a maternal request for cesarean population, a large body of literature exists that links maternal acceptance and adaptation to pregnancy to positive perceptions of the birth experience (Fawcett \& Knauth, 1996; Lederman et al., 1995; Mercer \& Stainton, 1984). The findings in this study on maternal acceptance and adaptation to pregnancy add new information to the literature about the importance of maternal role acceptance and the perception of the birth experience of women requesting a cesarean delivery.

Treads reported in the study indicate that increased acceptance of the maternal role may be associated with decreased maternal perceptions and beliefs that favor maternal planned vaginal delivery. This study suggests that increased acceptance and 
adaptation to the pregnancy, especially in older nulliparous women planning only one child, may lead to increased perception of vaginal birth as being threatening and unattainable. Increased maternal acceptance may increases the perception of risk for an emergent cesarean while in labor.

\section{Maternal Satisfaction with the Delivery Decision}

Multiple linear regression analysis revealed that the model which included the variables of history of infertility, internal and external control, acceptance of the maternal role, perceived partner support, maternal request; self efficacy, threat, and risk, accounted for $15.1 \%$ of the variance in maternal satisfaction with the delivery decision. An examination of the $\beta$ weights indicated that there were two significant predictor variables; acceptance of the maternal role and maternal request of mode of delivery. It was hypothesized that maternal request would moderate the relationship between perceived threat and satisfaction with the decision. The hypothesis was not supported.

No previous research was found that examined decisional satisfaction in the context of maternal request for mode of delivery. Previous research studies have found that women who face difficult health decisions are likely to experience decisional conflict and dissatisfaction (O’Connor, Jacobsen, \& Stacey, 2002). Past studies have found predictive relationships between decisional satisfaction and adequate partner and healthcare provider support in the context of genetic testing. The finding of this study extends the information on predictive relationships between maternal request of mode of delivery and maternal conflict and satisfaction with the decision. Specifically, this study showed that women planning a cesarean delivery reported more decisional conflict and less satisfaction with their decision at six weeks postpartum. Factors contributing to 
decisional dissatisfaction for women planning a cesarean delivery were identified as uncertainty about their choice being the best choice, feeling uninformed, feeling unclear about personal values, and feeling unsupported.

The study suggests that this is an area where additional information is needed regarding the role partner support plays in the maternal request for a cesarean delivery. An unpublished qualitative research study by this researcher, reported that the nulliparous women planning a cesarean reported receiving criticism from partners, family members, and coworkers about their decision for a cesarean delivery (MacMillan, 2008).

\section{Limitations of the Study}

The majority of the sample for both groups was age 25 years or older, white, married, and well educated women. The planned vaginal group was $79.5 \%$ white and the planned cesarean group was $88.2 \%$ white. In the U.S., almost one-half million unmarried adolescents give birth each year (Low, Martin, Sampselle, Guthrie \& Oakley, 2003). Additional the population of the U.S. in 2004 during the last census was reported as 58\% White, 12\% Black, 21\% Hispanic, 7\% Asian, and 2\% indigenous. The sample was not random sample, but recruited from the internet and flyers. Thus this study should not be generalized to all nulliparous women planning their delivery because of the homogenous sample. Though these limitations should be considered, the findings from this study are from a geographically diverse population, which represent 49 of the 50 states in the U.S. and both rural and urban areas.

Another limitation of the study is the small sample size for the planned cesarean group $(n=17)$. A sample of 27 was needed to assure adequate power for the number of variable and for model testing. Despite multiple recruitment strategies this was not 
achieved. It is, however, important to note that the 17 planned cesarean women represent $11.8 \%$ of the total sample of 144 . This percentage is above what is estimated as the occurrence rate of maternal request in the U.S.

This study was also limited by use of one newly developed instrument specific to the Health Belief Constructs of this study. Two subscales in particular, will require revisions before they are used for future research. The subscale which measured maternal perception of the physician role in the decision resulted in a non-normally distributed finding because of vaginal participant almost exclusively selecting one item on the scale. The perceived threat subscale showed a lower reliability than would be desired. The threat subscale was included in the model and hypothesis testing, but its relationship to the outcome variables was likely attenuated. The perception of the physician role in the decision was not included in the model and hypothesis testing because it did not meet normality assumptions for the analysis. This limits the conclusions that can be drawn about the cues to action construct of the Maternal Health Belief Model. However, a cue to action was still represented in the models with the husband/partner support variable.

\section{Implications for Nursing}

The findings from this study have implications for nursing practice in the areas of assessment of health beliefs about childbirth, education regarding options, benefits, risks, and potential side effects of decisions about childbirth. The development of decision supporting interventions for women making choices about method of delivery and other delivery options, such as elective induction of labor, are areas for nurses to also consider. 


\section{Assessment of Health Beliefs about Childbirth}

Nurses can incorporate these study findings to understand the importance of conducting thorough and holistic assessments that addresses pertinent cognitive, physiological, and psychosocial beliefs nulliparous women have about pregnancy and childbirth. Nurses should take a holistic approach to prenatal care and make sure that women have an opportunity to address more than just issues related to physical care during a routine prenatal visit. Communications between nurses and nulliparous women must be conducted in a manner the obtains information about self efficacy towards vaginal birth, maternal acceptance of the pregnancy role, partner support, state anxiety related to childbirth, as well as risk and benefits of medical decisions she may be considering.

Education Regarding Options, Benefits, Risks, and Potential Side Effects of Decisions

\section{about Childbirth}

Older nulliparous professional women are attending prenatal classes in declining numbers because they are questioning the relevance of the classes for them. The popularity of childbirth classes peaked in the 1980s and has been dropping in recent years as more women are opting for epidural anesthesia and perhaps elective cesarean deliveries. The nonprofit organization Childbirth Connection reports that in $2000,70 \%$ of first-time mothers attended a childbirth class, compared to $56 \%$ of first-time mothers in 2005. Offering prenatal education, and perhaps also prenatal care, in a different model to older women would enable the educational content to be specifically designed for the needs identified by the group. Women are often far away from extended family and close friends so that the traditional social support for women and their partners during 
pregnancy and childbirth is disappearing. This lack of traditional support and increased numbers of women who are working outside the home may have combined to create a social environment where women perceive they have no support and no time in which to attend childbirth classes.

Nurses should consider the findings of the study when making decisions about structuring prenatal care visits. The findings from the study support the need for offering older nulliparous women the benefits of prenatal care provided in a Centering Pregnancy model. Providing prenatal care and education in specially formed groups, where women are assigned based on similar due dates, ages, and assessed psychosocial and cultural needs has been shown an effective model for providing care for adolescent and women with cultural and language barriers (Robertson, Aycock, \& Darnell, 2008). When the traditional model of prenatal care is examined, it shows women waiting for long periods of time in a waiting room to see the healthcare provider for an average time of 5 minutes for what, in many instances, amounts to measuring the fundal height and listening for fetal heart tones. In the Centering Pregnancy model, individual prenatal care is generally dispensed with and replaced with ten 2-hour prenatal group sessions with 8 to 12 women who share similar due dates. Women are invited to join the group sessions after an initial prenatal assessment and laboratory testing is completed. The sessions comprise prenatal health care and education and begin at 12 to 16 weeks of pregnancy, concluding in the early postpartum. Within the group space, women learn self-care skills including measuring their own blood pressure and weight, which they record in their medical record and they receive an individual physical assessment from their prenatal care provider. The women then meet together as a group to discuss issues around the content 
of pregnancy, childbirth, and parenting. This group discussion, facilitated by the prenatal care provider, is stimulated by self-assessment sheets geared to the content plan for each session and completed by the women at the beginning of each session.

\section{Development of Decision Supporting Interventions}

Nurses can be instrumental in developing decisional support interventions that are specifically aimed at providing information about options, benefits, risks, and side effects of requesting an elective cesarean, elective induction or other intervention. Interventions aimed at values clarification would enable women to describe the anticipated outcomes of a decision. Nurses would be able to guide women with realistic information about the physical, emotional, and psychosocial impact of their decisions while assisting them to prioritize their personal perception of the importance of achieving the specific outcome. Interventions that guide women and their partners in the deliberation process and principals of shared decision making will potentially maternal perception of support and ultimately effect satisfaction with the decision.

\section{Implications for Healthcare}

The cost of healthcare in the U.S. has reached staggering new heights. It is important to understand how the public's acceptance of maternal request cesarean as a possible standard of care could deplete finite health care dollars; especially when in 2009, 4.9 million Americans did not even have access to basic health insurance. This number represented $19.2 \%$ of the non elderly population in the United States. With recent the health care reform bill, it appears that more Americans will now have access to insurance, but the debate over how the country will pay for this continues. If increased numbers of women perceive vaginal delivery as threatening and potentially harmful to themselves 
and to their babies, the number of women expressing the concern and requesting an elective cesarean could certainly increase. A $1 \%$ rise in elective cesarean would result in 40,000 additional cesarean births. Compared with elective cesarean delivery, vaginal delivery costs are less in direct cost and in the cost incurred from potential complications and future costs that may be incurred in later pregnancies if repeat cesareans are necessary. Cesarean delivery is associated with longer length of stay, higher occupancy rates, and maternal readmissions for post operative complications. Strategies to reduce the number of primary elective cesarean based on maternal request will assist in decreasing the potential for maternal and neonatal complications associated with a surgical delivery.

This study provides information about maternal decision making for elective cesarean and the increased potential for conflict and dissatisfaction which has been show to be predictive for blame when outcomes are not as expected. More often than not, having a baby is a time of great anticipation, high hopes, and joy for the parents and their families. Because pregnancy is a normal physiological process, most women progress through their prenatal course with expectations that everything will be absolutely normal, and that the infant will be healthy. When these expectations are not met, and the baby or mother is injured, joy turns to despair and grief. The process by which women are assisted and supported as they made decisions about their upcoming delivery may reduce the conflict and dissatisfaction with the decision. Understanding that communication and debriefing are essential when unanticipated outcomes occur may guide families and the healthcare provider during this difficult situation. 
Malpractice suits and the fear of them remain, however, an important distraction from the provision of patient care services in the United States. Obstetricians and gynecologists account for $20 \%$ of medical malpractice lawsuits; internal medicine, $18 \%$; family medicine, 16\%; general surgery, 15\%; orthopedic surgery, 14\%; pediatrics (Hale, 2006). Obstetrics leads in damages paid out by specialty followed by pediatrics, internal medicine, general surgery, orthopedic surgery, and family medicine; brain-damaged infants most expensive legal liability claim (Hale). Obstetricians experienced a 167\% increase of their malpractice premiums between 1982 and 1998, and rising steadily each year since (Hale). Midwives have experienced similar increases during this period of time. Many doctors and midwives are choosing to close or limit their practices. This produces what might be viewed as a triple negative for women who are pregnant, their healthcare providers, and the facilities that provide care. As experienced obstetricians and midwives leave the practice, those left behind are overburdened with increased patients. The newly emerging group of caregivers suffers from the loss of mentors to guide them through the initial years of their practice. The expectant women, who are hoping to deliver their babies safely, will have less experienced caregivers who are caring for larger number of women.

\section{Implication for Theory Development}

\section{Satisfaction with the Decision}

The results of this study demonstrate the usefulness of the HBM for understanding how maternal health beliefs can influence maternal satisfaction with the decisions made during pregnancy regarding the upcoming delivery. Maternal characteristics (internal and external control, acceptance of maternal role), perceived self 
efficacy, perceived threat, perceived risk, cues to action (husband/partner support, perception of provider role in the decision) and maternal request group accounted for a significant amount of the variance in maternal satisfaction with the decision for mode of delivery. Janz's HBM (1984) provided an appropriate framework to examine the specific relationships, between variables reported in past studies as being associated with maternal request, and the decisional process for maternal request of mode of delivery.

The HBM hypothesizes that individual's perceptions about their susceptibility to a condition and the perceived seriousness of the effects of the condition along with the perceived benefits and barriers associated with the action or treatment available will influence whether they will participate in preventative health care activities (Maiman \& Becker, 1974). The combined levels of susceptibility and threat provide the energy or force to act and the perception of benefits (less barriers) provides a preferred path of action. The stimulus necessary to trigger the decision making process or cue to action may be internal or external (e.g., mass media, interpersonal interactions, and communications with healthcare providers) (Rosenstock, 1974). Relationships were found between perceived self efficacy, perceived risk, perceived threat, self efficacy, and maternal acceptance of the maternal role and maternal request. Women planning a cesarean delivery considered themselves to be significantly less likely to be able to deliver vaginally if they were in labor, at more risk for harm if they did deliver vaginally, and to be more likely to need an emergency cesarean delivery. Additional women in the planned cesarean group reported a lower perception of being able to control their behavior and the environment surrounding a vaginal delivery than women who planned a vaginal delivery. Cues to actions were reported as the healthcare provider suggesting a 
cesarean delivery to $29 \%$ of the women planning a cesarean delivery. These findings also supported that women planning a cesarean reported more conflict and less satisfaction with their decision, even 6 weeks after delivery than women planning a vaginal birth. This relationship demonstrates that being informed, feeling supported and being clear about the benefits and outcomes of the decision are related to increased satisfaction and decreased conflict.

\section{Maternal Perception of the Birth Experience}

The results of this study suggest limited usefulness of the HBM for understanding how maternal health beliefs can influence maternal perception of the birth experience. Maternal characteristics (control, acceptance of motherhood role), perceived susceptibility, perceived threat, perceived risk, cues to action (husband/partner support, perception of provider opinion), and maternal request group did not account for a significant amount of the variance in maternal perception of the birth experience. The perception of the childbirth experience was shown to be highly personalized, and maternal views varied about what factors were important in a positive and satisfying experience. In this study the achievement of the goals set by women planning the upcoming delivery were shown to be significantly more important in the perception of the birth experience than the perceptions of risks, benefits, or susceptibility which are vital assumptions of the health belief model. As previously reported in the literature, women planning cesarean delivery reported higher levels of satisfaction with the birth experience and a higher percentage of the number of their goals that were fully achieved than women planning vaginal birth and whose birth resulted in an emergent cesarean. 


\section{Implications for Future Research}

The development of instruments that demonstrate satisfactory validity and reliability to measure the constructs of cues to action for women planning a cesarean are indicated. Future prospective and intervention studies are warranted to determine the generalizability of the findings of this study. This is the first study that has conducted that used the HBM to examine maternal decisional conflict and satisfaction and maternal request.

Research needs to be conducted on decisional counseling intervention guidelines that incorporate maternal health beliefs, goal setting, and evaluation of the risks and benefits of the decision. This type of intervention is appropriate for women making a variety of decisions regarding childbirth, not just maternal request of cesarean.

In summary, this study affirmed the importance of how maternal health beliefs, especially perceived self efficacy to deliver vaginally, perceived risk, and perceived threat are associated with maternal request of cesarean delivery and maternal conflict with the decision. Further research is needed to expand the knowledge base and develop targeted interventions related to decisional conflict and maternal health beliefs.

\section{Summary}

Historically the management of pregnancy and labor has been primarily expectant, and until recently the concept of requesting a cesarean delivery was not recognized as a possible option of women. Waiting for the onset of labor to signal the end of pregnancy may no longer be viewed as the only choice by women delivering their first baby. Making the decision to request a cesarean is a difficult decision for women planning their first childbirth. Women planning a cesarean delivery, despite reporting 
higher levels of satisfaction with the birth experience, continue to reported higher levels of conflict and less satisfaction with their decision than women planning a vaginal delivery at six weeks postpartum. To date, women planning a cesarean delivery have been supported in their decision making through informal counseling and client education. Practitioners need a framework to assess decision-making needs in clinical practice. Much of the ethical debate surrounding maternal request has centered on patient autonomy and the importance of informed consent. The development of evidence-based decision support tools and decision guides which can be used by practitioners and clients is vital to assisting women during the decision making process that surrounds childbirth. 


\section{References}

Agency for Healthcare Research and Quality. (2003). Vaginal birth after cesarean (VBAC). Retrieved September 27, 2008, from http://www.ahrq.gov/clinic/epcsums/vbacssum.htm

Allen, V., O'Connell, C., Liston, R., \& Baskett, T. (2005). Economic implications of method of delivery. Journal of Obstetrics and Gynecology, 193, 192-197.

American College of Nurse-Midwives (ACNM). (2004). Elective primary cesarean section. Retrieved June 10, 2010, from http://www.midwife.org/siteFiles/position/Elective_Primary_CS.pdf

American Journal of Obstetricians and Gynecologists. (2003). Surgery and patient choice: the ethics of decision making [ACOG Committee Opinion No. 289]. Obstetrics \& Gynecology, 89(5), 813-819.

Arney, W. R. (1982). Power and the profession of obstetrics. Chicago: The University of Chicago Press.

Association of Women's Health, Obstetric and Neonatal Nurses (AWHONN) News and Views. (2004). Position statement: Elective primary c-section. Retrieved June 25, 2010, from http://www.awhonn.org/awhonn/content.do?name=05_HealthPolicyLegislation/5 H_PositionStatements.htm.

Bailham, D., \& Joseph, S. (2003). Post-traumatic stress following childbirth: A review of the emerging literature and directions for research and practice. Psychology, Health \& Medicine, 8(2), 159-168. 
Baker, B. (1993). Health beliefs and self-efficacy of primiparas over age 35: A naturalistic inquiry. Unpublished dissertation, (Southern Illinois University at Carbondale), 1-134.

Beck, C. (1993). Teetering at the edge: A substantive theory of postpartum depression. Nursing Research, 42, 42-48.

Beck, C. T. (2004a). Post-traumatic stress disorder due to childbirth: The aftermath. Nursing Research, 53(4), 216-224.

Beck, C. \& Gable, R. (2002). Further validation of the postpartum depression screening scale. Nursing Research, 50, 155-164.

Beck, C., \& Watson, S. (2008). Impact of birth trauma on breastfeeding. Nursing Research, 57(4), 228-236.

Beckett, K. (2005). Choosing cesarean: Feminism and the politics of childbirth in the United States. Feminist Theory, 6, 251-275.

Benzies, K., Tough, S., Tofflemire, K., Frick, C., Faber, A., \& Newburn-Cook, C. (2006). Factors influencing women's decisions about timing of motherhood. Journal of Obstetric, Gynecologic, \& Neonatal Nursing, 35, 625-633.

Bergeron, V. (2007). The ethics of cesarean section on maternal request: A feminist critique of the American College of Obstetricians' and Gynecologists' position on patient-choice surgery. Bioethics, 21(9), 478-487.

Bergholt, T., Ostberg, B., Legarth, J., \& Weber, T. (2004). Danish obstetricians' personal preference and general attitude to elective cesarean on maternal request: A nation-wide postal survey. Obstetricia et Gynecologica Scandinavica, 83(3), $262-266$. 
Bernstein, P. (2007). Elective cesarean section: An acceptable alternative to vaginal delivery. Obstetrical/Gynecological Women's Health, 7(2), 154-157.

Bettes, B., Coleman, V., Zinberg, S., Spong, C., Portnoy, B., \& DeVoto, E. et al. (2007). Cesarean delivery on maternal request. Obstetrics and Gynecology, 109, 57-66.

Block, J. (2007). Pushed (1st Ed.). Cambridge, MA. Da Capo Press.

Blomquist, J., MacMillan, D., Quiroz, L., \& Handa, V. Maternal goals for childbirth associated with planned vaginal and planned cesarean birth. Unpublished.

Boivan, J., Sanders, K., \& Schmidt, L. (2006). Age and social position moderate the effect of stress on fertility. Evolution and Human Behavior, 27, 345-356.

Borders, N. (2006). After the afterbirth: A critical review of postpartum health relative to method of delivery. Journal of Midwifery and Women's Health, 51(242-248).

Bost, B. (2003). Cesarean delivery on demand: What will it cost? American Journal of Obstetrics and Gynecology, 188(1418-1423).

Bramadat, I. \& Driedger, M. (1993). Satisfaction with childbirth: Theories and methods of measurement. Birth, 20(1), $22-29$.

Bryanton, J., Gagnon, A., Johnson, C., \& Hatem, M. (2008). Predictors of women's perceptions of the childbirth Experience. Journal of Obstetric, Gynecologic \& Neonatal Nursing, 37(1), 24-35.

Byrom, A. (2004). Advanced maternal age: A literature review. British Journal of Midwifery, 12, 39-46.

Bunn, H., \& O'Conner, A. (1996). Validation of a decisional conflict scale in the context of psychiatry. Canadian Journal of Nursing Research, 28(3), 13-27. 
Burrows, L. J., Meyn, L. A., \& Weber, A. M. (2004). Maternal morbidity associated with vaginal versus cesarean delivery. Obstetrics and Gynecology, 103, 907-912.

Caughey, A. (2003). The economics of an elective cesarean delivery policy. $O B G$ Management, 15(11), 132-138.

Center for Disease Control. (2005). 2003 Assisted Reproductive Technology (ART) Report: Section 2 - ART cycles using fresh, nondonor eggs or embryos. Retrieved November 15, 2007, from http:/www.cdc.gov/ART/ART2003/sect2_fig313.htm\#Figure $\% 2011$

Childbirth Connections. (2006). New national survey results from mothers refute belief that women are requesting cesarean sections without medical reason. Retrieved September 10, 2007, from http://www.childbirthconnections.org/pdfs/ltmllpressrelease.pdf.

Christilaw, J. E. (2006). Cesarean section by choice: Constructing a reproductive rights framework for the debate. International Journal of Gynecology and Obstetrics, 94, 262-268.

Cleary-Goldman, J., Malone, F., Vidaver, J., Ball, R., Nyberg, D., \& Comstock, C. et al. (2005). Impact of maternal age on obstetric outcome. Obstetrics and Gynecology, 105, 983-990.

Cohen, J., \& Cohen, P. (1983). Applied multiple regression/correlation analysis for the behavioral sciences (2nd edition). Hillsdale, NJ: Erlbaum.

Cox, J., Holden, J., \& Sagovsky, R. (1987). Detection of postnatal depression: Development of the 10 item Edinburgh Postnatal Depression Scale. British Journal of Psychiatry, 150, 782-786. 
Cranley, M., Hedahl, K., \& Pegg, S. (1983). Women’s perceptions of vaginal and cesarean deliveries. Nursing Research, 32, 10-15.

Creswell, J. W. (2003). Research Design: Qualitative, Quantitative, and Mixed Methods Approaches. $2^{\text {nd }}$ Ed. New York: Sage Publications.

Culligan, P. (2008). The impact of pelvic floor dysfunction on sexuality: How should we counsel our patients? Obstetrics \& Gynecology, 111(5), 1037-1038.

Cunningham, G., Gant, N., Leveno, K., Gilstrap, L., Hauth, J., \& Wenstrom, D. (2001). Williams Obstetrics. (21 ${ }^{\text {st }}$ Ed.) New York: McGraw-Hill Professional.

Davis-Floyd, R., \& Johnson, C. (2006). Mainstreaming midwifes: The politics of change. New York: Routledge.

Day, M., \& Barton, J. (2005). The effect of fetal number on the development of hypertensive conditions of pregnancy. Obstetrics and Gynecology, 106, 927-931.

Day, R. (1977). Toward a process model of consumer satisfaction. In H. Hunt, Conceptualization and Measurement of Consumer Satisfation and Dissatisfaction (pp. 153-183). Cambridge, MA: Marketing Science Institute.

Declercq, E., Barger, M., Cabral, H., Evans, S., Kotelchuck, M., \& Simon, M. (2007). Maternal outcomes associated with planned primary cesarean births compared with planned vaginal births. Obstetrics and Gynecology, 109, 669-677.

Declercq, E., Sakala, C., Corry, M., \& Applebaum, S. (2006). Listening to mothers, II: Report of the second national U.S. survey of women's childbearing experiences. New York, New York. 
Deneux-Tharaux, C., Carmona, E., Bouvier-Colle, M. H., \& Breat, J. (2006). Postpartum maternal mortality and cesarean delivery. Obstetrics \& Gynecology, 108, 541548.

Department of Health and Human Services. (2007). Healthy People 2010. Retrieved September 27, 2008, from http://www.health.gov/healthypeople

Dilks, F. M., \& Beal, J. A. (1997). Role of self efficacy birth choice. Journal of Perinatal Neonatal Nursing, 11(1), 1-9.

Dodd, J. M., Crowther, C. A., Huertas, E., Guise, J. M., \& Horey, D. (2004, October 18). Planned elective repeat cesarean section versus planned vaginal birth for women with a previous caesarean birth. Cochrane Database of Systematic Reviews, 4, $143-151$.

Druzin, M. \& El-Sayed, Y. (2006). Cesarean delivery on maternal request: Wise use of finite resources: A view from the trenches. Seminal Perinatol, 30(5), 305-308.

Evanaki, J., Khakbazan, Z., Babaei, G., \& Noori, T. (2004). Reasons of choosing cesarean section as the delivery method by the pregnant women referred to healthtreatment centers in Rasht. HAYAT: The Journal of Tehran Faculty of Nursing \& Midwifery, 10, 101.

Fawcett. J., \& Knauth, D. (1996). The factor structure of the perception of birth scale. Nursing Research, 45, 83-86.

Fawcett, J., Pollio, N., \& Tully, A. (2007). Women's perceptions of cesarean and vaginal delivery: Another look. Research in Nursing \& Health, 15 (6), 439-446. 
Fenwick, J., Gamble, J., \& Hauck, Y. (2007). Believing in birth - choosing VBAC: The childbirth expectation of a self-selected cohort of Australian women. Journal of Clinical Nursing, 16(8), 1561-1570.

French, B., Kurezynski, T., Weaver, M., \& Pituch, M. (1993). Evaluation of the health belief model and decision making regarding amniocentesis in women of advanced maternal age. Health Education Quarterly, 19(2), 177-186.

Gamble, J., \& Creedy, D. (2001). Women's preference for a cesarean section: Incidence and associated factors. Birth, 28, 101-110.

Gardner, P. (2003). Previous traumatic birth: An impetus for requested cesarean birth. The Journal of Perinatal Education, 12, 1-5.

Garrett, B., Buettgens, M., Headen, I., \& Hulahan, J. (2010). The cost of failure to enact health reform: 2010 - 2020. Robert Woods Johnson Foundation. Retrieved March 23, 2010, from http://rwjf.org/files/research/57449.pdf

Gates, E. (2003). Communicating risk in prenatal genetic testing. Journal of Midwifery \& Women's Health, 49(3), 220-227.

Getahum, D., Oyelese, Y., Salihu, H., \& Ananth, C. (2006). Previous cesarean delivery and risks of placenta previa and placenta abruption. Obstetrics and Gynecology, $107,771-778$.

Gattelari, M. \& Ward. T. (2004). Independent effect of decisional conflict on tendency to blame doctor for bad outcomes when forgoing PSA testing for prostate cancer. Med Screen, 11:165-169.

Ghetti, C., Chan, B., \& Guise, J. (2004). Physician response to patient-requested cesarean delivery. Birth, 31, 280-284. 
Gilliam, M. (2006, March 27-29). Reproductive consequences. NIH State of-the-Science Conference: Cesarean Delivery on Maternal Request, Washington, DC: National Institute of Health, 57-60.

Gonen, R., Tamir, A., \& Degani, S. (2002, April). Obstetricians' opinions regarding patient choice in cesarean delivery. The American College of Obstetricians and Gynecologists, 99(4), 577-580.

Green, J. M., \& Baston, H. A. (2003). Feeling in control in labor: Concepts correlates and consequences. Birth, 30(4), 235-247.

Green, J., \& Baston, H. (2007). Have women become more willing to accept obstetric interventions and does this relate to mode of birth: Data from a prospective study. Birth, 34(1), 6-13.

Green, J.M., Coupland, V.A., \& Kitzinger, J. V. (1990). Expectations, experiences, and psychological outcomes of childbirth: A prospective study of 825 women. Birth $1990 ; 17,15-24$.

Gregory, K.D., Korst, L.M., Gornbein, J.A., \& Platt, L.D. (2002.). Using administrative data to identify indications for elective primary cesarean delivery. Health Serv Res. 2002 Oct; 37(5): 1387-401.

Hale, R.W. (2006). Medical professional liability revisited. Obstetrics Gynecology. $107,1224-1225$.

Hamilton, B. E., Martin, J. A., \& Ventura, S. J. (2007). Births: Preliminary data for 2006. National Center for Health Statistics. Retrieved November 15, 2007, from http://www.cdc.gov/nchs/products/pubs/pubd/hestats/prelimbirths05/prelimbirths 05.htm 
Hanna, B., Jarman, H., \& Savage, S. (2004). The clinical application of three screening tools for recognizing post-partum depression. International Journal of Nursing Practice, 79, 102-105.

Hannah, M. (2004). Planned elective cesarean section: A reasonable choice for some women? Canadian Medical Association Journal, 170 (5), 1503-1504.

Harer, W. B. Jr. (2000, March/April). Patient choice cesarean. The American College of Obstetricians and Gynecologists, 5(2), 12-16.

Health Grades. (2003). Patient-choice c-section rate rises 36\%: Healthgrades study.

Retrieved on June 10, 2010, from http://www.healthgrades.com/media/DMS/pdf/PatientChoiceStudy2005PressRele aseSept12.pdf .

Heaman, S., Joseph, K., Liston, R., Suave, R., \& Kramer, M. (2005). Risk of maternal postpartum readmission associated with mode of delivery. Obstetrics and Gynecology, 105, 836-842.

Herrman, J. (2008). Adolescent Perceptions of Teen Births. Journal of Obstetric, Gynecologic \& Neonatal Nursing, 37(1), 42-51.

Hodnett, E. (2002). Pain and women's satisfaction with the birth experience of childbirth: A systematic review. American Journal of Obstetrics and Gynecology, 186 (5), $160-162$.

Hodnett, E. D., \& Abel, S. M. (1986). Person-environment interaction as a determinant of labor length variables. Health Care for Women International, 7, 341-356. 
Hodnett, E., Gates, S., Hofmeyr, G., \& Sakala, C. (2003). Continuous support for women during childbirth. Cochrane Database of Systemic Reviews, 3, CD003766.DOI:10.1002/14651858.CD003766.

Hoyert, D. L. (2007). Maternal mortality and related concepts. Vital \& Health Statistics.Series 3, Analytical and Epidemiological Studies / [U.S.Dept.of Health and Human Services, Public Health Service, National Center for Health Statistics], (33), 1-13.

International Federation of Gynecology and Obstetrics (FIGO). (2004). Position statement: Primary elective cesarean. Retrieved on June 10, 2010, from, http://www.figo.org/news/figo-position-statement-professional-standards.

Jacobsson, B., Ladfors, L., \& Milson, I. (2004). Advanced maternal age and adverse perinatal outcome. Obstetrics and Gynecology, 104, 727-733.

Janis, I., \& Mann, L. (1977). Decision making: A psychological analysis of conflict, choice, and commitment. New York: The Free Press.

Janz, N., \& Becker, M. (1984). The health belief model: A decade later. Health Education Behavior, 11(1), 1-47.

Janz, N., Champion, V., \& Strecher, V. (2002). The health belief model. In K. Glanz, B. Rimer, \& F. M. Lewis (Eds.). Health Behavior and Health Education (3rd Ed., pp. 45-66). San Francisco, CA: Jossey-Bass.

Jolly, M., Sebire, N., Harris, J., Robinson, S., \& Regan, L. (2004). Obstetric risks of pregnancy in women less than 18 years old. Obstetrics \& Gynecology, 96, 962966. 
Jordan, B. ([1978] 1993). Birth in four cultures: A cross-cultural investigation of childbirth in Yucatan, Holland, Sweden and the United States (4th Ed.). Prospect heights, Ill: Waveland Press.

Joseph, K., Allen, A., Dodds, L., Turner, L., Scott, H., \& Liston, R. (2005). The perinatal effects of delayed childbearing. Obstetrics and Gynecology, 105(1410-1418

Kalish, R., McCullough, L., Gupta, M., Thalker, H., \& Chervenak, F. (2004). Intrapartum elective cesarean delivery: A previously unrecognized clinical entity. Obstetrics and Gynecology, 103, 1137-1141.

Kingdon, C., Baker, L., \& Lavender, T. (2006). Systematic review of nulliparous women's views of planned cesarean birth: The missing component in the debate about a term cephalic trial. Birth, 33(3), 229-237.

Kitzinger, S. (2006). Birth Crisis (1st Ed.). New York: Routledge.

Koroukian, S. (2004). Relative risk of postpartum complications in the Ohio Medicaid population: Vaginal versus cesarean delivery. Medical Care Research \& Review, 61,203

Land, P., Parry, L., Rane, K., \& Wilson, R. (2002, July/August). Personal preferences of obstetrician toward childbirth. Obstetrical and Gynecological Survey, 10.

Lavender, T., Hofmeyr, G., Neilson, J., Kingdon, C., \& Gyte, G. (2007). Caesarean section for non-medical reasons at term (Review). The Cochran Collaboration, Retrieved on April 2, 2007, from, http://www.thecochranelibrary.com

Lawson, K., \& Pierson, R. (2007). Maternal decisions regarding prenatal diagnosis: Rational choices or sensible decision? Journal Obstetrical Gynaecology Canada, $29(3), 240-246$. 
Lazarus, E. (1997). What do women want? Issues of choice, control, and class in American pregnancy and childbirth. In R. Davis-Floyd, \& C. Sargent (Eds.), Childbirth and Authoritative Knowledge (pp. 132-159). Berkeley and Los Angeles, CA: University of California Press.

Lederman, E., Work, B., \& McCann, D. (1995). Relationship of psychological factors in pregnancy to progress in labor. Nursing Research, 28(2), 94-97.

Lin, H., \& Xirasagar, S. (2005). Maternal age and the likelihood of a maternal request for cesarean delivery: A 5-year population-based study. American Journal of Obstetrics and Gynecology, 192, 848-855.

Lincoln, Y.S., \& Guba, E. G. (1985). Naturalistic Inquiry. Newbury Park, CA; Sage Publications.

Liu, C., \& Yang, M. (2007). Rethinking "woman's choice" of cesarean delivery. American Journal of Public Health, 93, 1036-1037.

Live Journal. (2008). Greater Atlanta area hospitals. Retrieved October 1, 2009, from, http://community.livejournal.com/atlanta/2781904.html

Loebel G., Zelop, C.M., Egan, J.F., \& Wax, J. (2004). Maternal and neonatal morbidity after elective repeat cesarean delivery versus a trial of labor after previous cesarean delivery in a community teaching hospital. Journal of Maternal \& Fetal Neonatal Medicine, 4, 243-246.

Lydon-Rochelle, M., Holt, V., Martin, D., \& Easterling, T. (2000). Journal of the American Medical Association, 283, 2411-2416.

Lyerly, D., \& Faden, R. (2007). Willingness to donate frozen embryos for stem cell research. Science, 10, $114-121$. 
MacDorman, M., Declercq, E., Menacker, F., \& Malloy, M. (2006). Infant and neonatal mortality for primary cesarean and vaginal births to women with "no indicated risk". United States, 1998-2001 Birth Cohorts. Birth, 33, 175-182.

MacDorman, M., Declercq, E., Menacker, F., \& Malloy, M. (2008). Neonatal mortality for primary cesarean and vaginal births to low-risk women: Application of an intention to treat model. Birth, 35(1), 3-8.

MacMillan, D. (2008). Taking control of the experience of pregnancy and birth. Unpublished.

Maiman, L. A., \& Becker, M. H. (1974). The health belief model: Origins and correlates in psychological theory. Health Education Monograph 2, 336-353.

Mancini, F., Carlson, C., \& Albers, L. (2007). Use of the postpartum depression screening scale in a collaborative obstetric practice. Journal of Midwifery \& Women's Health, 52, 429-434.

Marteau, T. M., Plenicar, M., \& Kidd, J. (1993). Obstetricians presenting amniocentesis to pregnant women. Journal of Reproductive and Infant Psychology, 11, 3-10.

Martin, K. (2003). Giving birth like a girl. Gender Society, 17(1), 54-72.

Marut, J., \& Mercer, R. (1979). Comparison of primiparas’ perceptions of vaginal and cesarean births. Nursing Research, 28, 260-266.

Mauthner, N. S. (2007). Feminist methodologies and epistemologies in Pertti Alasuutari, Julia Brannen \& Leonard Bickman (Eds) The Handbook of $21^{\text {st }}$ Century Sociology. Mayberry, L. (2006). Cesarean delivery on maternal request. Journal of Maternal-Child Nursing, 31, 286-289. 
McCourt, C., Weaver, J., Statham, H., Beake, S., Gamble, J., \& Creddy, D. (2007).

Elective cesarean section and decision making: A critical review of the literature. Birth, 34(1), 65-79.

Meddings, F., Phipps, F. M., Haith-Cooper, M., \& Haigh, J. (2007). Vaginal birth after caesarean section (VBAC): Exploring women's perceptions. Journal of Clinical Nursing, 16(1), 160-167.

Menacker, F. (2005). Trends in cesarean rates for first births and repeat cesarean rates for low-risk women: United States. National Vital Statistics Report, 54, 1-8.

Menacker, F., Declercq, E., \& Macdorman, M. (2006). Cesarean delivery: Background, trends, and epidemiology. Seminars in Perinatology, 241-241.

Mercer, R., \& Stainton, M. (1984). Perceptions of the birth experience: A cross-cultural comparison. Health Care for Women International, 5, 29-47.

Miesnik, S., \& Reale, B. (2007). A review of issues surrounding medically elective cesarean delivery. Journal of Obstetric, Gynecologic, \& Neonatal Nursing, 36(6), 605-613.

Miller, J., Thorton, E., \& Gittens, C. (2002). Influences of mode of birth and personality. British Journal of Midwifery, 10, 692-697.

Minkoff, H., Powderly, K., Chervenak, F., \& McCullough, L. (2004). Ethical dimensions of elective Primary cesarean delivery. Obstetrics and Gynecology, 103(2), 387392.

Montazeri, A., Torkan, B., \& Omidvar, S. (2007). The Edinburgh postnatal depression scale: Translation and validation study of the Iranian version. BMC Psychiatry, 7(11), 124-136. 
National Institute of Health (NIH). (2006). State of-the-science conference statement: Cesarean delivery on maternal request. Retrieved September 12, 2007, from http://consensus.nih.gov/2006/CesareanStatement_Final053106.pdf

Nelson, M. (1983). Working class women, middle class women and models of childbirth. Social Problems, 30, 284-297.

Nerum, H., Halvorsen, L., Sorlie, T., \& Oian, P. (2005). Maternal request for cesarean section due to fear of birth: Can it be changed through crisis-oriented counseling? Birth, 33(3), 221-228.

North American Nursing Diagnosis Association. (1992). Tenth conference for classification of nursing diagnoses. San Diego, CA: Author.

Northam, S., Polanchich, S., \& Restrepo, E. (2003). Births certificate methods in five hospitals. Public Health Nursing, 20(4), 318-327.

O'Conner, A. (1995). Validation of a decisional conflict scale. Medical Decision Making, $15,25-30$.

O’Conner, A., Jacobsen, M., \& Stacey, D. (2002). An evidence-based approach to managing women's decisional conflict. Journal of Obstetric, Gynecologic, \& Neonatal Nursing, 31(5), 570-581. Online Analytical Statistical Information System (Oasis). 2009. Retrieved May 2010, from http://oasis.state.ga.us/oasis/index.aspx

Orem, D. E. (1995). Nursing: Concepts of practice ( $5^{\text {th }}$ Ed.). Toronto: Mosby.

Pallant, J., Miller, J., \& Tennant, T. (2006). Evaluation of the Edinburgh Postnatal Depression Scale using Rashch analysis. BMC Psychiatry, 6(28), 104-114. 
Panting-Kemp, A., Geller, S. E., \& Nguyen, T. (2000). Maternal deaths in an urban perinatal network 1992-1998. American Journal of Obstetrics and Gynecology, $183,1207-1212$.

Pasco, G. (1988). Patient satisfaction in primary health care: A literature review and analysis. Evaluation Program Planning, 6, 185-210.

Poikkeus, P., Saisto, T., Unkila-Kallio, L., Punamaki, R., Repokari, L., \& Vilska, S. et al. (2006). Fear of childbirth and pregnancy-related anxiety in women conceiving with assisted reproduction. Obstetrics \& Gynecology, 108, 70-76.

Prochaska, J. O., \& Velicer, W. F. (1997). The transtheoretical model of health behavior change. American Journal of Health Promotion, 12(1), 38-48.

Reiger, K., \& Dempsey, R. (2006). Performing birth in a culture of fear: An embodied crisis of late modernity. Health Sociology Review, 15(4), 364-373.

Rempel, G., Cender, L., Lynan, M., Sandor, G., \& Farquharson, D. (2004). Parents perspectives on decision making after antenatal diagnosis of congenital heart disease. Journal of Obstetric, Gynecologic \& Neonatal Nursing, 33(1), 64-70.

Renz-Polster, H., David, M. R., Buist, A. S., Vollmer, W. M., Connor, E. A., \& Frazier, E. A. et al. (2005). Caesarean section delivery and the risk of allergic disorders in childhood. Clinical \& Experimental Allergy, 35, 1466-1472.

Ridley, T., Davis, P., Bright, J., \& Sinclair, D. (2002). What influences a woman to choose vaginal birth after cesarean? Journal of Obstetrics, Gynecologic, \& Neonatal Nursing, 31(6), 665-672.

Risser, N. (1975). Development of a scale to measure patient satisfaction with nurses and nursig in primary care settings. Nursing Research, 24, $45-52$. 
Robb, F., Alder, E., \& Prescott, R. (2005). Do older primigravidas differ from younger primigravidas in their emotional experience of pregnancy? Journal of Reproductive and Infant Psychology, 23, 135-141.

Robertson, B., Aycock, D., \& Darnell, L. (2008). Comparison on centering pregnancy to traditional care in Hispanic mothers. Maternal Child Health Journal, 54(1), 2734.

Robertson, E., Grace, S., Wallington, T., \& Stewart, D. (2004). Antenatal risk factors for postpartum depression: A synthesis of recent literature. General Hospital Psychiatry, 26(4), 289-295.

Robinson, P., Salmon, P., \& Yentis, S. (1998). Maternal satisfaction. International Journal of Obstetric Anesthesia, 7, 32-37.

Rosen, M., \& Thomas, L. (1989). The cesarean myth: Choosing the best way to have your baby. New York: Penguin.

Rosenstock, I. M. (1974). Historical origins of the health belief model. Health Education Monograph, 2, 332-340.

Rothman, B. K. (1986). The tentative pregnancy: How amniocentesis changes the experience of motherhood. New York: W.W. Norton \& Company.

Rubin, R. (1967). Attainment of the maternal role. Part 1: Processes. Nursing Research, $16,237-245$.

Rule, W. R., \& Traver, M.D. (1987). The anxiety sensitivity index: Construct validity and factor analytic structure. Journal of Anxiety Disorders. 1, 265-277.

Ryding, E. (1993). Investigation of 33 women who demanded a cesarean section for personal reasons. Acta Obstet Gynecol Scand, 72, 280-285. 
Saisto, T., \& Halmesmaki, E. (2003). Fear of childbirth: A neglected dilemma. Acta Obstetricia et Gynecologica Scandinavica, 82(3), 201-208.

Saisto, T., Salmela, A. K., Nurmi, J. E., Kononen, T., \& Halmesmaki, E. (2001). A randomized controlled trial of intervention in fear of childbirth. Obstetrics and Gynecology, 98(820-826).

Salam, M., Margolis, H., Mcconnell, R., McGregor, J., Avol, E., \& Gilliland, F. (2006, May). Mode of delivery is associated with asthma and allergy occurrences in children. Annals of Epidemiology, 15(5), 341-346.

Salmon, P., \& Drew, N. (1992). Multidimensional assessment of women's experience of childbirth: Relationship to obstetric procedure, antenatal preparation and obstetric history. Journal of Psychosomatic Research, 36(4), 317-327.

Samko, M., \& Schoenfeld, L. (1975). Hypnotic susceptibility and the Lamaze childbirth experience. American Journal of Obstetrics \& Gynecology, 121, 631-636.

Sampietro-Colom, L., Phillips, V., \& Hutchinson, A. (2004). Eliciting women's preferences in health care: A review of the literature. International Journal of Technology Assessment in Health Care, 20(2), 145-155.

Schachman, K., Lee, A., \& Lederman, P. (2004). Baby boot camp: Facilitating maternal role adaptation among military wives. Nursing Research, 52, 107-115.

Schardt, D. (2005). Delayed childbearing: Underestimated psychological implications. International Journal of Childbirth Education, 20, 34-37.

Shannon, D., \& Davenport, M. (2001). Using SPSS to solve statistical problems: A self instruction guide. Upper Saddle River, NJ: Merrill/Prentice-Hall. 
Simpkin, P. (2006). The experience of maternity in a woman's life. Journal of Obstetric, Gynecologic, \& Neonatal Nursing, 25(3), 247-252.

Simpson, K., \& Thorman, K. (2005). Obstetric "conveniences": Elective induction of labor, cesarean birth on demand, and other potentially unnecessary interventions. The Journal of Perinatal and Neonatal Nursing, 19, 134-144.

Soet, J. E., Brack, G. A., \& Diloria, C. (2003). Prevalence and predictors of women's experience of psychological trauma during childbirth. Birth, 30(1), 36-46.

Spielberger, C. D., Gorsuch, R. L., \& Lushene, R. E. (1970). Manual for the state-trait anxiety inventory. Palo Alto, CA: Consulting Psychologists Press.

Suplee, P., Dawley, K., \& Bloch, J. (2007). Tailoring postpartum nursing care for women of advanced maternal age. Journal of Obstetric, Gynecologic, \& Neonatal Nursing, 36, 616-623.

Taffel, S. M., Placek, P. J., \& Liss, T. (1987). Trends in the United States cesarean section rate and reasons for the 1980-85 rise. American Journal of Public Health, 77, 955-999.

Terhaar, M. (2003). The decision for cesarean birth. The Journal for Nurse Practitioners, $1(3), 141-147$.

Tillett, J. (2005). Should elective cesarean birth be an accepted option for women? Journal of Perinatal \& Neonatal Nursing, 19 (1), 4-6.

Tulman, L., Fawcett, J., Groblewski, L., \& Silverman, L. (1990). Changes in functional status after childbirth. Nursing Research, 39, 70-75.

Villar, J., Valladares, E., Wojdyla, D., Zavaleta, N., Carroli, G., \& Velazco, C. et al., \& WHO 2005 Global Survey on Maternal and Perinatal Health Research Group. 
(2006). Caesarean delivery rates and pregnancy outcomes: The 2005 WHO global survey on maternal and perinatal health in Latin American. Lancet, 367, 18191829.

Wagner, M. (2000). Choosing cesarean section. Lancet, 359, 1677-1680.

Waldenstrom, U. (2004). Why do some women change their opinion about childbirth over time? Birth, 31(2), 102-7.

Waldenstrom, U., Hildingsson, I., \& Ryding, E. (2006). Antenatal fear of childbirth and its association with subsequent caesarean section and experience of childbirth. British Journal of Obstetrics and Gynaecology, 113, 638-646.

Warner, R. M. (2008). Applied statistics: From bivariate through multivariate techniques. Los Angeles: Sage.

Wax, J., Cartin, A., Pinette, M., \& Blackstone, J. (2007). Patient choice cesarean - the Maine experience. Birth, 32(3), 203-206.

Weaver, J., Statham, H., \& Richards, M. (2007). Are there "unnecessary" cesarean sections? Perceptions of women and obstetricians about cesarean sections for nonclinical indications. Birth, 34(32-41).

Wijma, K., Wijma, B., \& Zar, M. (1998). Psychometric aspects of the W-DEQ: A new questionnaire for the measurement of fear of childbirth. Journal Psychosom Obstet Gynaecol, 19, 84-97.

Wiklund, I. (2007). Caesarean section on maternal request: Personality, fear of childbirth and signs of depression among first-time mothers. Stockholm: Karolinska Institute. 
Williams, H. (2008). The ethical debate of maternal choice and autonomy in cesarean delivery. Clinics in Perinatology, 35, 455-462.

Wohlgemuth, N., \& Lawson, K. (2007). Prenatal testing: Women's autonomy, motivation and decisional well-being. Society for Reproductive and Infant Psychology, 12, 812.

Women's Health Care Physicians, Task Force on Cesarean Delivery Rates. Evaluation of cesarean delivery. Washington: American College of Obstetricians and Gynecologists; 2000.

Zadoroznji, M. (1999). Social class, social selves, and social control in childbirth. Sociology of Health and Illness, 21, 267-289.

Zar, M., Wijma, K., \& Wijma, B. (2002). Relation between anxiety disorders and fear of childbirth during late pregnancy. Clin Psycho Psychother, 9, 122-130.

Zwelling, E. (2008). The emergence of high-tech birthing. Journal of Obstetric, Gynecologic, \& Neonatal Nursing , 37(1), 85-93. 
Appendix A

Participant Consent Form 


\section{Georgia State University \\ College of Health Science and Human Sciences \\ Byrdine F. Lewis School of Nursing}

\section{Informed Consent}

Title: Understanding the Health Beliefs of First Time Mothers.

Principal Investigators: Dr. Cecelia Grindel

Deborah MacMillan RN, CNM

$\begin{array}{ll}\text { Co Investigators: } & \text { Dr. Laura Kimble } \\ & \text { Dr. Sandra Hewell } \\ & \text { Dr. Victoria Handa }\end{array}$

\section{Purpose:}

You are invited to participate in a research study. The purpose of this study is to understand the health beliefs of first time mothers as they make decisions about their upcoming childbirth. We are inviting women to participate who are first time mothers who plan a cesarean birth and also first time mothers who plan a vaginal birth. A maximum of 128 women will be recruited for this study. If you decide to be in the study it will require approximately $1-2$ hours of your time over a 6 to 10 week period of time.

\section{Procedure for this study will be as follows:}

If you agree to be in this study, you will be asked to fill out a brief form that asks some basic questions: such as name, age, race number of children, and anticipated date of delivery. You will also be asked some basic questions about your past medical history to determine if you are eligible to be in the study.

If you are eligible, then you will be asked to fill out a brief questionnaire. This will take approximately 20 minutes of your time. An additional follow-up questionnaire will be available for you to fill out after you have delivered your baby at six weeks postpartum. This will also take approximately 15 to 20 minutes.

Once you enroll in the study you will receive a weekly email with educational information about nutrition and comfort measures for the remaining few weeks of your pregnancy and postpartum period. These emails will request that you go the study site and let us know when you deliver your baby so that we can contact you to fill out the 2 nd questionnaire at 6 weeks postpartum.

\section{Risks:}

In this study, we do not anticipate that you will have any more risks than you would in a normal day of life. However, recalling memories about events can sometimes be unpleasant or stressful. If that happens to you, we encourage you to contact your healthcare provider for a referral for counseling. If you should need counseling, any expense incurred would be your responsibility. 


\section{Benefits:}

Overall, we hope to gain information about what it is like for first time mothers to make decisions about their upcoming delivery. Participation may not benefit you personally. The educational information may be helpful to you.

\section{Voluntary Participation and Withdrawal:}

Participation in research is voluntary. You have the right not to be in the study. If you decide to be in the study and change your mind, you have the right to drop out at any time. You may skip questions or stop participating at any time. Whatever you decide, you will not lose any benefits to which you are otherwise entitled.

\section{Confidentiality:}

We will keep your records private to the extent allowed by law. We will use a study number rather than your email information on study records. No other personal identification will be obtained. Only the research team will have access to the information you provide. The data will be stored in the researcher's office on a secure server. The identification code key will be stored in a password and fire-wall protected computer. You will not be identified personally. However, it is important to notify you that no internet systems are $100 \%$ safe or secure.

\section{Contact Persons:}

Contact Mrs. Deborah MacMillan (478) 747-0986 (debby.macmillan@gcsu.edu) if you have questions about this study. If you have questions or concern about your rights as a participant in this research study, you may contact Susan Vogtner in the Office of Research Integrity at (404) 413-3513 or svogtner1@gsu.edu.

\section{Copy of Consent Form to Participant}

You may print a copy of this consent form for your records by clicking the print icon. If you are willing to volunteer, please indicate your consent by entering your email address and today's date in the space provided. After completing this click the submit button below. 
Appendix B

Recruitment Flyer 


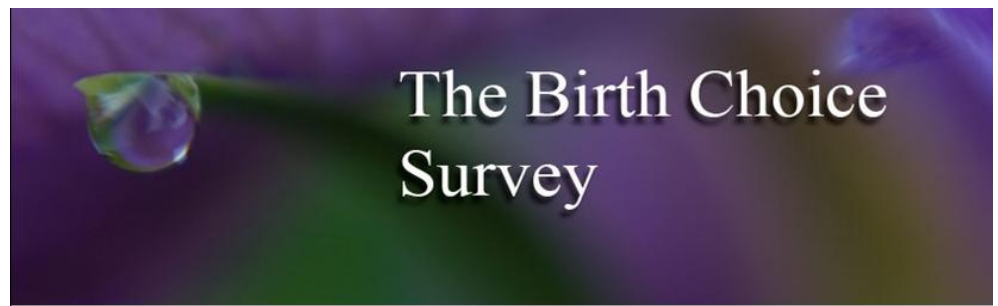

\title{
SHARE
}

Are you currently pregnant?

\section{CONNECT}

with consumer reviews about books and baby products for first time mothers.

\section{LEARN}

What other first time mothers believe

is important during childbirth

and postpartum.

\section{TAKE OUR SURVEY!}

Give feedback about what type of birth you are planning for your first baby. We want to know what decisions you have made during your pregnancy.

FIRST TIME MOTHERS PLANNING A CESAREAN DELIVERY we especially want to hear from you! FIRST TIME MOTHERS PLANNING A VAGINAL birth we want to hear about your decisions.

wพw. yourbirthchoice.com info@yourbirthchoice.com

\begin{abstract}
The purpose of The Birth Choice Survey is to provide women with a venue to give feedback about their decision making process during pregnancy as they plan their birth experiences. This research will help women and healthcare professional better understand the type of information that women are interested in receiving about the choices they have in childbirth. This study is especially interested in hearing from women who are having their first child. We want to hear from women who are planning all types of births: vaginal births in the hospital, vaginal births at home, and cesarean delivery where no medical indication is present.

Are you planning a cesarean delivery for your first child when there is no medical indication for a cesarean?

Take The Birth Choice Survey and tell us about this decision and what is important to you as a first time mother.

Are you planning a vaginal delivery?

If so, take The Birth Choice Survey and tell us about this decision and what is important to you as a first time mother
\end{abstract}

Help spread the word about The Birth Choice Survey! Please share this card with someone who is pregnant with their first baby. For more information visit www.yourbirthchoice/ 


\section{Appendix C}

Maternal Health Beliefs Eligibility Questionnaire 


\section{Section 1: Eligibility Screen}

A1. Are you currently pregnant?

$\square$ Yes

$\square$ No

A2. Are you within 3 months of your expected delivery date?

$\square$ Yes

$\square$ No

$\square$ Not sure

A3. Are you planning to deliver your baby at one of the hospitals listed: Medical Center of Central Georgia, Coliseum Medical Center, Houston County Medical Center, or Fairview Park Hospital?

$\square$ Yes

$\square$ No

$\square$ Not sure

A4. Is your pregnancy twins, triplets or more?

I'm expecting one baby

I'm expecting more than one baby

A5. Have you ever had a cesarean delivery?

Yes

No

Not sure

A6. Have you ever had surgery to remove a fibroid from the uterus or womb?

(myomectomy)

$\square$ Yes

$\square$ No

$\square$ Not sure

A7. In your current pregnancy, have you been diagnosed with placenta previa (placenta covering the cervix)?
$\square$ Yes
$\square$ No
$\square$ Not sure

A8. Is your baby currently in breech position (baby will be born feet first or bottom first)?
Yes 
$\square$ No

$\square$ Not sure

A9 How old are you? ___ _ years 
Appendix D

Study Schema 
MPVB recruitment

Responded to recruitment by flyer or website advertisement by

visiting the web site (372)

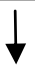

Provided no data (125)

$\downarrow$

Screened for

eligibility (247)

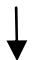

Some are ineligible (67).

Eligibility is confirmed by use of smart questionnaire.

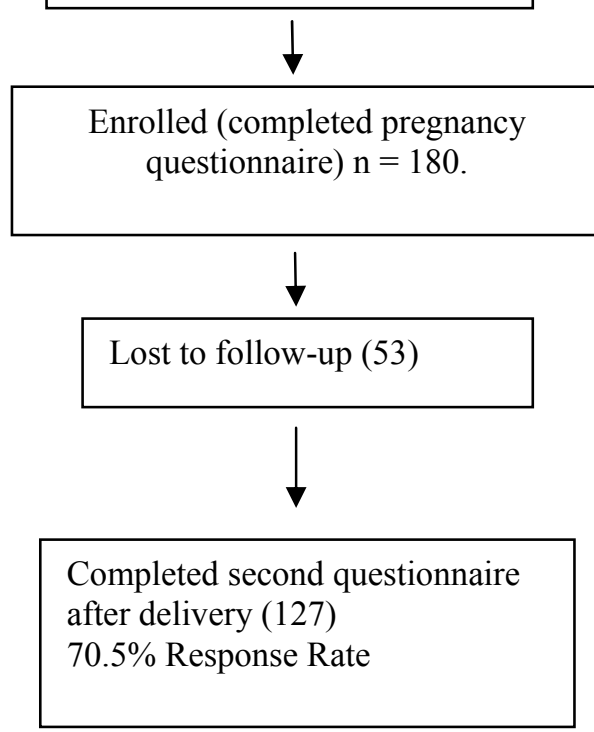

CDMR recruitment

Responded to recruitment by flyer or website advertisement by visiting the web site (36)

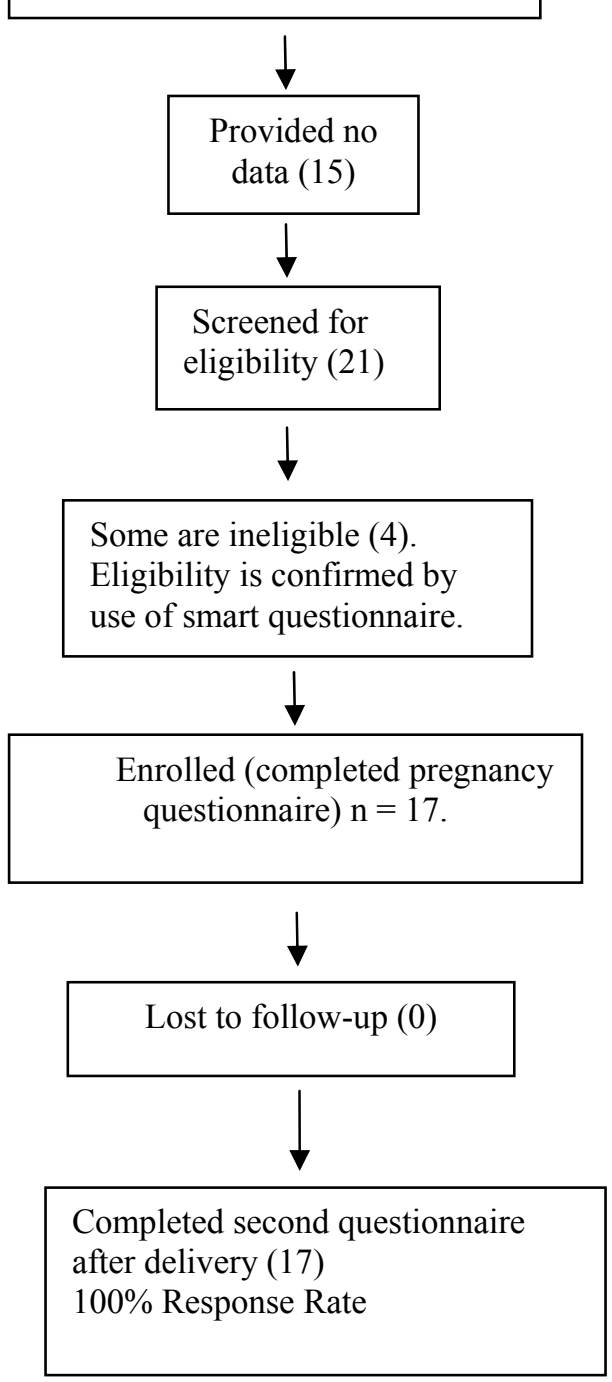


Appendix E

Questionnaire Measuring Attitudes About Labor and Delivery ExperienceVaginal Delivery 
J. S. Marut and R. T. Mercer

Please circle the number in the column that best describes the feeling state referred to in each question.

\begin{tabular}{l} 
Very Ext \\
\hline Example: How relaxed were you during labor? \\
5 \\
(This answer would indicate that you were very relaxed \\
though not extremely relaxed.) \\
\hline 1. How successful were you in using the breathing or \\
relaxation methods to help with contractions? \\
5
\end{tabular}

2. How confident were you during labor? 5

3. How confident were you during delivery? 5

4. How relaxed were you during labor? 5

5. How relaxed were you during delivery? 5

6. How pleasant or satisfying was the feeling state you experienced during delivery? 5

7. How well in control were you during labor? 5

8. How well in control were you during delivery? 5

9. To what extent did your experience of having a baby go along with the expectation you had before labor began? 5

10. To what extent do you consider yourself to have been a useful and cooperative member of the obstetric team? 5

\begin{tabular}{|c|c|c|c|}
\hline Not at all & Somewhat & Moderately & \\
\hline 1 & 2 & 3 & 4 \\
\hline 1 & 2 & 3 & 4 \\
\hline 1 & 2 & 3 & 4 \\
\hline 1 & 2 & 3 & 4 \\
\hline 1 & 2 & 3 & 4 \\
\hline 1 & 2 & 3 & 4 \\
\hline 1 & 2 & 3 & 4 \\
\hline 1 & 2 & 3 & 4 \\
\hline 1 & 2 & 3 & 4 \\
\hline 1 & 2 & 3 & 4 \\
\hline 1 & 2 & 3 & 4 \\
\hline
\end{tabular}


11. How useful was your partner in helping you through your labor? 5

12. How useful was your partner in helping you through delivery? 5

13. To what degree were you aware of events during labor? 5

$\begin{array}{llll}1 & 2 & 3 & 4\end{array}$

14. To what degree were you aware of events during delivery? 5

$\begin{array}{llll}1 & 2 & 3 & 4\end{array}$

Very Extre
during delivery? 5

16. Do you remember your labor as painful? 5

17. Do you remember your delivery as painful? 5

18. How scared were you during delivery? 5

19. Did you worry about your baby's condition during labor? 5

\begin{tabular}{|c|c|c|c|}
\hline Not at all & Somewhat & Moderately & \\
\hline 1 & 2 & 3 & 4 \\
\hline 1 & 2 & 3 & 4 \\
\hline 1 & 2 & 3 & 4 \\
\hline 1 & 2 & 3 & 4 \\
\hline 1 & 2 & 3 & 4 \\
\hline 1 & 2 & 3 & 4 \\
\hline 1 & 2 & 3 & 4 \\
\hline 1 & 2 & 3 & 4 \\
\hline 1 & 2 & 3 & 4 \\
\hline
\end{tabular}
5 
24. Did your partner (or other person) review your labor experience with you? 5

$\begin{array}{llll}1 & 2 & 3 & 4\end{array}$

25. Did you feel better after reviewing the labor and delivery experience? 5

26. Were you pleased with how your delivery turned out? 5

27. Were you able to enjoy holding your baby for the first time?

12

$\begin{array}{lll}2 & 4\end{array}$
5

28. How soon after delivery did you touch your baby?

$\begin{array}{ccccc}5 & 4 & 3 & 2 & 1 \\ \text { Immediately } & \text { Within } 1 \text { hour } & \text { Within } 2 \text { hours } & \text { Within } 4 \text { hours } & \text { Within } 8 \text { hours } \\ \text { longer } & & & \end{array}$

29. How soon after delivery did you hold your baby?
5 4 3 2 1 Immediately Within 1 hour Within 2 hours Within 4 hours or longer

Items in red are reverse coded, so that higher scores indicate a more positive birth experience.

(C) J. S. Marut and R. T. Mercer 
Appendix F

Modified Questionnaire Measuring Attitudes about Labor and Delivery ExperienceCesarean Delivery 


\section{$\underline{\text { Labor (pre-delivery procedures) subscale items }}$}

1. How relaxed were you before delivery?

2. How successful were you in using the breathing or relaxation methods to help relieve the tensions before delivery?

3. How relaxed were you during pre-delivery procedures (enema, catheterization, scrub)?

4. How confident were you before going to the delivery or operating room?

5. How confident were you when you were getting the anesthesia?

9. How well in control were you during pre-delivery procedures?

13. If partner was present, how useful was he/she in helping you when you were getting the anesthetic?

17. Do you remember your pre-delivery procedures as painful?

20. Did you worry about your baby's condition before delivery?

Baby subscale items

27. Were you able to enjoy holding your baby for the first time?

28. How soon after delivery did you touch your baby?

29. How soon after delivery did you hold your baby?

$\underline{\text { Delivery subscale items }}$

6. How confident were you during delivery?

7. How relaxed were you during delivery?

8. How pleasant or satisfying was the feeling state you experienced during delivery?

11. How well in control were you during delivery?

14. If partner was present, how useful was he/she in helping you through delivery?

15. To what degree were you aware of events during delivery?

16. How unpleasant was the feeling state you experienced during delivery? 
18. Do you remember your delivery as painful?

19. How scared were you during delivery?

21. Did you worry about your baby's condition during delivery?

22. Did the equipment used during labor bother you?

23. Was the delivery experience realistic as opposed to dream-like?

24. Did your partner (or other person) review your labor experience with you?

26. Were you pleased with how your delivery turned out?

Labor/delivery subscale items

10. To what extent did your experience of having a baby go along with the expectation you had before delivery began?

12. To what extent do you consider yourself to have been a useful and cooperative member of the obstetric team?

25. Did you feel better after reviewing the delivery experience? 
Appendix G

Decisional Conflict Scale 
A. Traditional Decisional Conflict Scale (DCS) - Statement Format: 16 item 5 response categories

This is our most tested version. Many people like the personal response format. However it is more difficult to respond to than questions in those with limited reading and response skills.

Note: We always precede the DCS with an option preference question, which is not included in scoring.

[See item 'A' below].

\section{My difficulty in making this choice}

A. Which [insert treatment/screening] option do you prefer? Please check $\square$ one.

\begin{tabular}{ll}
$\square$ & [Option 1] \\
$\square$ & [Option 2] \\
$\square$ & [Option 3] \\
\hline$\square$ & Unsure
\end{tabular}

B. Considering the option you prefer, please answer the following questions:

\begin{tabular}{|c|c|c|c|c|c|}
\hline & $\begin{array}{c}\begin{array}{c}\text { Strongly } \\
\text { Agree }\end{array} \\
{[0]}\end{array}$ & $\begin{array}{c}\text { Agree } \\
{[1]}\end{array}$ & $\begin{array}{c}\text { Neither } \\
\text { Agree } \\
\text { Or } \\
\text { Disagree } \\
{[2]}\end{array}$ & Disagree & $\begin{array}{c}\begin{array}{c}\text { Strongly } \\
\text { Disagree }\end{array} \\
{[4]}\end{array}$ \\
\hline 1. I know which options are available to me. & $\square$ & $\square$ & $\square$ & $\square$ & $\square$ \\
\hline 2. I know the benefits of each option. & $\square$ & $\square$ & $\square$ & $\square$ & $\square$ \\
\hline 3. I know the risks and side effects of each option. & $\square$ & $\square$ & $\square$ & $\square$ & $\square$ \\
\hline 4. I am clear about which benefits matter most to me. & $\square$ & $\square$ & $\square$ & $\square$ & $\square$ \\
\hline 5. I am clear about which risks and side effects matter most. & $\square$ & $\square$ & $\square$ & $\square$ & $\square$ \\
\hline $\begin{array}{l}\text { 6. I am clear about which is more important to me (the benefits } \\
\text { or the risks and side effects). }\end{array}$ & $\square$ & $\square$ & $\square$ & $\square$ & $\square$ \\
\hline 7. I have enough support from others to make a choice. & $\square$ & $\square$ & $\square$ & $\square$ & $\square$ \\
\hline 8. I am choosing without pressure from others. & $\square$ & $\square$ & $\square$ & $\square$ & $\square$ \\
\hline 9. I have enough advice to make a choice. & $\square$ & $\square$ & $\square$ & $\square$ & $\square$ \\
\hline 10. I am clear about the best choice for me. & $\square$ & $\square$ & $\square$ & $\square$ & $\square$ \\
\hline 11. I feel sure about what to choose. & $\square$ & $\square$ & $\square$ & $\square$ & $\square$ \\
\hline 12. This decision is easy for me to make. & $\square$ & $\square$ & $\square$ & $\square$ & $\square$ \\
\hline 13. I feel I have made an informed choice. & $\square$ & $\square$ & $\square$ & $\square$ & $\square$ \\
\hline 14. My decision shows what is important to me. & $\square$ & $\square$ & $\square$ & $\square$ & $\square$ \\
\hline 15. I expect to stick with my decision. & $\square$ & $\square$ & $\square$ & $\square$ & $\square$ \\
\hline 16. I am satisfied with my decision. & $\square$ & $\square$ & $\square$ & $\square$ & $\square$ \\
\hline
\end{tabular}

Decisional Conflict Scale $@$ AM O'Connor, 1993, revised 2005 
Appendix $\mathrm{H}$

Maternal Health Belief Questionnaire Pregnancy 


\section{Part 1: Basic information}

B1. Ethnicity: Do you consider your ethnicity to be Hispanic or Latino?

$\square$ Yes

$\square$ No

Not sure

B2. Race: For this question on racial background, you may select one or more choices:

Do you consider yourself to be:

$\square$ White/Caucasian

Black/African American

Asian

Native Hawaiian/Pacific Islander

American Indian/Alaskan Native

Other

$\square$ Refused

B3. If more than one race was selected, which do you consider to be your primary racial background?

(Select the one that best describes your primary racial background.)

$\square$ White/Caucasian

Black/African American

Asian

Native Hawaiian/Pacific Islander

$\square$ American Indian/Alaskan Native

Other

$\square$ Refused

B4. Please indicate your highest level of education (please pick one)

$\square$ Not answered

Elementary school

Junior high school

Some high school but did not graduate

High school diploma

$\square$ Some college courses but did not graduate

College diploma

$\square$ Graduate degree

B5: Please list the first three digits of your current 5-digit zip code

B6: Which best describes your marital status? 


\section{Married \\ Single \\ Divorced/ separated \\ Widowed}

B7. Please describe your tobacco use (please pick one)

$\square$ Never

$\square$ Past

$\square$ Present

B8. Have you been diagnosed with any of the following conditions? (check all that apply)

Diabetes

Gestational diabetes (pregnancy-related)

$\square$ Asthma

Depression

High blood pressure

B9. How would you describe this pregnancy (please pick one)

$\square$ Definitely planned ahead of time and I was happy to become pregnant

$\square$ Not planned, but I was happy to become pregnant

$\square$ Not planned, and I was not happy to become pregnant

B10. Are you planning to breast feed this baby?

$\square$ Yes

$\square$ No

$\square$ Not sure

Part 2: Pregnancy information

C1. Have you been pregnant before (not counting this pregnancy)?

$\square$ Yes

$\square$ No $\longrightarrow$ Skip to question $\mathrm{C} 7$

C2. How many miscarriages or abortions have you had?

C3. How many babies have you delivered?

C4. How many of your deliveries were vaginal births?

C5. How many of your deliveries were cesarean births? 
C6. Including miscarriages, abortions, and deliveries, how many pregnancies have you had? (This should be the total of $\mathrm{C} 2+\mathrm{C} 3$.)

C7. Please pick the option that best describes your CURRENT plans for your family size

I plan to have 1 or 2 children (including this pregnancy)

$\square$ I plan to have at least 3 children

I don't know

C8. Which doctor is taking care of you for your current pregnancy?

(Name of doctor or group)

C9. What is your expected due date?

Month

Day

Year

C10. What today's date?

Month

Day

Year

With this next question, we will ask you to rate how anxious or nervous you are about childbirth. How would you describe how nervous (or anxious or worried) you feel about childbirth?

\begin{tabular}{|c|c|c|c|c|}
\hline $\begin{array}{c}\text { Not at all } \\
\text { nervous }\end{array}$ & $\begin{array}{c}\text { Somewhat } \\
\text { nervous }\end{array}$ & $\begin{array}{c}\text { Moderately } \\
\text { nervous }\end{array}$ & Very nervous & $\begin{array}{c}\text { Extremely } \\
\text { nervous }\end{array}$ \\
\hline$\square$ & $\square$ & $\square$ & $\square$ & $\square$ \\
\hline
\end{tabular}

Goals for Birth

For this page of the questionnaire, we want you to think about the upcoming delivery of your child! 
- We want you to think about your wishes, goals and expectations for the whole birthing process (from when the process begins until the first hours after birth).

- You can include anything that is important to you.

Please list the goals you hope to achieve with respect to the delivery of your child. You can list anything that you hope to experience or accomplish. Be as specific as possible. After your delivery, we will ask you about the items on this list. Please note that you can list up to 5 goals:

1.

2.

3.

4.

5.

D3. Regarding the decision to plan a vaginal delivery or to scheduled cesarean birth, which best describes the role your doctor has played? Please choose the answer that best describes your decision.

I never discussed a cesarean with my doctor.

$\square$ I feel that my doctor did not want me to have a cesarean; I had to convince him/ her

My doctor did not suggest a cesarean, but agreed to it when I made the request

My doctor put pressure on me to have a cesarean, but I wouldn't agree.

My doctor and I talked about scheduled cesarean delivery and decided it wasn't a good option for me.

$\square$ My doctor and I made the decision together about planning a scheduled cesarean.

$\square$ I feel that my doctor did not want me to have a cesarean; I asked about it but couldn't convince him/her.

$\square$ I didn't want a scheduled cesarean, but my doctor convinced me I should have one.

$\square$ I didn't want a scheduled cesarean, but my doctor has made me feel like I have no other good choice. 
D4. Thinking about the method of delivery that you choose the statement that most accurately reflects your beliefs that were important to you as you made your decision to plan a vaginal delivery or request a cesarean delivery. (Drop down options - Agree, Disagree)

Vaginal birth is better because cesarean is not natural.

Cesarean delivery is safer for the baby.

Cesarean delivery is safer for the mother.

$\square$ Cesarean delivery is riskier for the baby.

$\square$ Cesarean delivery is riskier for the mother.

$\square$ If I have a cesarean delivery I will have more pain.

If I have a cesarean delivery I will have more pain.

If I have a cesarean delivery I will feel worse after the delivery.

D5. Why did you decide to choose to plan a vaginal delivery or request a scheduled cesarean delivery? Please pick the items that were important to YOU as you made your decision:

I think the type of delivery I choose is safer for the baby.

- If you pick this option, list at least one thing that will be safer for the baby:

I think the type of delivery I choose is safer for the mother.

○ If you pick this option, list at least one thing that will be safer for the mother:

I think it will allow me to pick the day of my delivery.

Other

D6. Do you think you have been given enough information about vaginal birth or cesarean birth?

$\square$ Yes

$\square$ No

$\square$ Not sure 
D7. If not, what would you like to know?

The following questions asks you to think about what you believe about to be true about what labor would be like for you if you were in labor. Please pick the answer that best describes what you believe.

SE1. If I am in labor, I will be able to deliver vaginally.

- Strongly Agree

Agree

Neither agree nor disagree

Disagree

Strongly Disagree

R1. If I am in labor, I am at risk for an emergency cesarean delivery.

Strongly Agree $=1$

Agree $=2$

Neither agree nor disagree $=3$

Disagree $=4$

Strongly Disagree $=5$

The next few questions are about the support your have received from your husband/partner during the pregnancy. Please select the answer that best describes what you believe.

S1. I made the decision about how I would deliver my baby by myself.

- Strongly Agree

Agree

Neither agree nor disagree

Disagree

Strongly Disagree

S2.My husband/partner and I made the decision about how I would delivery my baby together.

Agree

Neither agree nor disagree

Disagree 
Strongly Disagree

S3.My husband/partner has been critical of me during the pregnancy.

- Strongly Agree

Agree

Neither agree nor disagree

D Disagree

Strongly Disagree

S4.My husband/partner is understanding when I get upset.

Strongly Agree

Agree

Neither agree nor disagree

Disagree

Strongly Disagree

S5. My husband/partner feels I burden him with my feelings and problems.

Strongly Agree

Agree

Neither agree nor disagree

Disagree

Strongly Disagree

The next few questions are about how easy or difficult this pregnancy has been for you. Please select the answer that best represents how you feel.

M1.I have enjoyed this pregnancy.

Strongly Agree

Agree

Neither agree nor disagree

Disagree

Strongly Disagree

M2. This pregnancy has been hard for me.

Strongly Agree

Agree

Neither agree nor disagree

- Disagree

Strongly Disagree 
M3.This is a good time for me to be pregnant.

Strongly Agree

Agree

Neither agree nor disagree

Disagree

Strongly Disagree

M4.I have regrets about being pregnant at this time.

Strongly Agree

Agree

Neither agree nor disagree

Disagree

Strongly Disagree

M5. I can tolerate the discomforts of this pregnancy.

Strongly Agree

Agree

Neither agree nor disagree

Disagree

Strongly Disagree

M6.I find many things about this pregnancy unpleasant.

Strongly Agree

Agree

Neither agree nor disagree

D Disagree

Strongly Disagree

M7. I have found this pregnancy to be satisfying.

Strongly Agree

Agree

Neither agree nor disagree

D Disagree

Strongly Disagree 
M8. I have found it hard to get used to the changes brought about by this pregnancy.

Strongly Agree

Agree

Neither agree nor disagree

Disagree

Strongly Disagree 
Appendix I

Labor Agentry Scale 
Just as no two women are exactly alike, no two women have exactly the same experiences during childbirth. Please try to think about your baby's upcoming birth as vividly as you can. Think about what you think your feelings during the birth will be like. Of course, you would probably have many different feelings, but try to think generally what it will be like for you.

I think I will feel tense.

Almost always A lot but not always Alittle more than half the time About half the time $\mathrm{S}$ o $\mathrm{m}$ e $\mathrm{t} \mathrm{i} \mathbf{m}$ e $\mathbf{s}$ Never feel tense

$\bigcirc$

$\bigcirc$

$\bigcirc$

$\bigcirc$

O

O

I think I will feel important.

Almost always A lot but not always Alittle more than half the time About half the time $\mathbf{S}$ o $\mathbf{m}$ e $\mathrm{t}$ i $\mathrm{m}$ e s Never feel important

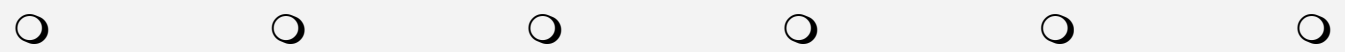

I think I will feel confident.

Almost always A lot but not always Alittle more than half the time About half the time $\mathbf{S}$ o $\mathbf{m}$ e $\mathbf{t}$ i $\mathbf{m}$ e $\mathbf{s}$ Never feel confident

O

O

O

O

O

0

I think I will feel in control.
Almost always
A lot but not always
A little more than half the time
About half the time
S o m e t i m e s Never feel in control
O
○
O
O
O
O

I think I will feel fearful.

$\begin{array}{cccccc}\text { Almost always } & \text { A lot but not always } & \text { Alittle more than half the time } & \text { About half the time } & \text { s o } \mathbf{m} \text { e } \mathbf{t} \text { i m e s } & \text { Never feel fearful }\end{array}$

I think I will feel relaxed.

Almost always A lot but not always A little more than half the time

About half the time

S o m e t i m e s Never feel relaxed

O

O

O

O

O

O 
I think I will feel good about my behavior

Almost always A lot but not always

A little more than half the time

About half the time

S o $\mathbf{m}$ e $\mathbf{t}$ i $\mathbf{m}$ e $\mathbf{s}$ Never feel good about my behavior

O

O

O

$\mathrm{O}$

O

O

I think I will feel helpless (powerless).

Almost always A lot but not always A little more than half the time

About half the time

S o m e t i m e s Never feel helpless

O

O

O

$\mathrm{O}$

O

O

I think I will be with people who care about me.

Almost always A lot but not always A little more than half the time

About half the time

Som e t i m e s

$\mathbf{N}$ e

$\begin{array}{lll}\mathbf{e} & \mathbf{r}\end{array}$

O

O

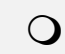

$\mathrm{O}$

O

O

I think I will feel feel like a failure.

\begin{tabular}{|c|c|c|c|c|c|c|c|c|}
\hline Almost always & A lot but not always & A little more than half the time & About half the time & Sometimes & $\mathbf{N}$ & e v & e & $r$ \\
\hline 0 & 0 & 0 & 0 & 0 & & 0 & & \\
\hline
\end{tabular}




\section{Appendix J}

Maternal Health Belief Postpartum Questionnaire: Planned Vaginal Birth 
Page 1 - Heading

Thank you for taking the postpartum questionnaire for first time mothers who were planning a vaginal birth. This is an important part of our study. This questionnaire has a total of 63 questions. You will be asked to submit after each set of 30 questions, but that does not mean the survey is finished. Please try and make sure that you answer all 63 of the questions. Please let us know by emailing info@yourbirthchoice.com if you encounter any difficulty with the survey. If you were planning a cesarean delivery please go to that survey.

Page 1 - Question 1 - Date and Time

On what day was your baby born?

Page 1 - Question 2 - Choice - One Answer (Bullets)

According to our records, during the end of your pregnancy you were planning a vaginal birth. If you were planning a hospital delivery, when you entered the hospital to deliver this baby, was that still your plan? (This refers to what you and your healthcare provider were planning when you came in to the hospital, even if that is not how your delivery turned out).

Yes, that was still my plan

No, my plan had changed

Not sure

Not applicable because I was planning a home delivery

If your plans changed, what was the reason?

Page 1 - Question 3 - Choice - One Answer (Bullets)

According to our records, during the end of your pregnancy you were planning a vaginal birth. If you were planning a home delivery, when you entered labor, was that still your plan? (This refers to what you and your healthcare provider were planning when you began labor, even if that is not how your delivery turned out).

Yes, that was still my plan

No, my plan had changed

Not sure

Not applicable, I was planning a hospital birth

If your plans changed, what was the reason? 
Page 1 - Question 4 - Open Ended - One or More Lines with Prompt

Please think about the "Goals for Birth" you listed on your Pregnancy Questionaire. Enter each goal below.

Goal $1=$ goal $1 \mathrm{pp}$

Goal 2 = goal2pp

Goal $3=$ goal $3 p p$

Goal $4=$ goal4pp

2. Goal $5=$ goal5pp

Page 1 - Question 5 - Rating Scale - Matrix

Please refer to the goals you listed above, and tell us whether the goal was achieved by your childbirth experience by clicking on each of the answers.

\begin{tabular}{|c|c|c|}
\hline G o a 1 & 1 & $=\mathrm{g} \circ \mathrm{al} 1 \mathrm{ach}$ \\
\hline $\mathrm{G}$ o a 1 & 2 & $\mathrm{~g}$ o a $12 \mathrm{a} \mathrm{ch}$ \\
\hline $\mathrm{G}$ o a 1 & 3 & $\mathrm{~g}$ o a 13 a c h \\
\hline $\mathrm{G}$ o a 1 & 4 & g o a 14 a c $h$ \\
\hline $\mathrm{G}$ o a 1 & 5 & g o a 15 \\
\hline
\end{tabular}

Completely Achieved $=$

Somewhat Achieved $=2 \quad$ Not Achieved at all $=3$

O

O

O

O

O $\bigcirc$

$\mathrm{O}$

0

$\bigcirc$

$\mathrm{O}$

Page 1 - Heading

Please tell us which of these procedures or treatments you received for your childbirth and delivery.

Page 1 - Question 6 - Choice - One Answer (Bullets)

Pitocin or oxytocin to stimulate labor contractions when you were already in labor.

Yes $=1$

No $=2$

Not sure $=3$

Page 1 - Question 7 - Choice - One Answer (Bullets) Induction of labor

Yes $=1$

No $=2$

Not sure $=3$

If yes, please tell us why? Variable = inductionwhy (string) 
Page 1 - Question 8 - Choice - One Answer (Bullets)

Epidural for anesthesia or pain control

Y Yes $=1$

No $=2$

Not sure $=3$

Page 1 - Question 9 - Choice - One Answer (Bullets)

Repair of tears or lacerations

Yes $=1$

No $=2$

Not sure $=3$

Page 1 - Question 10 - Choice - One Answer (Bullets)

Episiotomy

Yes $=1$

) $\mathrm{No}=2$

Not sure $=3$

Page 1 - Question 11 - Choice - One Answer (Bullets)

Forceps delivery

Y Yes $=1$

No $=2$

Not sure $=3$

Page 1 - Question 12 - Choice - One Answer (Bullets)

Vacuum delivery

(1) Yes $=1$

No $=2$

Not sure $=3$

Page 1 - Question 13 - Choice - One Answer (Bullets)

Cesarean delivery

Yes $=1$ 
No $=2$

Not sure $=3$

Page 1 - Question 14 - Choice - One Answer (Bullets)

If you had a cesarean delivery, please tell us the circumstances

Cesarean without any labor $=1$

Cesarean during labor, but before becoming fully dilated $=2$

C Cesarean during labor, after becoming fully dilated $(10 \mathrm{~cm})=3$

Not Applicable $=4$

If you had a cesarean without any labor, please tell us why = cwhy

Page 1 - Question 15 - Open Ended - Comments Box

Please tell us how long your were in labor? 
Appendix K

Maternal Health Beliefs Postpartum Questionnaire: Planned Cesarean Birth 
Page 1 - Heading

Thank you for taking the postpartum questionnaire for first time mothers who were planning a scheduled cesarean birth. This is an important part of our study. This questionnaire has a total of 61 questions. You will be asked to submit after each set of 30 questions, but that does not mean the survey is finished. Please try and make sure that you answer all 61 of the questions. Please let us know by emailing info@yourbirthchoice.com if you encounter any difficulty with the survey. If you were planning a vaginal delivery please go to that survey.

Page 1 - Question 1 - Date and Time

On what day was your baby born?

Month Day $\quad$ Year $\quad$ Time

Date/Time

Page 1 - Question 2 - Choice - One Answer (Bullets)

According to our records, during the end of your pregnancy you were planning a cesarean birth. When you entered the hospital to deliver this baby, was that still your plan? (This refers to what you and your healthcare provider were planning when you came in to the hospital, even if that is not how your delivery turned out).

Yes, that was still my plan

No, my plan had changed

Not sure

If your plans changed, what was the reason?

Page 1 - Question 3 - Open Ended - One or More Lines with Prompt

Please think about the "Goals for Birth" you listed on your Pregnancy Questionaire. Enter each goal below.

Goal 1

Goal 2

Goal 3

Goal 4

2. Goal 5

Page 1 - Question 4 - Rating Scale - Matrix

Please refer to the goals you listed above, and tell us whether the goal was acheived by your childbirth experience by clicking on each of the answers.

$\begin{array}{lllllccc}\text { G } & \text { o } & \text { a } & 1 & 1 & \text { Completely Achieved =1 } & \text { Somewhat Achieved = } 2 & \text { Not Achieved at all = 3 } \\ \text { G } & 0 & \text { a } & 1 & 2 & O & O & O \\ \text { G } & 0 & \text { a } & 1 & 3 & O & O & O \\ \text { G } & 0 & \text { a } & 1 & 4 & O & O & O\end{array}$


G
o
$\mathrm{a}$

1

5

O

O

○

Page 1 - Heading

Please tell us which of these procedures or treatments you received for your childbirth and delivery.

Page 1 - Question 5 - Choice - One Answer (Bullets)

Pitocin or oxytocin to stimulate labor contractions when you were already in labor.

Yes $=1$

No $=2$

Not sure $=3$

Page 1 - Question 6 - Choice - One Answer (Bullets)

Induction of labor

Y Yes

No

Not sure

If yes, please tell us why? inductionwhy

Page 1 - Question 7 - Choice - One Answer (Bullets)

Epidural for anesthesia or pain control

Yes

No

Not sure

Page 1 - Question 8 - Choice - One Answer (Bullets)

Episiotomy

Yes

) No

- Not sure

Page 1 - Question 9 - Choice - One Answer (Bullets)

Forceps delivery

- Yes

- No

- Not sure 
Page 1 - Question 10 - Choice - One Answer (Bullets)

Vacuum delivery

Yes

No

Not sure

Page 1 - Question 11 - Choice - One Answer (Bullets)

Cesarean delivery

Yes

No

Not sure

Page 1 - Question 12 - Choice - One Answer (Bullets)

If you had a cesarean delivery, please tell us the circumstances

Cesarean without any labor

- Cesarean during labor, but before becoming fully dilated

Cesarean during labor, after becoming fully dilated $(10 \mathrm{~cm})$

Not Applicable

If you had a cesarean without any labor, please tell us why

Page 1 - Question 13 - Open Ended - Comments Box

Please tell us how long your were in labor?

$0=$ did not labor 
Appendix L

Medical Center of Central Georgia Letter of Exemption 
From: Bernard.MVB

Sent: Fri 9/4/2009 8:58 AM

To: Clark.Julie

Subject: RE: Debby Macmillan's Study

As long as she is only passing out recruitment materials for the non-MCCG study and not actually

performing the interviews, etc, it is still exempt.

\section{Bernard}

From: Clark.Julie

Sent: Friday, September 04, 2009 08:20

To: Bernard.MVB

Subject: Debby Macmillaan's Study

Bernard,

Sorry to bother you again regarding this matter, but regarding Debby Macmillan's study to survey pregnant women about their decision making process of whether to have a c-section birth or a vaginal delivery, she now wants to recruit patients that are seen at the Anderson Health Clinic. Will she still classify as exempt from the IRB Process or will this change her status since she is recruiting patients? I will wait to here from you before any recruitment of patients is done.Thanks.

Julie Clark, RN, MSN, FNP-BC

Chair of Nursing Research Council

PALS Coordinator

Learning Center MSC 131

The Medical Center of Central Georgia

777 Hemlock Street

Macon, Georgia 31201-2102

(478) 633-1851

clark.julie@mccg.org

mccg.org email firewall made the following annotation

CONFIDENTIALITY NOTICE:

The information transmitted in this e-mail message, including any attachments, is for the sole use of the intended recipient(s) or entity to which it is addressed and may contain confidential, privileged and/or proprietary information. Any unauthorized review, retransmission, use, disclosure, dissemination or other use of,or taking any action in reliance upon this information by persons or entities other than the intended recipient is prohibited. If you are not the intended recipient, you are hereby notified that any reading, dissemination, distribution, copying, or other use of this message or its attachments is strictly prohibited. If you have received this message in error, please notify the sender immediately by reply e-mail, or by calling (478) 633-7272, and destroy the original message, attachments and all copies thereof on all computers and in any other form. Thank you. The Medical Center Of Central Georgia. http://www.mccg.org/

$* * * * * * * * * * * * * * * * * * * * * * * * * * * * * * * * * * * * * * * * * * * * * * * * * * * * * * * * * * * * *$

09/08/09, 12:08:22 
Appendix M

Web Page Directions to Participants 
The purpose of The Birth Choice Survey is to provide women with a venue to give feedback about their decision making process during pregnancy as they plan their birth experiences. This information will help women and healthcare professional better understand the type of information that women are interested in receiving about the choices they have in childbirth. This study is especially interested in hearing from women who are having their first child. We want to hear from women who are planning all types of births: vaginal births in the hospital, vaginal births at home, and cesarean delivery where no medical indication is present.

If you experience problems while taking the survey these can be reported to info@thebirthchoicesurvey.com. Thank you for your participation in The Birth Choice Survey Project.

\section{$\underline{\text { INSTRUCTIONS }}$}

- This survey will ask you detailed questions about the decisions you have made during your pregnancy regarding what type of birth you want. It will also ask you questions about your general health before and during pregnancy. It will take about 30 minutes to complete, depending on your birth experience and your internet connection.

- Some questions are designed to make sure that you are eligible to be in this study. For example - you must be pregnant and within 8 to 10 week of delivery. You should not have a medical condition that makes it necessary that you choose a cesarean delivery: for example surgery on your uterus to remove fibroids. You also need to be pregnant with only one baby.

- We will ask you to read an informed consent which briefly explains this research study and provides you information about who to contact if you have any concerns about the study. You can print a copy of the informed consent to keep if you would like to.

- You will be asked for your email address. This is important because it will allow us to remind you about the last part of our study: the postpartum survey. After you deliver your baby we want to hear about how satisfied you are with your birth choice and the decisions that you made before delivery. Your email will be used to link the first prenatal survey with the postpartum survey. We promise that we will only use the email address for this purpose. We do not sell or use that information for any other reason. This is the only identifiable information we will ask you for.

- We have attempted to make the survey usable from all newer browser-andoperating-system combinations. 
Appendix N

Letter of Introduction to Participants 


\section{Dear Research Participant,}

On behalf of our research team, I would like to thank you for participating in our research study. The gift of your time will help healthcare professionals to understand what information is important to women who are planning their baby's birth. Please share our link with any friends who are also expecting their first baby and encourage them to complete our survey.

Over the next week, you will receive another email with information about our Birth Choice Newsletter. In the newsletter you will find information that we hope you will enjoy as you await the birth of your baby.

Deborah MacMillan

Assistant Professor

Georgia College \& State University 
Appendix $\mathrm{O}$

Power Analysis 
Calculations to estimate sample size were conducted based on guidelines for multiple linear regression analysis. Hypothesis 1.1 and 1.2 along with the moderating effect of maternal request (maternal request $\mathrm{X}$ perceived threat interaction) involves 8 independent variables. For purposes of sample size calculation, two additional potential control variables were included. Thus maximum total of independent variables anticipated was $\mathrm{k}=10$. Warner (2008) recommends an $\mathrm{N}$ of $104+\mathrm{k}$ as the minimum number of subjects to test for the significance of $\mathrm{R} 2$ and the significance of individual predictors. Thus a minimum sample size of 110 subjects to test the hypotheses with an alpha of .05 was needed. An attrition rate of $14 \%$ was estimated (Warner, 2008). To calculate the targeted sample size the following formula was used: $110 /(1-.14)=128$ participants. In order to prevent an unbalanced design that would make it impossible to compare the maternal request groups, a minimum of $20 \%$ of the sample should have been women requesting cesarean delivery $(n=26)$ with a goal of $50 \%$ of the sample being women requesting cesarean delivery. Despite multiple recruitment strategies, only 17 women were recruited who met the study inclusion criteria for CDMR.

To have sufficient power to address the study hypotheses, recruitment of a large enough sample of nulliparous women, especially those who elect cesarean delivery was a concern. The conservative estimate of $4 \%$ was used for the occurrence rate of maternal choice, so a population of 2000 deliveries was needed to obtain 80 potential participants who choose cesarean delivery; understanding that of this group not all women would meet all the study eligibility criteria. Recruitment from multiple geographic areas was undertaken to increase the generalizability of the study findings. Diversity of the sample was carefully monitored, to address gaps in past research about maternal choice which 
failed to identify sufficient non - Caucasian participants because of methods used to recruit the sample. 
Appendix $\mathrm{P}$

Maternal Reason for Planning Cesarean Delivery 
Women planning a cesarean delivery were asked if they had considered a vaginal as one of the options for their delivery and if so why they choose not to make this decision.

\begin{tabular}{|c|c|c|}
\hline Reason for decision & $\begin{array}{c}\text { Planned Cesarean } \\
\mathrm{n}=17\end{array}$ & $\begin{array}{c}\text { Planned Vaginal } \\
\mathrm{n}=127\end{array}$ \\
\hline $\begin{array}{c}\text { Scheduled cesarean is safer } \\
\text { for the baby. }\end{array}$ & $5(29.4 \%)$ & $2(1.6 \%)^{1}$ \\
\hline $\begin{array}{c}\text { Scheduled cesarean is safer } \\
\text { for the mother. }\end{array}$ & $3(17.6 \%)$ & $2(1.6 \%)^{1}$ \\
\hline $\begin{array}{c}\text { Scheduled cesarean would } \\
\text { be less painful for them than } \\
\text { a vaginal delivery }\end{array}$ & $2(11.7 \%)$ & 0 \\
\hline $\begin{array}{c}\text { She would feel better after } \\
\text { the birth, with a cesarean. }\end{array}$ & $1(5.8 \%)$ & 0 \\
\hline $\begin{array}{c}\text { She could pick the day of } \\
\text { her delivery by planning a } \\
\text { cesarean. }\end{array}$ & $1(5.8 \%)$ & 0 \\
\hline $\begin{array}{c}\text { Physician suggested } \\
\text { cesarean delivery for her. }\end{array}$ & $5(29.4 \%)^{3}$ & 0 \\
\hline
\end{tabular}

1. Four women reporting requesting a cesarean, but being unable to convince their physician to agree to this request.

2. One woman stated that if her baby was estimated to be over 9 pounds, her physician had agreed to schedule a cesarean at 38 weeks gestation.

3. Perceived reasons for the suggestion by the physician were history of endometriosis and infertility, history of polycystic ovary syndrome and infertility, advanced maternal age, past medical concerns related to back surgery and high risk pregnancy with positive AFP Screening. 
Appendix Q

Maternal Reason for Planning Vaginal Delivery 
Women planning a vaginal delivery were asked if they had considered a scheduled cesarean as one of the options for their delivery and if so why they choose not to make this decision.

\begin{tabular}{|l|c|c|}
\hline \multicolumn{1}{|c|}{ Reason for decision } & $\begin{array}{c}\text { Planned Cesarean } \\
\mathrm{n}=17\end{array}$ & $\begin{array}{c}\text { Planned Vaginal } \\
\mathrm{n}=127\end{array}$ \\
\hline Riskier for the baby & 0 & $39(30.7 \%)$ \\
\hline Riskier for the mother & 0 & $43(30.7 \%)$ \\
\hline Increased pain & 0 & $42(33.1 \%)$ \\
\hline $\begin{array}{l}\text { Longer recovery } \\
\begin{array}{l}\text { Reported they received } \\
\text { some information } \\
\text { regarding elective } \\
\text { cesarean delivery. }\end{array}\end{array}$ & 0 & $76(59.8 \%)$ \\
\hline $\begin{array}{l}\text { Elective cesarean never } \\
\text { considered to be an } \\
\text { option for them. }\end{array}$ & 0 & $110(86.6 \%)$ \\
\hline $\begin{array}{l}\text { Talked to their doctor } \\
\text { about scheduled cesarean } \\
\text { but decided it was not the } \\
\text { best choice for them. }\end{array}$ & 0 & $10(7.8 \%)$ \\
\hline $\begin{array}{l}\text { Physicians had put } \\
\text { pressure on them to have } \\
\text { a cesarean, but that they } \\
\text { did not agree to the } \\
\text { decision. }\end{array}$ & 0 & $3(2.4 \%)$ \\
\hline $\begin{array}{l}\text { Requested a cesarean, and } \\
\text { being unable to convince } \\
\text { the provider to agree to } \\
\text { this decision. }\end{array}$ & 0 & \\
\hline
\end{tabular}


Appendix R

Goal Categories with Selected Examples 


\begin{tabular}{|c|c|}
\hline Goal & Specific examples \\
\hline Desire to avoid complications & $\begin{array}{l}\text { "hopefully no serious complications" } \\
\text { " no harm come to me" }\end{array}$ \\
\hline Healthy mother & "healthy me" \\
\hline Healthy baby & "to have a healthy baby" \\
\hline Adequate pain control & "getting adequate medication to deal with pain" \\
\hline Avoid intervention & $\begin{array}{l}\text { "No inductions, or rupturing of the bag of waters" } \\
\text { "not hooked to any monitors" } \\
\text { "No episiotomy" }\end{array}$ \\
\hline Duration of the birth experience & "fast delivery" \\
\hline $\begin{array}{l}\text { Desire for partner/family to be } \\
\text { supportive }\end{array}$ & $\begin{array}{l}\text { "establish a better relationship with the father" } \\
\text { "Need husband to support all decisions during } \\
\text { labor" } \\
\text { "have my husband 'catch' the baby " } \\
\text { "to feel a good connection with my husband" } \\
\text { "Family here" }\end{array}$ \\
\hline External control & $\begin{array}{l}\text { "caring hospital staff" } \\
\text { "Not to have to labor" } \\
\text { "Birth in my birthing pool" }\end{array}$ \\
\hline Internal control & $\begin{array}{l}\text { "Endure the process until the end" } \\
\text { "To remain calm \& confident throughout } \\
\text { labor/birth" }\end{array}$ \\
\hline
\end{tabular}




\begin{tabular}{|l|l|}
\hline Fulfillment & \multicolumn{1}{|c|}{ "To be in control of my own delivery" } \\
\hline Bonding/breastfeeding & "An empowering, life-changing birth experience " \\
"to have an empowering birth" & "breastfeed and bond with baby right away after \\
\hline Ease of recovery & "my body becomes normal again" \\
\hline Maternal role attainment & "Concerned about postpartum depression " \\
& "I wish to always be there for her no matter what" \\
& "find a different occupation" \\
"Nurture her" \\
"always have food" \\
"Be the best mom I can be"
\end{tabular}


Appendix S

Goals Reported by Women Planning Cesarean or Vaginal Birth

Data represents the number

of women reporting at least one goal from each category. 


\begin{tabular}{|l|c|c|}
\hline Category & $\begin{array}{c}\text { Planned Cesarean } \\
(\mathrm{n}=17)\end{array}$ & $\begin{array}{c}\text { Planned Vaginal } \\
(\mathrm{n}=127)\end{array}$ \\
\hline Desire to avoid complications & $7(41.1 \%)$ & $53(41.7 \%)$ \\
\hline Healthy mother & $3(17.6 \%)$ & $6(4.7 \%)$ \\
\hline Healthy baby & $8(47.1 \%)$ & $66(51.9 \%)$ \\
\hline Adequate pain control & $3(17.6 \%)$ & $23(18.1 \%)$ \\
\hline Avoid interventions & $0(0 \%)$ & $118(92.9 \%)$ \\
\hline Duration of the birth experience & $1(5.8 \%)$ & $24(18.8 \%)$ \\
\hline Desire for partner/family to be & $12(70.5 \%)$ & $27(21.3 \%)$ \\
\hline supportive and involved & & \\
\hline External control & $13(76.4 \%)$ & $126(99.2 \%)$ \\
\hline Internal control & $3(5.8 \%)$ & $37(29 / 1 \%)$ \\
\hline Fulfillment & $2(11.8 \%)$ & $17(13.4 \%)$ \\
\hline Bonding/Breastfeeding & $9(52.9 \%)$ & $57(44.9 \%)$ \\
\hline Ease of recovery & $3(17.6 \%)$ & $6(4.7 \%)$ \\
\hline Maternal role attainment & $0(0 \%)$ & $35(27.5 \%)$ \\
\hline
\end{tabular}


Appendix T

Correlation Tables for Study Variables 
Relationship between demographic and obstetrical variables and outcome variables

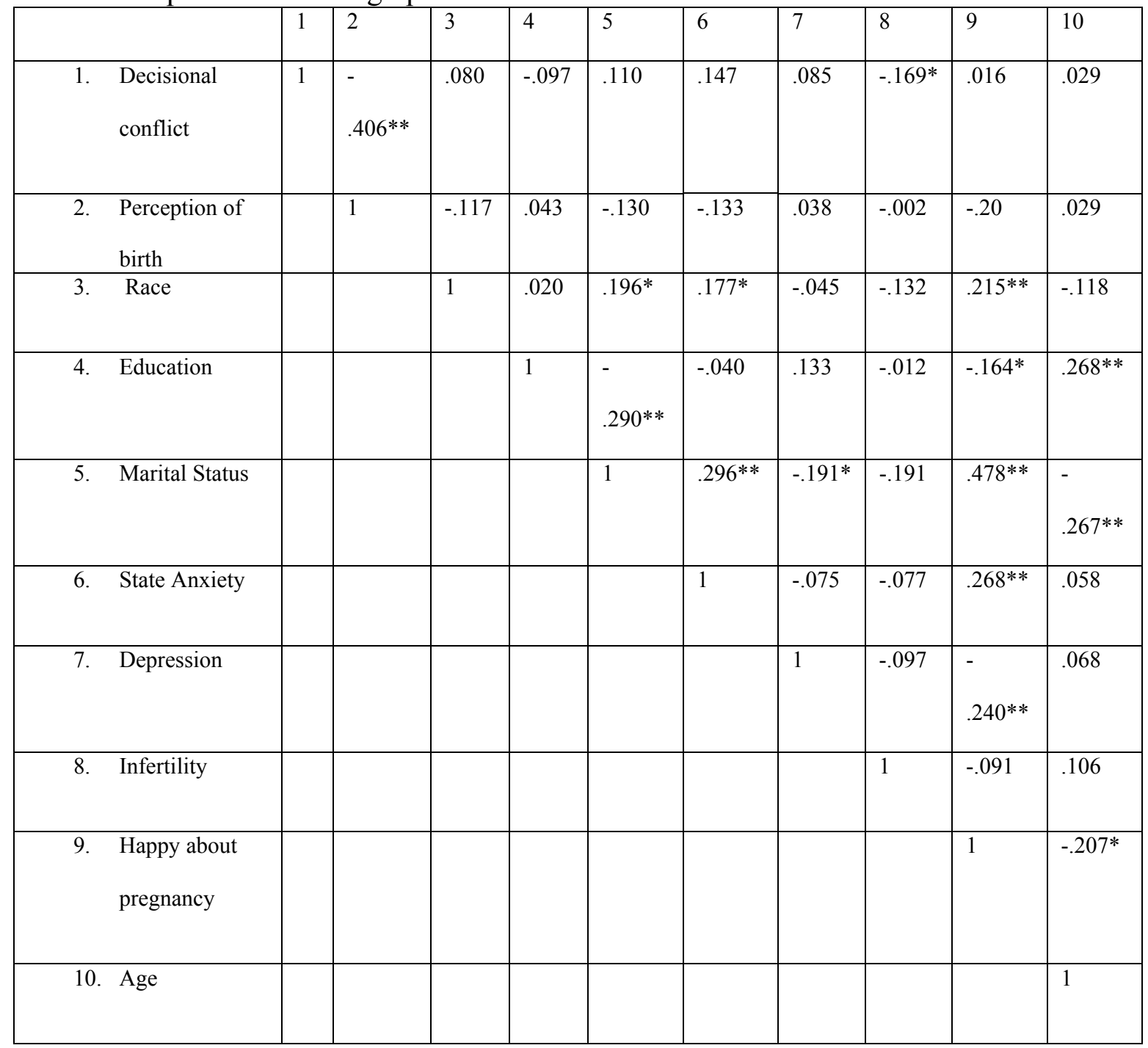

$* \mathrm{p}<.05$ two tailed $* * \mathrm{p}<.01$ two tailed $* * * \mathrm{p}<.001$ two tailed 


\section{Appendix U}

Correlation Tables for Study Variables 
Relationships between maternal health belief variables

\begin{tabular}{|c|c|c|c|c|c|c|c|}
\hline & 1 & 2 & 3 & 4 & 5 & 6 & 7 \\
\hline $\begin{array}{l}\text { 1. Self efficacy } \\
\text { towards birth } \\
\text { (control) }\end{array}$ & 1 & $.427 * * *$ & $.321 * * *$ & -.053 & $.255 * *$ & $-.215 * *$ & -.140 \\
\hline $\begin{array}{l}\text { 2. Acceptance of } \\
\text { maternal role }\end{array}$ & & 1 & $.397 * * *$ & -.112 & .128 & -.104 & -.042 \\
\hline 3. Partner support & & & 1 & -.024 & .013 & -.085 & -.017 \\
\hline $\begin{array}{l}\text { 4. Ability to deliver } \\
\text { vaginally } \\
\text { (susceptibility) }\end{array}$ & & & & 1 & $-.538 * * *$ & $.352 * * *$ & $.583 * * *$ \\
\hline $\begin{array}{ll}\text { 5. } & \text { Risk of emergent } \\
\text { cesarean (risk) }\end{array}$ & & & & & 1 & $-.175^{*}$ & $-.383 * * *$ \\
\hline $\begin{array}{ll}6 . & \text { Threat of vaginal } \\
& \text { delivery (threat) }\end{array}$ & & & & & & 1 & $.426 * * *$ \\
\hline $\begin{array}{l}\text { 7. Maternal request } \\
\text { group }\end{array}$ & & & & & & & 1 \\
\hline
\end{tabular}

